\title{
Uma Arquitetura de Question-Answering Instanciada no Domínio de Doenças Crônicas
}

\author{
Luciana Farina Almansa
}

\author{
DisSERTAÇÃO APRESENTADA \\ $\mathrm{AO}$ \\ Departamento de ComputaÇÃo e Matemática \\ DA
}

Faculdade de Filosofia, Ciência e letras de Ribeirão Preto DA

UNIVERSIDADE DE SÃo PAUlo

PARA

OBTENÇÃO DO TÍTULO

$\mathrm{DE}$

Mestre em CiÊnCIAS

Programa: Programa Interunidades de Pós-Graduação em Bioinformática da Universidade de São Paulo Orientador: Profa. Dra. Alessandra Alaniz Macedo

Durante o desenvolvimento deste trabalho a autora recebeu auxílio financeiro da CAPES 


\section{Uma Arquitetura de Question-Answering Instanciada no Domínio}

de Doenças Crônicas

Esta é a versão original da dissertação elaborada pela candidata Luciana Farina Almansa, tal como submetida à Comissão Julgadora. 
Dedico à todas as pessoas que fizeram parte dessa jornada. 


\section{Agradecimentos}

Aos meus pais que sempre me apoiaram e me forneceram a estrutura educacional e emocional necessária.

A todos os professores que passaram até hoje na minha vida e me proporcionaram todo conhecimento e aprendizado para minha formação acadêmica, profissional e pessoal.

Aos meus amigos, pelo incentivo e pelo apoio constante.

À Coordenação de Aperfeiçoamento de Pessoal de Nível Superior (CAPES) por ter financiado esta pesquisa.

À Universidade de São Paulo, pela oportunidade de nela estudar e desenvolver este projeto.

À minha orientadora, Profa. Dra. Alessandra Alaniz Macedo, pela dedicação e contribuição para a concretização deste trabalho e por ter contribuído para meu crescimento científico, intelectual e pessoal.

Aos secretários e técnicos do Departamento de Computação e Matemática e do Programa Interunidades de Pós-Graduação em Bioinformática pelo apoio com as questões burocráticas e técnicas. À Lariza Laura de Oliveira pelas conversas, pelo apoio científico e por me acalmar em muitos momentos difíceis.

À Juliana C. de Lima Rodrigues que muito me apoiou durante toda a concretização deste projeto. Aos meus colegas do laboratório deixo meu muito obrigada pelo apoio nos momentos difíceis do projeto e pelas risadas e conversar descontraídas.

Enfim, agradeço profundamente à todos que de alguma forma fizeram parte desse projeto e dessa jornada que foi o mestrado. 
"Nunca é alto o preço a se pagar pelo privilégio de pertencer a si mesmo" Friedrich Nietzsche 


\section{Resumo}

\section{ALMANSA, L. F. Uma Arquitetura de Question-Answering Instanciada no Domínio de}

Doenças Crônicas. 2016. 104 f. Dissertação (Mestrado) - Instituto de Matemática e Estatástica, Universidade de São Paulo, São Paulo, 2016.

Nos ambientes médico e de saúde, especificamente no tratamento clínico do paciente, o papel da informação descrita nos prontuários médicos é registrar o estado de saúde do paciente e auxiliar os profissionais diretamente ligados ao tratamento. A investigação dessas informações de estado clínico em pesquisas científicas na área de biomedicina podem suportar o desenvolvimento de padrões de prevenção e tratamento de enfermidades. Porém, ler artigos científicos é uma tarefa que exige tempo e disposição, uma vez que realizar buscas por informações específicas não é uma tarefa simples e a área médica e de saúde está em constante atualização. Além disso, os profissionais desta área, em sua grande maioria, possuem uma rotina estressante, trabalhando em diversos empregos e atendendo muitos pacientes em um único dia. O objetivo deste projeto é o desenvolvimento de um Framework de Question Answering (QA) para suportar o desenvolvimento de sistemas de QA, que auxiliem profissionais da área da saúde na busca rápida por informações, especificamente, em epigenética e doenças crônicas. Durante o processo de construção do framework, estão sendo utilizados dois frameworks desenvolvidos anteriormente pelo grupo de pesquisa da mestranda: o SisViDAS e o FREDS, além de desenvolver os demais módulos de processamento de pergunta e de respostas. O QASF foi avaliado por meio de uma coleção de referências e medidas estatísticas de desempenho e os resultados apontam valores de precisão em torno de 0,7 quando a revocação era 0,3, para ambos o número de artigos recuperados e analisados eram 200. Levando em consideração que as perguntas inseridas no QASF são longas, com 70 termos por pergunta em média, e complexas, o QASF apresentou resultados satisfatórios. Este projeto pretende contribuir na diminuição do tempo gasto por profissionais da saúde na busca por informações de interesse, uma vez que sistemas de QA fornecem respostas diretas e precisas sobre uma pergunta feita pelo usuário.

Palavras-chave: Question Answering, Extração de Informação, Recuperação de Informação e Processamento de Linguagem Natural. 


\section{Abstract}

\section{ALMANSA, L. F. A Question-Answering Architecture Instantiated on the Domains of}

Chronic Disease. 2016. 104 f. Dissertação (Mestrado) - Instituto de Matemática e Estatística, Universidade de São Paulo, São Paulo, 2016.

The medical record describes health conditions of patients helping experts to make decisions about the treatment. The biomedical scientific knowledge can improve the prevention and the treatment of diseases. However, the search for relevant knowledge may be a hard task because it is necessary time and the healthcare research is constantly updating. Many healthcare professionals have a stressful routine, because they work in different hospitals or medical offices, taking care many patients per day. The goal of this project is to design a Question Answering Framework to support faster and more precise searches for information in epigenetic, chronic disease and thyroid images. To develop the proposal, we are reusing two frameworks that have already developed: SisViDAS and FREDS. These two frameworks are being exploited to compose a document processing module. The other modules (question and answer processing) are being completely developed. The QASF was evaluated by a reference collection and performance measures. The results show 0,7 of precision and 0,3 of recall for two hundred articles retrieved. Considering that the questions inserted on the framework have an average of seventy terms, the QASF shows good results. This project intends to decrease search time once QA systems provide straight and precise answers in a process started by a user question in natural language.

Keywords: Question Answering, Information Extraction, Information Retrieval, Natural Language Processing. 


\section{Sumário}

$\begin{array}{ll}\text { Lista de Abreviaturas } & \text { viii }\end{array}$

$\begin{array}{ll}\text { Lista de Símbolos } & \text { ix }\end{array}$

Lista de Figuras $\quad$ x

Lista de Tabelas $\quad$ xiii

1 Introdução $\quad 1$

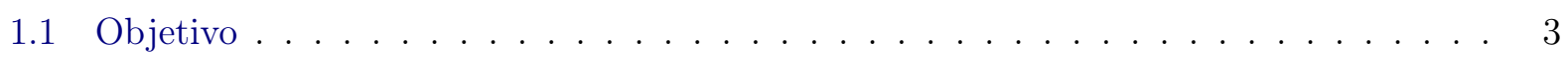

1.2 Materiais e Métodos . . . . . . . . . . . . . . . . . . 3

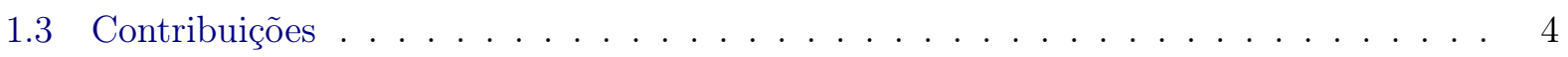

1.4 Organização do Trabalho . . . . . . . . . . . . . . . . . . . . 4

2 Fundamentos Teóricos $\quad 5$

2.1 Recuperação de Informação . . . . . . . . . . . . . . . . . . . . . . 5

2.1.1 Modelos Clássicos de RI: Booleano, Vetorial e Probabilístico . . . . . . . . . . 8

2.1 .2 Expansão de Consultas . . . . . . . . . . . . . . . . . . . . . . . . . 9

2.1 .3 Avaliações de Sistemas de RI . . . . . . . . . . . . . . . . . . . . . . . 10

2.2 Extração de Informação . . . . . . . . . . . . . . . . . . . . . . . . . . . 11

2.2.1 Mineração de Texto . . . . . . . . . . . . . . . . . . . . . . . 12

2.2 .2 Aprendizado de Máquina . . . . . . . . . . . . . . . . . . . 14

2.2 .3 Dicionários . . . . . . . . . . . . . . . . . . . . . . . . . 15

2.3 Sistemas de Question-Answering . . . . . . . . . . . . . . . 16

2.3.1 Processamento da Questão . . . . . . . . . . . . . . . . . 17

2.3 .2 Processamento de Documentos . . . . . . . . . . . . . . . . . . . . 19

2.3 .3 Processamento da Resposta . . . . . . . . . . . . . . . . . . . . . . . . . 19

2.3 .4 Avaliação de Sistemas de QA . . . . . . . . . . . . . . . . 20

3 Trabalhos Relacionados: Sistemas de QA 22

3.1 Histórico dos Sistemas de QA . . . . . . . . . . . . . . . . . . . 22

3.2 Sistemas de QA Atuais . . . . . . . . . . . . . . . . . 23

3.2.1 Sistemas de QA nos Domínios da Saúde . . . . . . . . . . . . . . . . 26

3.3 Sistemas de QA no Brasil . . . . . . . . . . . . . . . . . . . 27

3.4 Comparativo dos Sistemas de QA . . . . . . . . . . . . . . . . . 28 
4 Trabalhos de Suporte $\quad 30$

4.1 Framework para Sistema de Vigilância para Doenças Crônicas (SisViDAS) . . . . . . 30

4.2 Framework para Redução da Descontinuidade Semântica em Imagens Médicas (FREDS) 33

5 Question Answering Surveillance Framework (QASF) 40

5.1 Arquitetura do QASF . . . . . . . . . . . . . . . . . . . 40

$5.1 .1 \quad$ Processamento da Questão . . . . . . . . . . . . . . . . . . . . . . 41

5.1 .2 Processamento dos Documentos . . . . . . . . . . . . . . . 45

5.1 .3 Processamento da Resposta . . . . . . . . . . . . . . . . . . . . 46

5.2 Modelagem do QASF . . . . . . . . . . . . . . . . . . . . . . 49

5.3 Interfaces do QASF . . . . . . . . . . . . . . . . . . 55

6 Avaliação do QASF $\quad 56$

6.1 Coleções de Referência . . . . . . . . . . . . . . . . . . . . . . . . 56

6.1 .1 AskHERMES . . . . . . . . . . . . . . . . . . . 57

6.1.2 FnATI (Fine-needle Aspiration Thyroid Images) . . . . . . . . . . . . . 57

6.1.3 EDRMrSa (Epigenetic Data Related between Medical Records and Scientific

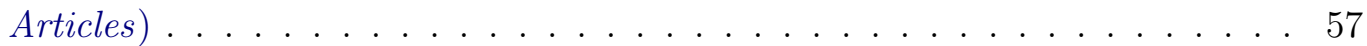

6.2 Avaliação dos Módulos do QASF . . . . . . . . . . . . . . . . . . . 59

6.2 .1 Processamento da Questão . . . . . . . . . . . . . . . . . . . 60

6.2 .2 Processamento de Documentos . . . . . . . . . . . . . . . . . . . . . 64

6.2 .3 Processamento da Resposta . . . . . . . . . . . . . . . . . . . . . . . 69

$\begin{array}{lll}7 & \text { Conclusões } & 73\end{array}$

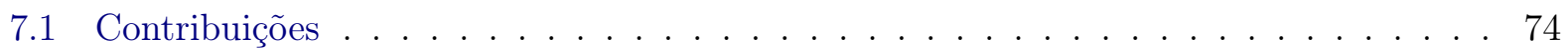

7.2 Dificuldades e Limitações . . . . . . . . . . . . . . . . . . . . . . . 74

7.3 Trabalhos Futuros . . . . . . . . . . . . . . . . . . . . . 74

$\begin{array}{ll}\text { A Prontuários dos Paciente Simulados } & 76\end{array}$

$\begin{array}{lr}\text { Referências Bibliográficas } & \mathbf{8 0}\end{array}$ 


\section{Lista de Abreviaturas}

\begin{tabular}{|c|c|}
\hline AIML & Artificial Intelligence Markup Language \\
\hline $\mathrm{AM}$ & Aprendizado de Máquina (Machine Learning) \\
\hline $\mathrm{CAD}$ & Sistema de Apoio ao Diagnóstico (Computer Aided Diagnosis) \\
\hline CLEF & Conference and Labs of the Evaluation Forum \\
\hline EI & Extração de Informação (Information Extraction) \\
\hline FAQ & Perguntas Frequentes (Frequently Asked Question) \\
\hline FREDS & Framework para Redução da Descontinuidade Semântica em Imagens Médicas \\
\hline IARPA & Intelligence Advanced Research Projects Activity \\
\hline KNN & k-Vizinhos mais Próximos ( $k$-Nearest Neighbor $)$ \\
\hline LHS & Sistemas de Aprendizado em Saúde (Learning Healthcare System) \\
\hline MLP & Multilayer Perceptron \\
\hline MSKCC & Memorial Sloan-Kettering Cancer Center \\
\hline MT & Mineração de Texto (Text Mining) \\
\hline NER & Reconhecimento de Entidades Nomeadas (Named Entity Recognation) \\
\hline NIST & National Institute of Standards and Technology \\
\hline NLTK & Natural Language Toolkit \\
\hline PAAF & Punção Aspirativa por Agulha Fina (Fine Needle Aspiration Biopsy) \\
\hline PAE & Programa de Aperfeiçoamento do Ensino \\
\hline PLN & Processamento de Linguagem Natural (Natural Language Processing) \\
\hline POS-tagging & Etiquetador Morfossintático (Part-of-Speech Tagger) \\
\hline QA & Perguntas e Respostas (Question Answering) \\
\hline QASF & Question Answering Surveillance Framework \\
\hline RGB & Vermelho, Verde e Azul (Red, Green and Blue) \\
\hline RI & Recuperação de Informação (Information Retrieval) \\
\hline SisViDAS & Framework para Sistema de Vigilância para Doenças Crônicas \\
\hline SQAS & Shallow Question Answering System \\
\hline START & SynTactic Analysis using Reversible Transformation \\
\hline SVM & Máquina de Vetores de Suporte (Support Vector Machine) \\
\hline TIFF & Tagged Image File Format \\
\hline TREC & Text Retrieval Conference \\
\hline $\mathrm{UC}$ & UNIX Consultant \\
\hline UML & Unified Modeling Language \\
\hline MLS & Unified Medical Language System \\
\hline
\end{tabular}




\section{Lista de Símbolos}

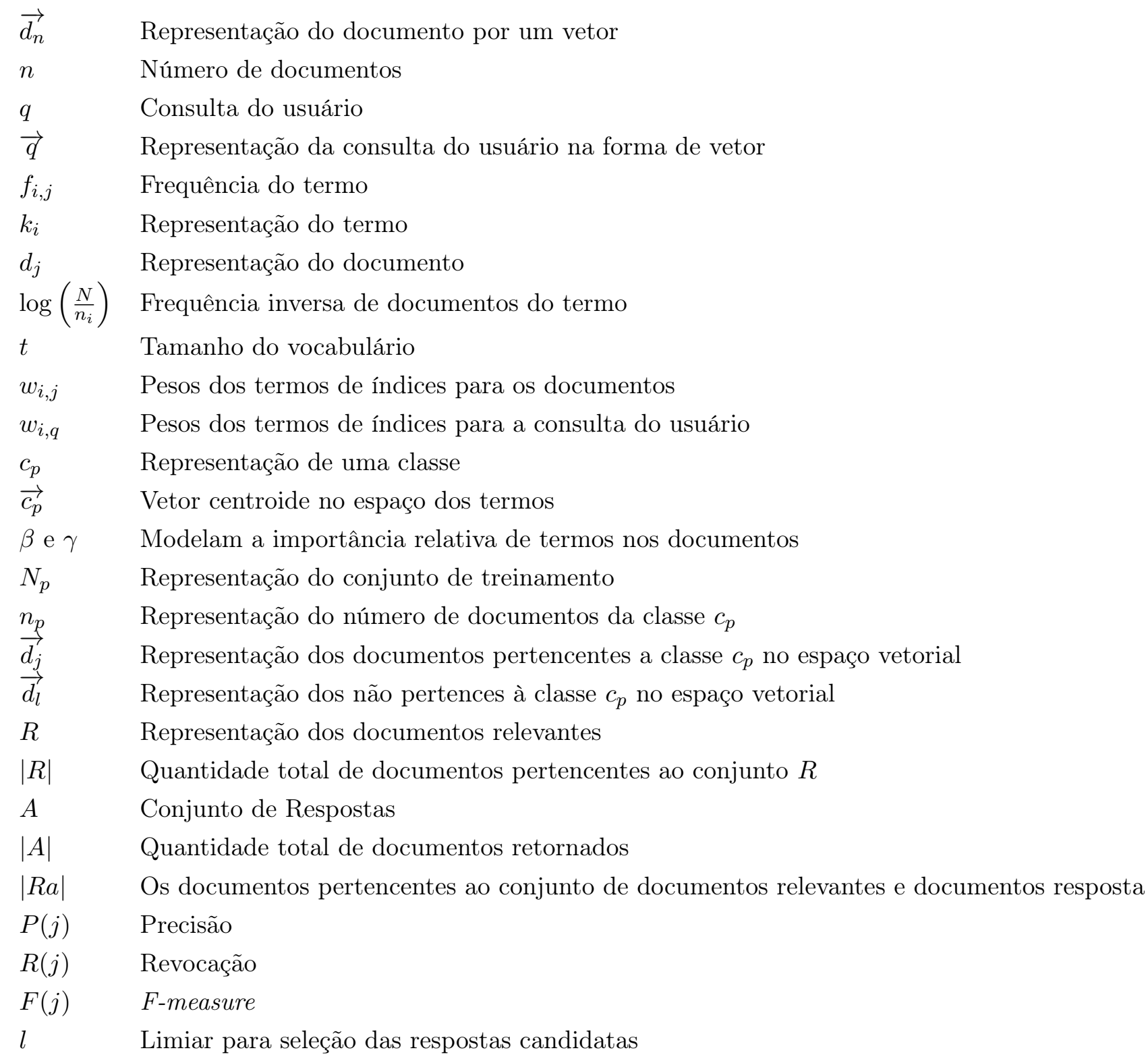




\section{Lista de Figuras}

1.1 Número de citações de artigos científicos, segundo o MEDLINE, apresentados por década sem a discriminação de idiomas e somente no idioma inglês. Fontes: MEDLINE (2003a,b). * A década de 2010 compreende as citações do período entre Janeiro de 2010 e Novembro de 2014 . . . . . . . . . . . . . . . . . . . . . . . . . . 2

2.1 Esquema de funcionamento de um sistema de Recuperação de Informação. . . . . . . 6

2.2 Arquitetura genérica de um sistema de RI. Fonte: Baeza-Yates e Ribeiro-Neto (1999). 7

2.3 Apresentação de algumas técnicas de Extração de Informação. (1) As stopwords foram desconsideradas. (2) Busca por palavras importantes do texto. (3) Transformação do texto, em formato não-estruturado, em uma representação estruturada na forma de matriz. (O texto utilizado para demonstração das técnicas de Extração de Informação é baseado em Ciccacci et al. (2013).) . . . . . . . . . . . . . . . . . . . . . . . . . 12

2.4 Exemplo de stemming. . . . . . . . . . . . . . . . . . . . . . . . 13

2.5 Exemplos de análises morfo/sintática e semântica. ～. . . . . . . . . . . . . 13

2.6 Superfície de separação com as margens maximizadas. Fonte: Medeiros (2004). . . . 15

2.7 Arquitetura genérica de um sistema de Question-Answering. . . . . . . . . . . . . 16

2.8 Exemplos de informações implícitas que podem ser descobertas nessa etapa. O objetivo principal é encontrar as palavras que estão sublinhadas por meio da análise do conteúdo da questão. . . . . . . . . . . . . . . . . . . . . . . . . . . . . 17

2.9 Exemplo de conversão de uma pergunta, em linguagem natural, em um vetor de palavras-chave. . . . . . . . . . . . . . . . . . . . . . . . 19

2.10 Exemplo de comparação entre a estrutura gramatical da resposta candidata e da resposta correta. Neste contexto, a ordem das cores de ambas as frases devem estar alinhadas. . . . . . . . . . . . . . . . . . . . . 20 
4.1 Estrutura do framework SisViDAS: (a) Módulo para criação e atualização da coleção de artigos. (b) Interface de busca. (c) Coleção online de artigos científicos. (d) Ontologias do domínio. (e) Recuperação de artigos científicos de repositórios online. (f-g-j) Processamento textual dos artigos recuperados dos repositórios online e dos prontuários inseridos, apoiados pelo módulo base do processamento textual composto pelas técnicas de Processamento de Linguagem Natural. (h) Database local com a coleção já processada. (i-n-m) Interface com o usuário, recebe como entrada prontuários médicos do paciente e retorna grupos de risco e os abstracts de artigos científicos mais relevantes. (k) Módulo que mede a similaridade entre prontuário médico do paciente e artigos científicos. (l) Processo de acesso aos artigos pré-processados e retorna os que tem os maiores graus de similaridade. (o) Artefatos linguísticos, como, por exemplo, UMLS. (p) Reconhecimento de conceitos. BASEADO EM (Pollettini et al., 2014). . . 31

4.2 Interfaces do usuário do SisViDAS (Pollettini, 2011) . . . . . . . . . . . . . 34

4.3 Estrutura do framework FREDS. BASEADO EM: (Pessotti, 2012) . . . . . . . . . . 35

4.4 Interface do usuário do framework FREDS. . . . . . . . . . . . . . . . . . . . . 38

5.1 Arquitetura da proposta do QASF . . . . . . . . . . . . . . . . . 41

5.2 Análise da questão por correspondência de padrões. Primeiramente, a pergunta é analisada afim de descobrir os elementos gramaticais que à compõe. Em seguida, o sujeito da questão é enviado para o banco de dados WordNet e, por fim, a definição do sujeito é recebida pelo QASF. . . . . . . . . . . . . . . . . . . 42

5.3 Primeira etapa de construção do vetor de palavras-chaves do QASF. Primeiramente, o QASF elimina os pronomes interrogativos (' $\mathrm{X}$ ' na cor vermelha), em seguida, as stopwords são eliminadas ('X' na tonalidade alaranjada) e por fim, as pontuações são eliminadas ('X' na tonalidade azul) . . . . . . . . . . . . . . . . . 43

5.4 Segunda etapa de construção do vetor de palavras-chaves do QASF. Primeiramente, o QASF envia as palavras do vetor para o WordNet retornar seus sinônimos. Caso não haja sinônimos, o QASF solicita que o WordNet busque pelos termos hiperônimos do termo que está sendo avaliado. . . . . . . . . . . . . . . . . . . . . . 44

5.5 Final da segunda etapa de construção do vetor de palavras-chaves do QASF. O processo de lematização é representado pela tonalidade vermelha. A aplicação da técnica de stemming é apresentada nas tonalidades azul e verde. Contudo, a tonalidade verde representa também a redução de duas palavras que possuem o mesmo radical a um único elemento no vetor de palavras-chave final. . . . . . . . . . . . . . . . . . . . . 44

5.6 Exemplo do processo de preparação dos parágrafos dos abstracts que serão analisados pelo QASF. A letra "t" da palavra "the" (em negrito) foi convertida para minúscula uma vez que ela representa início de frase. Em seguida, as palavras sublinhadas na "Frase normal" e na "Frase modificada" mostram o processo de transformação por meio das técnicas de stemming e lematização. Em seguida, o "vetorPalavras" (criado no módulo anterior) e a "Frase modificada" (frase candidata modificada) são comparadas entre si na busca por padrões de correspondência. Estes padrões podem ser visualizados nas palavras destacadas em tonalidades vermelha e rosa. Caso o limiar $l$ seja 2, por exemplo, esta frase pode ser considerada uma frase candidata. . . 
5.7 Apresentação do primeiro método de cálculo da similaridade. O primeiro passo, o QASF busca pelas palavras sinônimas nas frases candidatas as substituem pela palavra-chave. Quando o QASF encontrar as palavras "cancer" e "malignant neoplastic disease" nas frases candidatas, o framework substituirá essas duas palavras pela palavra-chave "carcinoma". Em seguida, os radicais das palavras que compõem a pergunta e as respostas candidatas são extraídas por meio de técnicas de stemming e lematização e, por fim, o cálculo da similaridade por meio do cosseno do ângulo entre a pergunta e as frases candidatas modificadas é realizado. . . . . . . . . . . . 48

5.8 Apresentação do segundo método de cálculo da similaridade. Neste modelo, a questão e as frases candidatas permanecem no formato original e a similaridade é calculada por meio do cosseno do ângulo entre a pergunta do usuário e cada resposta candidata. 49

5.9 Diagrama de caso de uso do QASF . . . . . . . . . . . . . . . 50

5.10 Diagrama de atividades do QASF . . . . . . . . . . . . . . . 51

5.11 Diagrama de classes do QASF. O QASF é composto da união dos frameworks SisViDAS + FREDS com as classes desenvolvidas pela aluna mestranda. O diagrama é baseado em: Pollettini (2011) e Pessotti (2012) . . . . . . . . . . . . . 54

5.12 Interfaces do usuário do QASF . . . . . . . . . . . . . . . . . . 55

6.1 Prontuário simulado do Paciente 2 da EDRMrSa. . . . . . . . . . . . . . . . . . 59

6.2 Questão criada a partir do prontuário simulado do Paciente 2 da EDRMrSa. . . . . . 59

6.3 Respostas retornadas pelo WordNet para o vetor de palavras do Paciente 2. . . . . . 62

6.4 Vetor de palavras resultante da primeira etapa de criação do vetor final de palavraschaves do QASF do Paciente 2. . . . . . . . . . . . . . . . . . . 63

6.5 Vetor final de palavras-chave resultante da primeira etapa de criação do vetor palavraschaves do QASF do Paciente 2. O vetor apresenta os termos sinônimos e hiperônimos dos sete primeiro termos do vetor final completo. . . . . . . . . . . . . . 63

6.6 Precisão x Revocação média na recuperação de artigos científicos variando a quantidade máxima de artigos a serem recuperados. . . . . . . . . . . . . . . . 67

6.7 Exemplos de respostas candidatas do Paciente $2 \ldots \ldots$. . . . . . . . . . 68

6.8 Resultado do cálculo da similaridade. (a) Primeira maneira de calcular a similaridade ("cosseno1"). Nessa maneira, as palavras sinônimas são substituídas por uma palavra principal e as técnicas de stemming e lematização são aplicadas. (b) Segunda maneira de calcular a similaridade ("cosseno2"). A similaridade é calculada entre a pergunta e as frases candidatas na forma gramatical original. . . . . . . . . . . . . 70

6.9 Precisão média calculada para os dois métodos de calcular o cosseno. (a) Precisão média variando a quantidade de artigos recuperados. (b) Precisão média por paciente. 71 


\section{Lista de Tabelas}

2.1 Representação de um documento na forma de informação estruturada de uma matriz

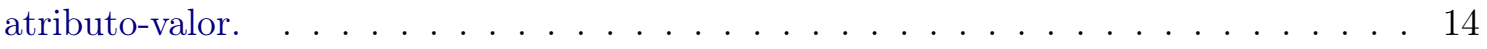

2.2 Apresentação das expressões que iniciam perguntas em inglês e seus respectivos significados. Fonte: Srihari e Li (1999). . . . . . . . . . . . . . . . . . . . . 18

3.1 Sistematização de alguns sistemas de QA da literatura e suas respectivas abordagens. 29

6.1 Classificação de uma coleção de referência em classes pelo QASF. Os valores foram obtidos com o auxílio da técnica de validação cruzada ( $k$-fold $)$, cujo $k=10 . \quad \ldots$. . . 60

6.2 Número de termos que obtiveram respostas retornadas pelo WordNet em função da quantidade total de termos criados por prontuário. Na tabela, cada linha representa um prontuário distinto. A coluna "Total" apresenta a quantidade total de termos gerados por prontuário e a coluna "Resp" apresenta a quantidade de termos que obtiveram algum retorno do WordNet. Ambas as colunas variam em função do número de palavras que compõem o termo ("Uma", "Duas", "Três" ou "Quatro"). . . . . . . . . 61

6.3 Número de palavras que compõem o vetor de palavras-chave de cada questão processada pelo QASF. . . . . . . . . . . . . . . . . . . . . . . 64

6.4 Acurácia alcançada pelos extratores de características em função dos classificadores avaliados. Os valores dos extratores que apresentaram melhorar desempenho foram destacados em negrito. . . . . . . . . . . . . . . . . . . 65

6.5 Percentual de mudança com a agregação da morfologia. . . . . . . . . . . . . . . 66

6.6 Matriz de confusão do pior caso (DWT+COOC+MORPHO e MLP). As linhas representam as classes reais e as colunas as classes preditas. As células representam a quantidade de núcleos classificada em relação a classe real e a classe predita pelo

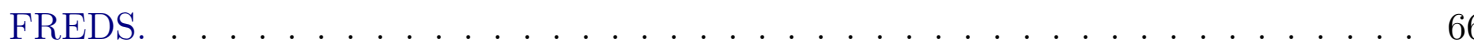

6.7 Quantidade de respostas candidatas recuperadas de acordo com o tamanho da coleção de documentos recuperada. . . . . . . . . . . . . . . . . . . . . 68 


\section{Capítulo 1}

\section{Introdução}

No ambiente médico, especificamente no tratamento clínico do paciente, o papel da informação descrita nos prontuários médico é registrar o estado de saúde do paciente e auxiliar os profissionais diretamente ligados ao tratamento das pessoas. A investigação dessas informações em escalas regionais ou até mesmo nacionais apoiadas por pesquisas biomédicas podem apoiar o desenvolvimento de padrões de prevenção e tratamento de enfermidades. Estes padrões, por sua vez, podem ser transformados em protocolos, diretrizes e materiais educativos que colaboram no tratamento do paciente (Shortliffe e Cimino, 2013). Nesse sentido, Shortliffe e Cimino (2013) vislumbram o futuro de sistemas computacionais médicos como "Learning Healthcare Systems" (LHS). Segundo esses pesquisadores, sistemas LHS funcionarão de acordo com um ciclo de informação, cujo os dados distribuídos de prontuários eletrônicos do paciente serão submetidos a base de dados de registros médicos e de pesquisa científica para serem processados e gerarem conhecimento.

Na área da saúde, os artigos científicos são uma importante fonte de informações e de descobertas relevantes de informação. Os artigos científicos podem ser agrupados de acordo com seu conteúdo-chave ou área de especialidade em bibliotecas digitais como, por exemplo, o PubMed ${ }^{1}$. À medida que os artigos são inseridos, a rede de informação vai aumentando e se tornando cada vez mais rica e complexa para buscar informações desejadas (Cohen e Hunter, 2008; Rzhetsky et al. , 2009). Este contexto dificulta o bom aproveitamento das informações contidas nos artigos científicos pela sociedade, em geral, e pela comunidade científica e profissional da área da saúde. Nos últimos cinquenta anos, a produção científica tem apresentado um aumento crescente no número de publicações (Larsen e von Ins, 2010). O número de artigos citados nas últimas décadas cresceu na ordem de milhões de citações. Este aumento pode ser confirmado e visualizado nas informações estatísticas disponibilizadas pelo MEDLINE ${ }^{2}$ e apresentadas na Figura 1.1. O eixo horizontal dessa figura apresenta o número de citações de artigos científicos por décadas, desde 1950 a 2010. O eixo vertical apresenta a quantidade de artigos citados na ordem de milhões.

\footnotetext{
${ }^{1}$ http://www.ncbi.nlm.nih.gov/pubmed

${ }^{2}$ O MEDLINE é uma base de dados de referências indexadas de jornais das áreas de biomedicina e áreas relacionadas (MEDLINE, 2004)
} 


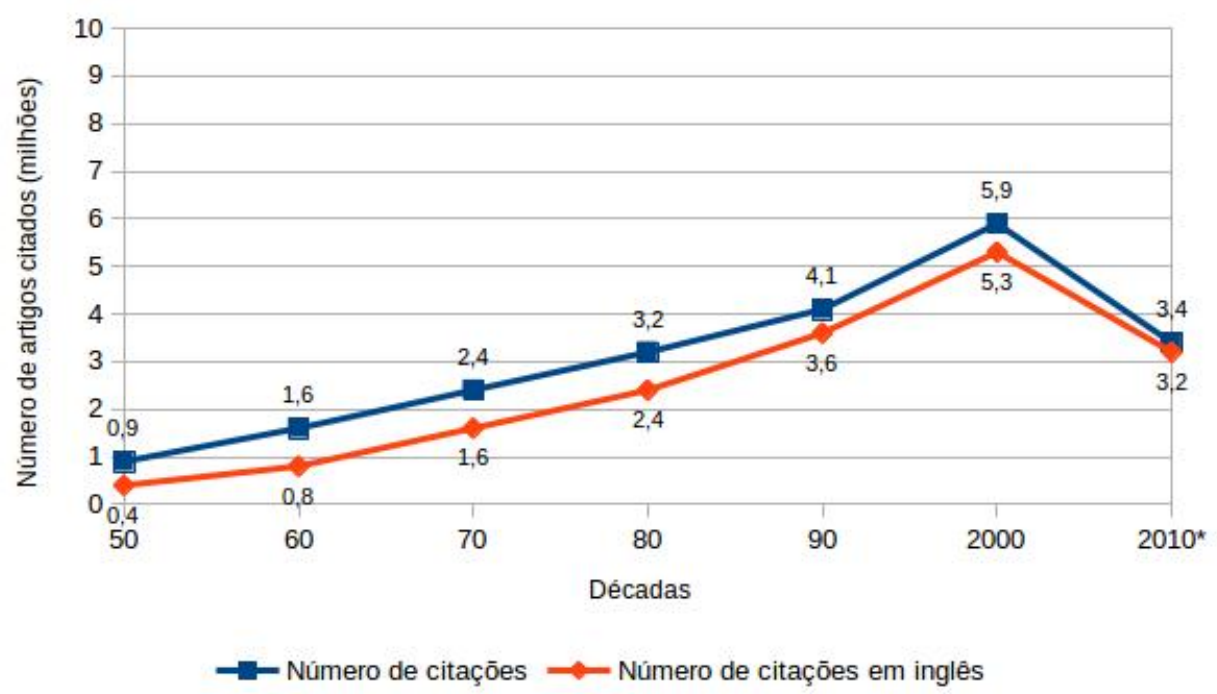

Figura 1.1: Número de citações de artigos científicos, segundo o MEDLINE, apresentados por década sem a discriminação de idiomas e somente no idioma inglês. Fontes: MEDLINE (2003a,b). * A década de 2010 compreende as citações do período entre Janeiro de 2010 e Novembro de 2014.

Na Figura 1.1, o gráfico apresenta, entre os anos de 1950 e 2014, um crescimento constante na quantidade de artigos citados. Praticamente a cada década houve um aumento de um milhão de citações. Contudo, no período entre as duas últimas décadas (1990 e 2000), esta diferença duplicou, alcançando quase dois milhões de artigos citados em apenas dez anos. O aparente decréscimo no número de citações entre 2010 e 2014 pode ser explicado pelo fato de que a década de 2010 é caracterizada apenas por um período de quatro anos (2010 a 2014). Nesse pequeno período, o número de citações é ligeiramente superior ao número de citações realizadas durante toda a década de oitenta. Outro dado importante apresentado na Figura 1.1 é a comparação entre o "Número de citações" e o "Número de citações em inglês". Na área médica, nos últimos cinquenta anos, os artigos no idioma inglês são os mais citados. A quantidade de citações somam um total de aproximadamente 17,3 milhões (MEDLINE, 2003b).

Devido a grande quantidade de artigos científicos disponíveis, ler artigos científicos é uma tarefa que exige tempo e disposição. Quando um profissional quer conhecer melhor um assunto específico, ele precisa buscar por artigos científicos em revistas ou em repositórios online, que, possivelmente, tenham a informação desejada. Além da quantidade de artigos, a busca por informações desejadas tende a ser árdua e complexa devido a quantidade de artigos científicos escritos, algumas vezes, em idiomas diferente da língua nativa e em diferente estruturações e formatos, resultando na necessidade do usuário de formulação de expressões de consultas mais eficientes e minuciosas.

A área médica está em constante atualização sobre novos tratamentos, medicações e procedimentos. Os profissionais da área, em sua grande maioria, possuem uma rotina estressante, trabalhando em diversos empregos e atendendo muitos pacientes em um único dia (ABS, 2005). Os sistemas computacionais de Recuperação de Informação (RI) e Question Answering (QA) são ferramentas que podem auxiliar esses profissionais da saúde no processo de mineração da informação e redução do tempo consumido no processo de busca.

Para Baeza-Yates e Ribeiro-Neto (1999), os sistemas de RI são responsáveis pela representação e pela organização das informações, de modo que o acesso à informação seja facilitado para o usuário. Na literatura científica, foram identificadas tentativas de construção de mecanismos com- 
putacionais de relacionamentos de informações na área da saúde. Mourão et al. (2015) propuseram um sistema de relacionamento e recuperação multimodal de informações médicas baseado em casos clínicos. O sistema recupera imagens médicas ou casos clínicos, a partir de uma abordagem que utiliza expansão de termos da consulta com base em thesauri médico e técnicas de recuperação de informação multimodal. Thong e Son (2015) desenvolveram um sistema de auxílio ao diagnóstico médico baseado em técnicas de lógica fuzzy e sistema de recomendação. Pollettini et al. (2014) desenvolveram um sistema de vigilância para doenças crônicas para alertar profissionais da saúde sobre problemas no desenvolvimento de seus pacientes. Esse sistema relaciona informações científicas de artigos e prontuários médico do paciente, a partir de relacionamentos conceituais.

Uma das desvantagens dos sistemas de RI é a quantidade de documentos retornados como resultado do processo de recuperação de informação (Kolomiyets e Moens, 2011). Na tentativa de minimizar esse problema, os sistemas de QA podem ser utilizados. Para Kolomiyets e Moens (2011), os sistemas de QA são um tipo de sistema de recuperação de informação mais sofisticado. Em sistemas de QA, a informação que o usuário necessita é apresentada em linguagem natural e, como resultado do processo, respostas curtas e diretas são retornadas ao usuário. Desse modo, a principal diferença entre os sistemas de RI e de QA é o tipo de resultado retornado pelo processo de busca. Os sistemas de RI consideram o documento, em sua totalidade, importante para ser apresentado ao usuário. Nos sistemas de QA, os trechos específicos são considerados relevantes para o usuário.

\section{$1.1 \quad$ Objetivo}

O objetivo deste trabalho é o desenvolvimento de um Framework ${ }^{3}$ de Question Answering, chamado Question Answering Surveillance Framework (QASF) para apoiar profissionais de computação a criar sistemas de QA que auxiliem profissionais da área da saúde na busca rápida e direta por informações da área da saúde.

\subsection{Materiais e Métodos}

Durante o processo de construção do QASF foram utilizados dois frameworks desenvolvidos anteriormente por alunos do grupo de pesquisa desta mestranda: o SisViDAS (Pollettini et al., 2014) e o FREDS (Macedo et al., 2016). O SisViDAS é um framework que recupera artigos científicos associados à fatores de riscos descritos em prontuários médico do paciente e alerta especialistas da área da saúde sobre problemas no desenvolvimento humano. O FREDS recupera laudos de exames médicos associados à informações de imagens de diagnóstico de Punção Aspirativa de Tireoide com Agulha Fina. Ambos os frameworks compõem parte do processo de recuperação de documentos para a extração de respostas candidatas do QASF.

Os outros componentes do QASF, processador da pergunta e processador da resposta, foram desenvolvidos pela mestranda apoiada por alunos de iniciação científica do grupo de pesquisa. Estes componentes foram desenvolvidos utilizando a linguagem de computação Python ${ }^{4}$, apoiada,

\footnotetext{
${ }^{3}$ Segundo Roberts e Johnson (1996) "Frameworks são modelos de sistemas reutilizáveis, total ou parcialmente, descrito por um conjunto de classes abstratas e a forma como elas colaboram entre si."

${ }^{4}$ https://wiki.python.org/moin/
} 
principalmente, pela biblioteca de processamento de linguagem natural $N L T K^{5}$ e pela biblioteca de aprendizado de máquina scikit-learn ${ }^{6}$

\subsection{Contribuições}

Este projeto contribui com a construção de um framework de software que permite a criação de sistemas do tipo Question Answering. Os sistemas buscam as respostas em diferentes tipos de fontes de dados (artigos científicos, registros médicos e laudos de exames médicos), de acordo com o nível de permissão de acesso ao usuário. A arquitetura do framework foi construída para suportar a transição entre domínios de aplicação. Neste sentido, para alterar o domínio é necessário apenas a atualização da base de artigos científicos utilizada para a busca pela informação de interesse e a troca das ontologias e dicionários do domínio. Neste primeiro momento de construção e primeiras avaliações do framework de QA, o domínio de aplicação em epigenética ${ }^{7}$ e doenças crônicas foi utilizado. As respostas retornadas pelo sistema de QA são uma tentativa de diminuir o tempo gasto por profissionais da saúde na busca por informações de interesse.

\subsection{Organização do Trabalho}

Este documento está estruturado da seguinte forma: no Capítulo 2, os fundamentos teóricos que apoiam a construção do framework e do sistema de QA propostos são apresentados. Esses fundamentos teóricos são: (i) Recuperação de Informação, (ii) Extração de Informação e (iii) Sistemas de Question Answering. No Capítulo 3, o estado da arte é descrito descrevendo os trabalhos relacionados. No Capítulo 4 são apresentados os trabalhos de suporte de uma das etapas de processamento do framework QASF. No Capítulo 5, a arquitetura e a modelagem do QASF são detalhadas e no Capítulo 6, as avaliações são apresentadas. Por fim, no Capítulo 7, as conclusões do trabalho e os trabalhos futuros são apresentados e discutidos.

\footnotetext{
${ }^{5}$ http://www.nltk.org/

${ }^{6}$ http://scikit-learn.org/stable/

${ }^{7}$ Estudos em medicina genômica sugerem que seres humanos expostos a fatores de risco no início da vida como, por exemplo, a escassez de alimentos, aliados à fatores ambientais podem sofrer influências na expressão do gene e, como resultado, na vida adulta desenvolverem doenças crônicas (as doenças cardiovasculares, a diabetes e a obesidade). A epigenética é a área da Biologia que estuda essas influências na expressão do gene (Barker, 2001).
} 


\section{Capítulo 2}

\section{Fundamentos Teóricos}

No desenvolvimento de sistemas Question Answering de apoio à profissionais da área da saúde, essencialmente, conceitos e tecnologias de Recuperação de Informação e de Extração de Informação são utilizados para relacionar a consulta formulada pelo usuário em busca da informação desejada e os documentos manipulados para gerar uma resposta objetiva ao usuário final.

Os mecanismos computacionais de Recuperação de Informação buscam as informações relevantes a serem manipuladas para a geração de relacionamentos. Na Extração de Informação, mecanismos de Mineração de Texto e Aprendizado de Máquina são investigados para a geração e o relacionamento dos conceitos identificados. O resultado da integração desses mecanismos pode ser representado por redes de relacionamento de informações do domínio. Portanto, neste capítulo, os conceitos de Recuperação de Informação, de Extração de Informação e de Sistemas de Question Answering são apresentados.

\subsection{Recuperação de Informação}

O volume das publicações disponíveis em bibliotecas digitais e em repositórios da Web está crescendo consideravelmente nos últimos anos. À medida que este volume aumenta, alguns problemas como, por exemplo, a complexidade e a lentidão na busca por informações de interesse e a existência do gap semântico entre "o que" o usuário deseja buscar e "como" ele expressa essa informação na criação de uma consulta surgem. Para minimizar estes problemas, cientistas da área da Ciência da Computação concentram seus esforços na definição de métodos eficientes para manipular grandes quantidades de informações em tarefas de coleta e de indexação de informações (Frakes e Baeza-Yates, 1992).

Para os autores Baeza-Yates e Ribeiro-Neto (1999), a Recuperação de Informação (RI) é um processo que se estende desde a representação da informação até o seu acesso, tal que a representação e a organização da informação facilite a obtenção dos dados por parte do usuário. Na Figura 2.1, um exemplo de como o processo de recuperação de documentos é realizado - desde a preparação da informação a ser utilizada na pesquisa até a apresentação ao usuário das informações recuperadas - é apresentado. O processo de recuperação de informação pode ser executado em diferentes tipos de documentos textuais. Na Figura 2.1 (1), os tipos de documentos escolhidos para demonstrar o processo de recuperação foram os "Artigos Científicos" e os "Prontuários Médico do Paciente". Esses tipos de documentos foram escolhidos para comporem a exemplificação do processo de recuperação de informação devido ao fato de se relacionarem diretamente à proposta deste trabalho. Neste sen- 

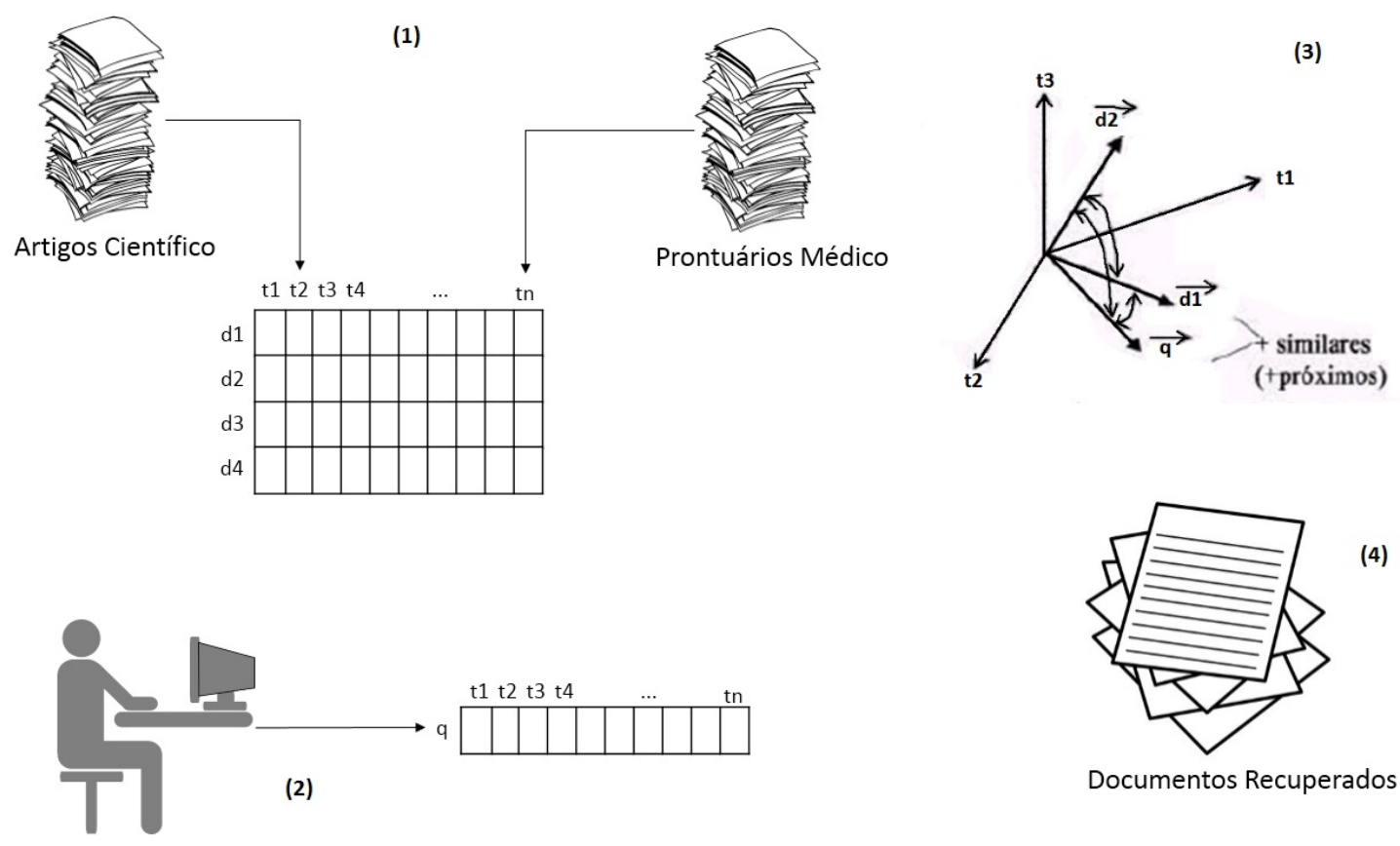

Figura 2.1: Esquema de funcionamento de um sistema de Recuperação de Informação.

tido, relacionamentos entre informações de "Artigos Científicos" e "Prontuários Médico do Paciente" são criados.

A primeira etapa do processo de recuperação de informação é transformar os documentos que poderão ser recuperados em um modelo de dados adequado para as técnicas computacionais que recuperam documentos. Na Figura 2.1 (1), o modelo de dados apresentado é a matriz de atributo/documento, cuja cada linha da matriz representa um documento da coleção, cada coluna da matriz um termo do conjunto de palavras da coleção e cada célula à frequência do termo em cada documento. No contexto de RI, a célula é o peso da palavra no documento. Esse peso pode ser definido usando diferentes tipos de atribuições de pesos, o mais simples é a frequência dos termos no documento.

A próxima etapa do processo de RI é iniciada pelo usuário inserindo no sistema de recuperação de documentos as palavras que podem representar a sua consulta na busca dos documentos de interesse. O buscador de conteúdos da internet Google ${ }^{1}$ realiza processamento semelhante. Quando há o desejo de buscar sites que correspondam a um interesse específico, o usuário digita no buscador palavras que representam o conteúdo desejado. Essas palavras compõem uma consulta computacional que tanto no Google quanto nos demais sistemas de RI, é transformada em um modelo de dado que seja condizente com o modelo de dados da coleção de documentos disponíveis (ou sites, no caso do Google) para recuperação da informação (ver Figura 2.1 (2)). Em seguida, os documentos disponíveis para recuperação e a consulta feita pelo usuário são convertidos para o modelo de representação de informações onde ambos podem ser comparados. Na Figura 2.1 (3), o modelo de representação vetorial é apresentado. Cada documento é representado por um vetor $\overrightarrow{d_{n}}$, cujo $n$ representa o número de documentos disponíveis para recuperação, e a consulta do usuário é representado por $\vec{q}$. Posteriormente, a similaridade entre a consulta e cada documento é calculada. Este cálculo pode ser realizado usando a medida do cosseno do ângulo formado entre a consulta do usuário e

\footnotetext{
${ }^{1}$ https://www.google.com.br/
} 
cada documento. Os resultados com valores mais elevados do cálculo de similaridade correspondem aos documentos mais similares à consulta do usuário. Por fim, esses documentos são retornados ao usuário (ver Figura 2.1 (4)). Na literatura computacional, os autores Baeza-Yates e Ribeiro-Neto apresentam uma arquitetura genérica de um sistema de recuperação de informação. Esta arquitetura é apresentada na Figura 2.2.

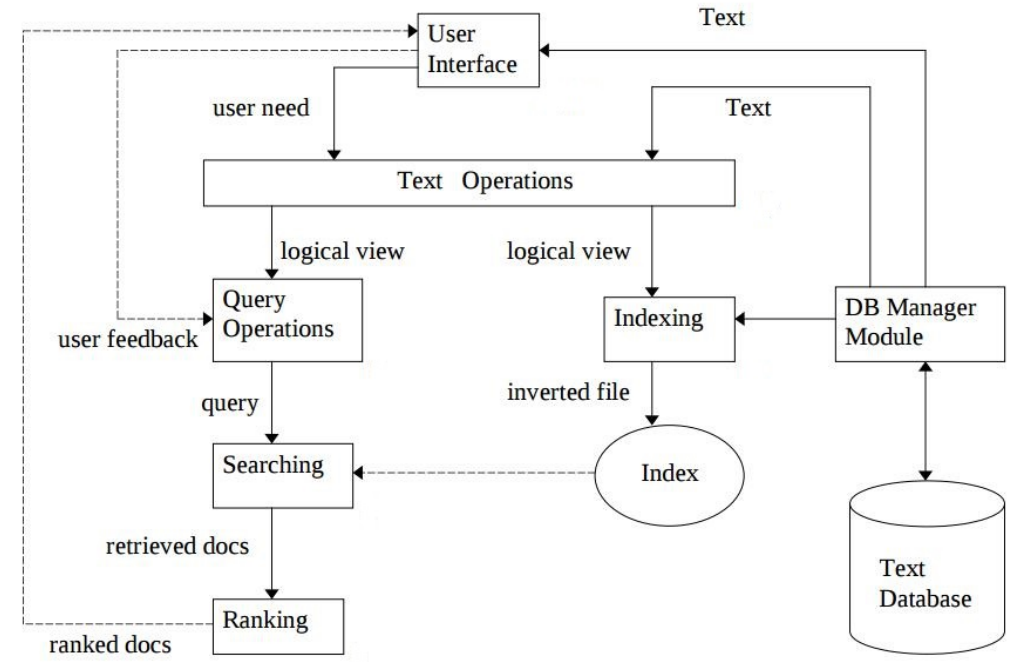

Figura 2.2: Arquitetura genérica de um sistema de RI. Fonte: Baeza-Yates e Ribeiro-Neto (1999).

De acordo com a Figura 2.2, os documentos que são utilizados na recuperação de informações são armazenados em uma base de texto (Text Database). Define-se também uma visão(ões) lógica(s) (logical view) dos documentos por meio das especificações (i) dos documentos a serem utilizados, (ii) das operações a serem realizadas na transformação dos documentos em uma visão lógica ( Text Operations) e/ou (iii) das estruturas de elementos que poderão ser recuperadas. Após definir a visão lógica dos documentos, o gerenciador de banco de dados (DB Manager Module) inicia o processo de Indexação (Indexing) gerando o índice (Index) representado por um arquivo invertido (inverted file). O índice é um "facilitador" que permite buscas (Searching) a grandes quantidades de dados de forma rápida e eficiente (Baeza-Yates e Ribeiro-Neto, 1999).

Após a indexação da base de documentos é possível recuperar os documentos a partir da consulta. O usuário descreve em uma expressão de busca o que deseja buscar (user need) usando as interfaces de usuário (User Interfaces). Essa expressão passa por um processo de transformação (Text Operations), semelhante aos documentos indexados e, posteriormente, por um processo específico para a criação da consulta computacional (Query Operations). Ao final dessa processo, as consultas que são representações computacionais do que o usuário deseja são criadas. Em seguida, as consultas são processadas pelos sistemas de recuperação de documentos com o intuito de recuperar os documentos de interesse (Searching) (Baeza-Yates e Ribeiro-Neto, 1999). Por fim, os documentos recuperados (retrieved docs) são ordenados (ranking) por meio de alguma métrica de similaridade.

Uma tentativa de aprimorar os resultados obtidos no processo de recuperação dos documentos (ranked docs) é por meio do processo de retroalimentação (user feedback). O usuário examina os documentos retornados pela consulta e indica os documentos mais relevantes para o contexto pesquisado. Posteriormente, essas informações de relevância dos documentos são adicionadas a 
consulta tornando-a mais próxima das necessidades do usuário (Baeza-Yates e Ribeiro-Neto, 1999). Mais informações de expansão de consultas estão na Seção 2.1.2

Os sistemas de recuperação de informação podem ir além de uma simples recuperação de informação que satisfaça uma consulta. Eles podem abordar também problemáticas de processamento de linguagem natural como, por exemplo, a ambiguidade, a sinonímia e as negações (Cardoso, 2004). Nesse sentido, a recuperação de informação pode envolver uma análise aprofundada, agregando dados e informações que não necessariamente estejam explicitados no texto. O processo de recuperação pode utilizar vários modelos de recuperação. Os modelos clássicos são booleano, vetorial e probabilístico.

\subsubsection{Modelos Clássicos de RI: Booleano, Vetorial e Probabilístico}

O modelo booleano utiliza os conceitos da Álgebra Booleana (Muller, 1954). Nesse modelo, os termos dos documentos são representados por pesos binários, ou seja, se eles estão presentes no documento recebem o valor 1, caso contrário 0. A relevância de um documento é calculada por meio da comparação entre documentos e a consulta feita pelo usuário na forma de uma expressão booleana composta por termos e operadores lógicos. As principais deficiências desse modelo são a dificuldade de tradução do desejo do usuário em uma expressão booleana de busca e o fato das decisões serem baseadas em critérios binários (Baeza-Yates e Ribeiro-Neto, 1999; Singhal, 2001).

O modelo vetorial propõe o uso de correspondências parciais para representar os termos dos documentos. O uso desse modelo é motivado pelo fato dos pesos binários serem fatores limitantes para uma busca mais assertiva. Assim, a indexação de termos nas consultas e nos documentos recebem pesos não-binários. Os pesos, nesse modelo, são calculados por meio de uma medida estatística chamada $t f-i d f$ (abreviação do inglês term frequency - inverse document frequency) (Baeza-Yates e Ribeiro-Neto, 1999). O intuito desta medida é avaliar a importância de um termo em um documento em relação a uma coleção de documentos. Baeza-Yates e Ribeiro-Neto (2013) adotam as Equações 2.1a e 2.1b, respectivamente, para os cálculos tf-idf.

$$
\begin{gathered}
T F_{i}=1+\log \sum_{j=1}^{N} f_{i, j} \\
I D F_{i}=\log \left(\frac{N}{n_{i}}\right)
\end{gathered}
$$

cujo $f_{i, j}$ é a frequência do termo $k_{i}$ no documento $d_{j}$ e $\log \left(\frac{N}{n_{i}}\right)$ é a frequência inversa de documentos do termo $k_{i}$. Posteriormente, os pesos $t f-i d f$ encontrados são utilizados no cálculo do grau de similaridade entre os documentos da base de documentos e a consulta criada pelo usuário. Geralmente, os documentos são ordenados em ordem decrescente de similaridade (Baeza-Yates e Ribeiro-Neto, 1999, 2013).

Para calcular a similaridade entre um documento $d_{j}$ e uma consulta do usuário $q$, representações vetoriais $t$-dimensionais são criadas, cujo $t$ é o tamanho do vocabulário, que armazena os pesos dos termos de índices $\left(w_{i, j}\right.$ para os documentos e $w_{i, q}$ para a consulta do usuário). O resultado da similaridade é o cálculo da correlação entre os vetores $\overrightarrow{d_{j}}$ e $\vec{q}$, ou seja, o cosseno do ângulo entre esses dois vetores (Baeza-Yates e Ribeiro-Neto, 1999). O cálculo é apresentado na Equação 2.2, cujos $\left|\overrightarrow{d_{j}}\right|$ e $|\vec{q}|$ representam, respectivamente, as normas (comprimento do vetor no espaço vetorial) dos 
vetores de documentos e da consulta.

$$
\begin{aligned}
\operatorname{sim}\left(d_{j}, q\right) & =\frac{\overrightarrow{d_{j}} \bullet \vec{q}}{\left|\overrightarrow{d_{j}}\right| \times|\vec{q}|} \\
& =\frac{\sum_{i=1}^{t} w_{i, j} \times w_{i, q}}{\sqrt{\sum_{i=1}^{t} w_{i, j}^{2}} \times \sqrt{\sum_{i=1}^{t} w_{i, q}^{2}}}
\end{aligned}
$$

Para Baeza-Yates e Ribeiro-Neto (1999), o modelo vetorial é simples, rápido e eficiente, quando comparado com outros métodos de recuperação de informação, além de ser um dos modelos mais conhecidos e utilizados. Contudo, como desvantagem, este modelo retorna conjuntos de respostas custosos de serem aprimorados sem o auxílio de artifícios como, por exemplo, a expansão de consultas.

O modelo probabilístico foi apresentado na década de setenta pelos professores Stephen Robertson e Karen Sparck Jones (Robertson e Spärck Jones, 1976). O modelo é conhecido também como Modelo de Independência Binária (Baeza-Yates e Ribeiro-Neto, 1999). A proposta desse modelo é utilizar dados da consulta do usuário para gerar um conjunto preliminar de documentos que possa satisfazer a consulta. Em seguida, por meio de interações com o usuário, que decide quais documentos são relevantes, o modelo refina a recuperação dos documentos tornando o conjunto recuperado mais próximo das necessidades reais do usuário (Bonfim, 2006).

\subsubsection{Expansão de Consultas}

Um dos problemas do processo de recuperação de informação é a dificuldade do usuário em expressar para os sistemas de RI as suas necessidades de busca. Para minimizar este problema, e, consequentemente, melhorar o desempenho dos sistemas de RI, pesquisadores da área estudam a aplicação de técnicas computacionais para atuar na ampliação dos termos já apresentado pela consulta e na reavaliação dos pesos das consultas (Baeza-Yates e Ribeiro-Neto, 1999).

A retroalimentação (feedback) de informação relevante é uma das técnicas mais comuns em recuperação de informação para o aprimoramento das consultas construídas pelo usuário. A técnica consiste em avaliar um pequeno grupo de documentos recuperados pelo sistema de RI e encontrar quais são os documentos retornados mais relevantes. A ideia é extrair deste grupo seleto de documentos os termos e as expressões mais relevantes que possam ser utilizados na reestruturação das consultas do usuário em consultas subsequentes. Nesse contexto, as abordagens podem ser divididas em: (i) retroalimentação de dados relevantes apoiado pelo usuário (Relevance Feedback) (ii) análise automática local dos documentos e (iii) análise automática global dos documentos (Baeza-Yates e Ribeiro-Neto, 1999).

As técnicas de relevância de feedback variam conforme o modelo de recuperação de informação utilizado. Por exemplo, para o modelo vetorial a abordagem de feedback mais conhecida é a de Rocchio (Rocchio, 1971). Esta abordagem parte do pressuposto que os usuários dos sistemas que avaliam os documentos tem a percepção de quais documentos devem ser considerados relevantes e irrelevantes (Baeza-Yates e Ribeiro-Neto, 1999, 2013; Manning et al., 2008; Xu e Croft, 1996). A abordagem de Rocchio prevê a interpretação humana do conjunto de treinamento de documentos como informação de feedback. Seguindo o modelo vetorial, cada documento $d_{j}$ é representado por 
um vetor de termos ponderado, dado por:

$$
\overrightarrow{d_{j}}=\left(w_{1, j}, w_{2, j}, \ldots, w_{t, j}\right)
$$

cujo $w_{i, j}$ é o peso do termo no documento $d_{j}$ e $t$ o tamanho do vocabulário. Os termos dos documentos de treinamento que pertencem a uma dada classe $c_{p}$ oferecem retroalimentações positivas. Por outro lado, os termos não pertencentes à $c_{p}$ oferecem alimentações negativas. Em seguida, as informações obtidas no processo de retroalimentação são sintetizadas em um vetor centroide $\overrightarrow{c_{p}}$ no espaço dos termos. O cálculo do vetor centroide é dado pela equação apresentada a seguir. Esta equação corresponde à fórmula de Rocchio (Hull, 1993) adaptada para classificação de texto.

$$
\overrightarrow{c_{p}}=\frac{\beta}{n_{p}} \sum_{d_{j} \in c_{p}} \overrightarrow{d_{j}}-\frac{\gamma}{N_{t}-n_{p}} \sum_{d_{l} \notin c_{p}} \overrightarrow{d_{l}}
$$

cujos $\beta$ e $\gamma$ modelam a importância relativa de termos nos documentos relacionados e não relacionados à classe $c_{p} . N_{p}$ representa o conjunto de treinamento e $n_{p}$ o número de documentos da classe $c_{p} \cdot \overrightarrow{d_{j}}$ é a representação dos documentos pertencentes a classe $c_{p}$ no espaço vetorial e $\overrightarrow{d_{l}}$ os não pertences à classe $c_{p}$. Após a definição do vetor centroide, um novo documento pode ser comparado calculando a sua distância até o centroide (Baeza-Yates e Ribeiro-Neto, 1999, 2013).

As abordagens de análise automática local e global de documentos implicam na identificação de termos sinônimos e complementares às consultas do usuário. Algumas das principais fontes de conhecimento para a expansão das consultas do usuário são as ontologias, os dicionários e os tesauri (Cardoso, 2004). Na abordagem global, todos os documentos da coleção são utilizados para criar um thesauri que, posteriormente, será apresentado ao usuário para seleção dos termos da expansão da consulta. Por outro lado, a abordagem local utiliza os documentos retornados pela consulta do usuário para determinar automaticamente os termos que serão utilizados na expansão da consulta (Baeza-Yates e Ribeiro-Neto, 1999).

\subsubsection{Avaliações de Sistemas de RI}

A avaliação de sistemas de recuperação da informação não é uma tarefa trivial, pois exige a construção de uma coleção de referência, a escolha das métricas a serem utilizadas e uma metodologia para a comparação dos resultados (Silva et al., 2003). Nos dias atuais existem conferências que disponibilizam coleções de referências para avaliação de sistemas de RI. Uma das mais conhecidas é a TREC ${ }^{2}$ (Text Retrieval Conference), que é mantida pelo NIST (National Institute of Standards and Technology) e pelo IARPAde ( Intelligence Advanced Research Projects Activity). A TREC disponibiliza coleções de referências que objetivam proporcionar um ambiente controlado para avaliação de métodos de recuperação de informação. Os grupos participantes da conferência recebem um conjunto de dados (coleção de referência) e uma situação-problema a ser solucionada. Cada grupo apresenta sua solução e os resultados obtidos. Após a avaliação dos resultados, um workshop para discussão desses resultados e trocas de ideias é realizado (Voorhees e Harman, 2001).

$\mathrm{Na}$ avaliação de sistemas de recuperação de informação, as métricas mais utilizadas para avaliação de desempenho são a precisão (do inglês, precision), a revocação (do inglês, recall) e a $F$-measure. Seja $|R|$ a quantidade total de documentos pertencentes ao conjunto $R$ de documentos

\footnotetext{
${ }^{2}$ http://trec.nist.gov/
} 
relevantes. Após o processo de recuperação de documentos, o sistema retorna um conjunto resposta $A$ de documentos, onde $|A|$ é a quantidade total de documentos retornados. Os documentos pertencentes, ao mesmo tempo, aos conjuntos de documentos relevantes e documentos resposta são representados por $|R a|$. Revocação é o número de documentos relevantes (conjunto $R$ ) que foram recuperados do conjunto total de documentos, enquanto que a precisão é o número de documentos recuperados do conjunto total de documentos (conjunto $A$ ) que são relevantes. A $F$-measure é uma medida que avalia o desempenho geral do sistema utilizando os resultados da precisão $P(j)$ e da revocação $R(j)$ sumarizados na forma de média harmônica. O resultado da $F$-measure $F(j)$ é um valor entre 0 e 1 . Quanto mais próximo do 0 está esse resultado, menos documentos relevantes o sistema retornou ou, quanto mais próximo do 1, mais documentos relevantes o sistema retornou (Baeza-Yates e Ribeiro-Neto, 1999). Nas Equações 2.5a, 2.5b e 2.5c são apresentadas as fórmulas para calcular, respectivamente, a revocação, a precisão e a F-measure.

$$
\begin{gathered}
R(j)=\frac{|R a|}{|R|} \\
P(j)=\frac{|R a|}{|A|} \\
F(j)=\frac{2}{\frac{1}{R(j)}+\frac{1}{P(j)}}
\end{gathered}
$$

\subsection{Extração de Informação}

A Extração da Informação (EI) é uma área da Ciência da Computação que objetiva: (i) buscar a combinação de informações relevantes ao mesmo tempo que descartam informações irrelevantes (Cowie e Lehnert, 1996; Grishman, 1997) (ver Figura 2.3 (1)); e (ii) localizar e extrair informações relevantes as quais remetem a um referente específico expressas em linguagem natural em documentos textuais de maneira automática. Por exemplo, no contexto de textos biomédicos, técnicas de EI podem localizar e extrair informação relevante de abreviações de nomes de doenças, como o T2DM (Type 2 Diabetes Mellitus) (ver Figura 2.3 (2)); e (iii) converter as informações extraídas em estruturas que facilitem a manipulação e análise (ver Figura 2.3 (3)).

Os sistemas das áreas de RI e de EI possuem diferenças entre si. O primeiro tipo de sistema tem como objetivo a recuperação dos documentos com base em uma consulta realizada pelo usuário e o outro extrai informações relevantes do conteúdo dos documentos. Nesse sentido, as áreas de RI e EI são complementares (Álvarez, 2007; Gaizauskas e Wilks, 1998). O processo de extrair informações de documentos pode utilizar diferentes áreas de estudo da Ciência da Computação. Por exemplo, quando o foco é a análise e a busca automática de informações relevantes em textos não estruturados, abordagens da área de Mineração de Texto (MT) são utilizadas (Cohen e Hunter, 2008). Contudo, se o foco for na automatização, na criação e no aprendizado de regras para buscar e extrair as informações relevantes, as abordagens empregadas são as da área de Aprendizado de Máquina (Álvarez, 2007). Na literatura, especificamente nas abordagens de Aprendizado de Máquina, uma das técnicas que vêm sendo empregada com certa frequência é a Máquina de Vetores de Suporte (do inglês, Support Vector Machine) (Ben Abacha e Zweigenbaum, 2015; Chali et al. , 2015; Yen et al., 2013). Uma terceira abordagem de EI é o uso de dicionários, ou seja, uma lista 
(3) Representação de um documento

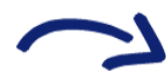
na forma de informação estruturada

\begin{tabular}{|c|c|c|c|c||c|}
\hline & $t_{1}$ & $t_{2}$ & $\ldots$ & $t_{M}$ & $C$ \\
\hline \hline$d_{1}$ & $a_{11}$ & $a_{12}$ & $\ldots$ & $a_{1 M}$ & $C_{1}$ \\
\hline$d_{2}$ & $a_{21}$ & $a_{22}$ & $\ldots$ & $a_{2 M}$ & $C_{2}$ \\
\hline$\ldots$ & $\ldots$ & $\ldots$ & $\ldots$ & $\ldots$ & $\ldots$ \\
\hline$d_{N}$ & $a_{N 1}$ & $a_{N 2}$ & $\ldots$ & $a_{N M}$ & $C_{N}$ \\
\hline
\end{tabular}

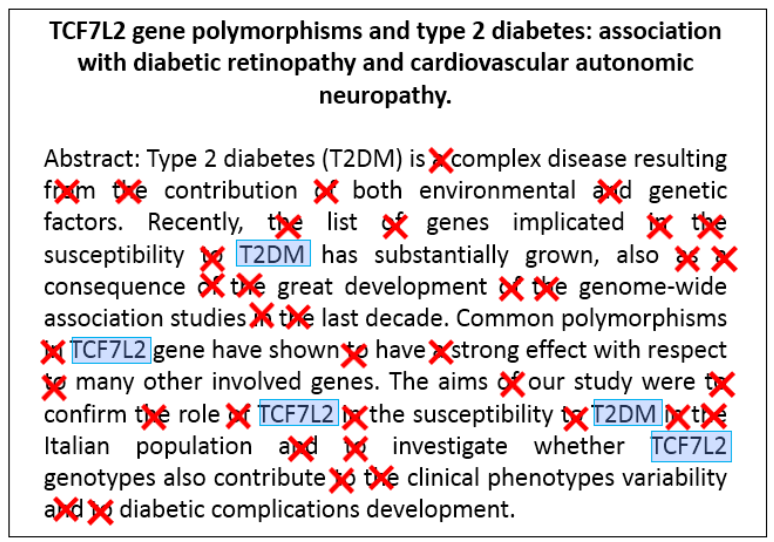

(1) Stopwords

(2) Reconhecimento de Entidades Nomeadas

Figura 2.3: Apresentação de algumas técnicas de Extração de Informação. (1) As stopwords foram desconsideradas. (2) Busca por palavras importantes do texto. (3) Transformação do texto, em formato nãoestruturado, em uma representação estruturada na forma de matriz. (O texto utilizado para demonstração das técnicas de Extração de Informação é baseado em Ciccacci et al. (2013).)

de termos pertencentes ao domínio da aplicação que serão procurados no texto. A seguir, as três principais abordagens de extração da informação são apresentadas.

\subsubsection{Mineração de Texto}

A Mineração de Texto (MT) é uma área da Ciência da Computação responsável pela descoberta e obtenção de informações relevantes em documentos de textos (Salton e McGill, 1986). Neste sentido, o intuito da MT é transformar informação textual em informações para análises posteriores. Alguma das principais tarefas de MT são extração de conceitos/entidades, categorização e agrupamento de texto e análise de sentimentos. Geralmente, estas análises são divididas em quatro etapas: (1) Coleta de Documentos, (2) Pré-Processamento, (3) Extração de Conhecimento e (4) Avaliação e Interpretação dos Resultados (Matsubara et al., 2003).

A "(1) Coleta de Documentos" representa a seleção e a recuperação dos documentos relevantes para o contexto da aplicação. A etapa de "(2) Pré-Processamento" é composta por técnicas computacionais que preparam o texto para os processamentos mais complexos. Geralmente, as atividades realizadas durante esta etapa são a limpeza, o tratamento dos dados e a redução dos atributos a serem processados nas próximas etapas (Moura et al., 2010). A tokenização é a separação do documento em termos. Esta separação pode utilizar como delimitador o espaço em branco, a quebra de linha ou algum carácter específico. Após o texto ser tokenizado, a próxima etapa é a remoção dos termos comuns do documento, ou seja, as stopwords. As stopwords são compostas por preposições, advérbios, artigos, entre outras classes gramaticais das palavras. Por fim, o stemming é um método que reduz o termo ao seu radical, por meio da remoção de elementos das palavra como, por exemplo, os afixos e as vogais temáticas (Bird et al., 2009). Na Figura 2.4, um exemplo de stemming é apresentado. Neste exemplo, várias palavras similares pertencentes a mesma família são reduzidas ao mesmo radical. 


\begin{tabular}{|c|c|}
\hline Palavras & Stem \\
\hline Computacionalmente & \\
Computador & Comput \\
Computadores & Computar \\
Computacional & \\
\hline
\end{tabular}

Figura 2.4: Exemplo de stemming.

A terceira etapa da MT é a "(3) Extração do Conhecimento". Em textos não estruturados, diferentes níveis de análise podem ser realizados, são eles: o sintático, o semântico e o morfológico (Jurafsky e Martin, 2000). A análise sintática é a avaliação da relação de um termo aos demais termos da sentença. A análise semântica avalia o significado de elementos como as palavras, as frases e os seus relacionamentos. Neste sentido, a sinonímia (palavras diferentes com mesmo significado, ex. perto $\rightarrow$ próximo) e a antonímia (palavras com sentidos contrários uma a outra, ex. perto $\rightarrow$ longe) são examinadas (Wilhelm et al., 2013). A análise morfológica avalia a gramática de cada palavra da frase isoladamente. Na Figura 2.5, exemplos de análise sintática e morfológica são apresentados para a mesma sentença. Na computação, existem abordagens que realizam análises morfo/sintáticas como, por exemplo, o etiquetador morfossintático (do inglês, Part-of-Speech Tagger (POS-Tagging)), e análises semânticas como, por exemplo, as abordagens de reconhecimento de entidades nomeadas (do inglês, Named Entity Recognition (NER) (Jurafsky e Martin, 2000; NLTK, 2015; Wilhelm et al., 2013).

\section{"João comprou uma casa"}

Análise morfológica: João_substantivoPróprio comprou_verbo uma_artigo casa_substantivoComum

Análise sintática: João_sujeito comprou_núcleoDoPredicadoVerbal_(comprou uma casa)

uma adjuntoAdnominal casa núcleoDoObjetoDireto_(uma casa)

Figura 2.5: Exemplos de análises morfo/sintática e semântica.

O POS-tagging pode ser baseado em abordagens compostas por regras ou probabilidade. A NLTK, por exemplo, é uma biblioteca de PLN para a linguagem computacional Python que utiliza a abordagem estatística para etiquetar as palavras dos textos. Nesse sentido, a NLTK analisa qual é a tag mais provável para cada palavra (NLTK, 2015). O NER busca e classifica palavras de acordo com categorias pré-definidas como, por exemplo, localização e nomes próprios. As abordagens são baseadas em (i) técnicas de Aprendizado de Máquina (Nadeau e Sekine, 2007) como, por exemplo, as Árvores de Decisão (do inglês, Decision Trees) (Sekine, 1998) e as Máquinas de Vetores de Suporte (do inglês, Support Vector Machine) (Asahara e Matsumoto, 2003), (ii) expressões regulares e (iii) modelos sequenciais como, por exemplo, Modelos Ocultos de Markov (do inglês, Hidden Markov Models) (Bikel et al., 1997). Por fim, a etapa de "(4) Avaliação e Interpretação dos Resultados" é responsável por validar as informações extraídas anteriormente (Matsubara et al., 2003).

Muitas vezes, a representação da informação no formato não-estruturado pode comprometer a eficiência dos algoritmos de EI. Nesse sentido, a transformação desta informação para um formato estruturado é um passo importante. Um dos modelos mais comuns desse tipo de conversão é a Bag-of-Words. Nesse modelo, cada documento é representado como um vetor dos termos existentes 
no documento. Na Tabela 2.1, um exemplo de representação de um conjunto de documentos no formato estruturado de uma matriz atributo-valor é apresentado (Matsubara et al., 2003).

\begin{tabular}{|c|c|c|c|c||c|}
\hline & $t_{1}$ & $t_{2}$ & $\ldots$ & $t_{M}$ & $C$ \\
\hline \hline$d_{1}$ & $a_{11}$ & $a_{12}$ & $\ldots$ & $a_{1 M}$ & $C_{1}$ \\
\hline$d_{2}$ & $a_{21}$ & $a_{22}$ & $\ldots$ & $a_{2 M}$ & $C_{2}$ \\
\hline$\ldots$ & $\ldots$ & $\ldots$ & $\ldots$ & $\ldots$ & $\ldots$ \\
\hline$d_{N}$ & $a_{N 1}$ & $a_{N 2}$ & $\ldots$ & $a_{N M}$ & $C_{N}$ \\
\hline
\end{tabular}

Tabela 2.1: Representação de um documento na forma de informação estruturada de uma matriz atributovalor.

onde $C=\left(C_{1}+C_{2}+\ldots+C_{N}\right)$ representa a classe à qual o documento pertence, o $N$ representa o número total de documentos (exemplos) e o $d$ representa cada documento que é composto por $M$ termos (atributos), ou seja, a representação de cada documento é $d_{N}=\left(a_{N 1}+a_{N 2}+\ldots+a_{N M}\right)$, onde, $a_{N M}$ refere-se a um valor associado ao $M$-esimo termo do $N$-esimo documento. Este valor pode ser calculado por medidas como tf-idf (Baeza-Yates e Ribeiro-Neto, 1999; Matsubara et al. , 2003).

\subsubsection{Aprendizado de Máquina}

Aprendizado de Máquina (AM) (do inglês, Machine Learning) é uma subárea da Inteligência Artificial que estuda o desenvolvimento e o aprimoramento de técnicas computacionais que auxiliem as máquinas a aprender novos conhecimentos, habilidades e/ou reorganizar o conhecimento existente de forma automática (Nguyen e Armitage, 2008; Shi, 1992). Os sistemas de AM possuem o diferencial de aprender com a experiência, ou seja, o algoritmo cria uma base de conhecimento e a aperfeiçoa constantemente, implicando na melhora do desempenho do sistema. As técnicas de AM são aplicadas em diversos tipos de problemáticas como, por exemplo, no auxílio ao diagnóstico médico, no reconhecimento de elementos de interesse na escrita natural e no marketing (Nguyen e Armitage , 2008).

A classificação de dados é uma das tarefas que mais utilizam AM. Nesse sentido, as abordagens de AM criam um classificador, baseado em um conjunto de informações cujo resultado é conhecido, que deve ser capaz de prever à qual classe um dado desconhecido pertence. Um dos algoritmos de AM usado na classificação de dados textuais é a Máquina de Vetores de Suporte (do inglês, Support Vector Machine - SVM). A SVM é um algoritmo do tipo supervisionado, ou seja, o algoritmo necessita de um conjunto de dados rotulados para poder aprender e ser capaz de classificar dados desconhecidos (Lorena e de Carvalho, 2007). O objetivo das SVM (Boser et al., 1992) é determinar o hiperplano ótimo, ou seja, encontrar a superfície de separação que apresenta as margens maximizadas. Para alcançar este objetivo, a SVM utiliza, como método de aprendizado, o princípio indutivo de Minimização do Risco Estrutural ${ }^{3}$. Neste sentido, a máquina consegue alcançar bom desempenho ao generalizar, ou seja, classificar dados desconhecidos, mesmo que o domínio do problema seja desconhecido. Os vetores de suporte resultantes do processo de treinamento são padrões extraídos dos dados de entrada aproximados da superfície de decisão (Haykin, 2001; Takahashi , 2015).

\footnotetext{
${ }^{3} \mathrm{O}$ princípio indutivo de Minimização do Risco Estrutural procura minimizar o erro do conjunto de treinamento (risco empírico) ao mesmo tempo que procura minimizar o erro do conjunto de teste (Santos, 2002; Vapnik, 2013).
} 


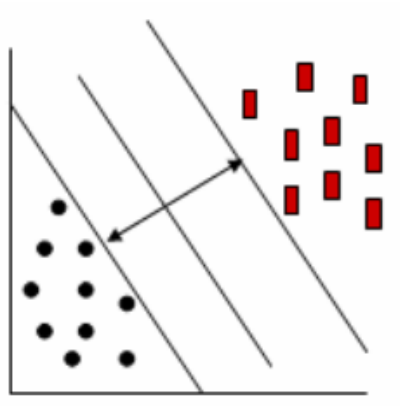

Figura 2.6: Superfície de separação com as margens maximizadas. Fonte: Medeiros (2004).

Segundo Smola et al. (2000), as SVM são atrativas devido à sua capacidade de generalização sem a incidência de overfitting, ou seja, sem que o classificador se torne especialista no conjunto de treinamento e perca a sua capacidade de classificação quando inserido um novo exemplo desconhecido. Joachims (1998) explora o uso de SVM na classificação de texto. Para o autor, a primeira etapa é a transformação do texto em um outro formato representativo mais adequado para o algoritmo de AM. Alguns pontos são notáveis e essenciais na utilização de SVM para a classificação de texto como, por exemplo, (i) a sua capacidade de aprendizado independente da dimensionalidade do espaço de características e (ii) o aproveitamento de grande parte da informação extraída dos textos (outros classificadores mineram as informações antes de utilizá-las).

\subsubsection{Dicionários}

A abordagem de dicionários para extração de informação em documentos utiliza modelos de dados do domínios de interesse, que possibilitam a busca por ocorrências no texto. Algumas desvantagens dessa abordagem são a restrição de termos do dicionário e a imprecisão no reconhecimento de alguns termos devido à variação ortográfica (Tsuruoka e Tsujii, 2004).

A ontologia é um modelo de dados utilizado para inferir objetos de um domínio. Uma das primeiras definições sugere que ontologia é uma descrição de conceitos e seus relacionamentos, demonstrada em um vocabulário representacional (Gruber, 1993). A ontologia consiste em definições precisas e em um conjunto formal de axiomas, que delimitam a interpretação e o uso dos termos presentes no vocabulário (Gruber, 1993). As ontologias podem ser utilizadas, por exemplo, no auxílio à categorização de imagens por meio da inserção de informações textuais como anotações em imagens. Uma vantagem do seu uso em repositórios de dados visuais é a possibilidade de buscar imagens por meio da busca das anotações ontológicas, em vez de utilizar atributos visuais da imagem (Lopes et al., 2007).

Outro modelo de dados amplamente utilizado por pesquisadores da área da saúde e medicina é a UMLS (do inglês, Unified Modelling Language System). Este modelo de dados é conhecido por facilitar a criação de sistemas de informações e serviços com alto grau de eficácia e interoperabilidade, por meio da distribuição de chaves terminológicas e da classificação e codificação de normas biomédicas (Bodenreider, 2004). A UMLS é um sistema composto por conhecimentos ontológicos e terminológicos acumulados ao longo dos anos, utilizado em abordagens automáticas e semiautomática de análise textual (Brin, 1999). 


\subsection{Sistemas de Question-Answering}

Segundo Athenikos e Han (2010), os sistemas de Question Answering (QA) tem como objetivo fornecer informações diretas e precisas sobre uma pergunta proposta pelo usuário do sistema. Para realizar esta tarefa, estes sistemas utilizam técnicas computacionais, principalmente, das áreas de Extração de Informação e Recuperação de Informação (Allam e Haggag, 2012). Os sistemas de QA podem ser considerados uma otimização dos sistemas de RI pois, ao mesmo tempo que os sistemas de RI retornam documentos completos que, muitas vezes, o usuário não tem tempo de ler em busca da "resposta desejada", os sistemas de QA retornam respostas curtas e diretas (Allam e Haggag, 2012).

Quando o usuário deseja fazer uma busca por informações de interesse nos sistemas de QA, o primeiro passo é elaborar uma questão que traduza a sua necessidade de busca. Por exemplo, caso o usuário queira procurar os sintomas da gripe, uma pergunta como "Quais são os principais sintomas da gripe?" deve ser formulada. Dependendo da arquitetura dos sistemas de QA, eles podem responder a vários formatos de perguntas, sendo que o mais comum e simples é o factual, ou seja, perguntas que se baseiam em fatos como, por exemplo, "Quando aconteceu a Segunda Guerra Mundial?". Com o avanço das pesquisas da área, outros tipos de perguntas mais complexas puderam ser incluídas como, por exemplo, as questões com múltiplas respostas ("Quais os países vencedores da Copa do Mundo de Futebol?"), as questões de definição ("O que é FBI?") e as questões do tipo "Por que" ("Por que aconteceu o golpe militar no ano de 1964?") (Allam e Haggag , 2012). Em geral, sistemas de QA apresentam uma arquitetura básica composta por três módulos principais: (i) processamento da questão, (ii) processamento do documento e (iii) processamento da resposta (Hirschman e Gaizauskas, 2001). Na Figura 2.7, a arquitetura genérica de um sistema QA com a expansão dos módulos principais é ilustrada.

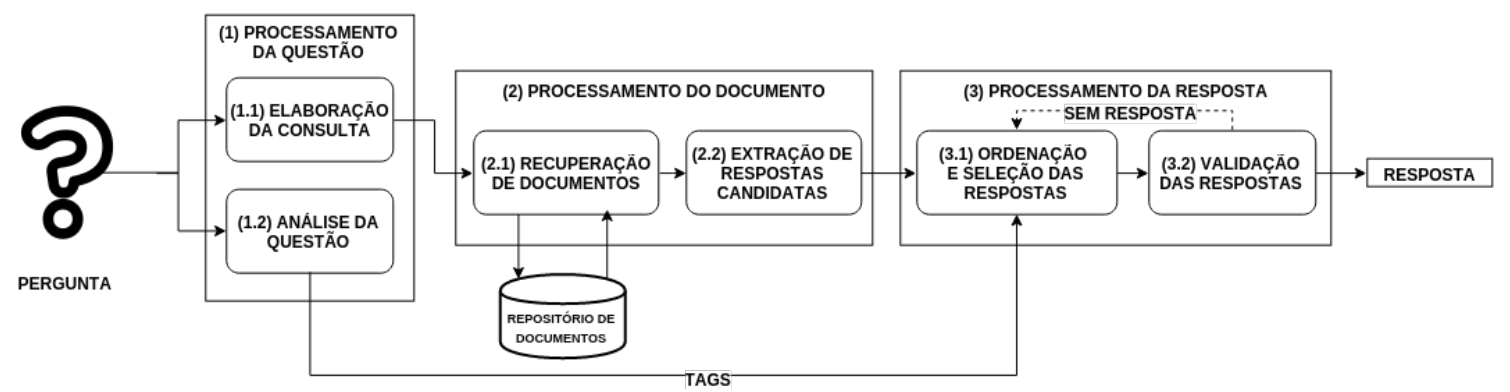

Figura 2.7: Arquitetura genérica de um sistema de Question-Answering.

A etapa "(1) Processamento da Questão" consiste (i) na transformação da pergunta, realizada pelo usuário em linguagem natural em uma consulta em linguagem computacional e (ii) na compreensão da pergunta com o intuito de extrair informações que auxiliem na seleção das respostas candidatas. Na etapa "(2) Processamento do Documento", a consulta, gerada anteriormente, é utilizada na recuperação de documentos relevantes e na extração de respostas candidatas. E, por fim, na etapa "(3) Processamento da Resposta", as respostas candidatas são ordenadas com base na análise da similaridade entre a pergunta e as respostas candidatas e apresentadas ao usuário (Athenikos e Han , 2010). Os sistemas de QA são conhecidos por apresentarem uma única resposta para a pergunta do usuário, contudo, eles podem apresentar várias respostas ordenadas por relevância. As etapas da arquitetura genérica de sistemas de QA são detalhadas a seguir. 


\subsubsection{Processamento da Questão}

A etapa de "Processamento da Questão" é a primeira etapa do processo de Question-Answering. Um dos objetivos desta etapa é extrair e inferir informações-extras, muitas vezes implícitas, na questão. Essas informações extras são fundamentais na seleção das respostas candidatas como, por exemplo, o tema (cidades, pessoas e organizações) ou o tipo da questão (definição e múltiplas respostas). Outro objetivo desta etapa é converter a questão inserida pelo usuário, em linguagem natural, em uma consulta em linguagem computacional. Esta consulta é utilizada, posteriormente, na etapa de "Processamento dos Documentos".

A etapa de Processamento da Questão é normalmente dividida em dois módulos: (1.1) Elaboração da Consulta e (1.2) Análise da Questão. O módulo de Análise da Questão é composto pelas tarefas de: (i) análise da questão e (ii) análise do foco da questão. Este módulo é um dos mais complexos e importantes de um sistema de QA, pois em uma questão há informações explícitas (as entidades que compõem a sentença) e implícitas (a análise do contexto e a ambiguidade), e, caso uma questão seja classificada equivocadamente, todas as demais etapas são comprometidas, assim como a resposta final retornada para o usuário (Allam e Haggag, 2012). Na Figura 2.8, exemplos de questão e dos tipos de informações-extras buscadas nesta etapa são apresentados. As palavras sublinhadas são exemplos de informações implícitas buscadas nessa etapa.

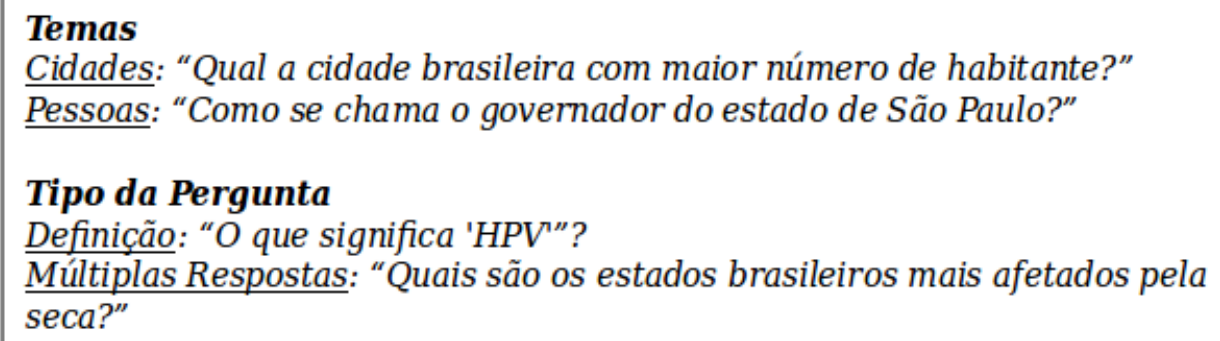

Figura 2.8: Exemplos de informações implícitas que podem ser descobertas nessa etapa. O objetivo principal é encontrar as palavras que estão sublinhadas por meio da análise do conteúdo da questão.

A análise da questão fornece informações importantes que podem ser utilizadas na localização e na verificação das respostas candidatas. Neste sentido, a descoberta do tipo de pergunta feita pelo usuário (O que?, Por que?, Quem?, Como?, Quando? ou Onde?) pode indicar qual é o tipo da resposta esperada. Na Tabela 2.2, um exemplo de mapeamento dos tipos de questão e seus significados é apresentado. A primeira coluna apresenta as palavras comumente utilizadas na construção das perguntas e na segunda coluna, as tags, traduzidas do inglês, relacionadas ao tipo de resposta esperada são apresentadas. Estas tags são enviadas para as etapas subsequentes de processamento do sistema. Os elementos da tabela fazem parte de um conjunto de regras para extração de informação que Srihari e Li (1999) utilizam em seus trabalhos. 


\begin{tabular}{|c|c|}
\hline Tag & Significado \\
\hline Who/Whom & Pessoa \\
\hline When & Tempo \\
\hline Where/What place & Localização \\
\hline What time day & Tempo \\
\hline What day week & Dia \\
\hline What/Which month & Mês \\
\hline What brand & Produto \\
\hline What & Nome \\
\hline How far/tall/high & Comprimento \\
\hline How large/hifh/small & Area \\
\hline How heavy & Peso \\
\hline How rich & Dinheiro \\
\hline How often & Frequência \\
\hline How many & Número \\
\hline How long & Duração \\
\hline Why/For what & Razão \\
\hline
\end{tabular}

Tabela 2.2: Apresentação das expressões que iniciam perguntas em inglês e seus respectivos significados. Fonte: Srihari e Li (1999).

Uma das abordagens mais simples utilizada na descoberta das classes da pergunta é por meio da correspondência de padrões. Geralmente, a ordem das palavras na sentença é capaz de sugerir as classes à qual a questão pertence. Por exemplo, na pergunta "Quando Barack Obama nasceu?" a palavra "Quando" sugere tempo/data, enquanto que "nasceu" especifica qual data é procurada e "Barack Obama" indica o sujeito ao qual a pergunta se refere. Devido à complexidade da tarefa de classificação, vários autores sugerem o uso de outras abordagens. Por exemplo, Zhang e Lee (2003) sugerem o uso de Máquina de Vetores de Suporte (do inglês, Support Vector Machine), ao mesmo tempo que Monz (2003) sugere a análise morfossintática, que é o processo de atribuição de tags computacionais que podem representar as classes gramaticais do idioma aos elementos da sentença.

A análise do foco da questão refere-se ao ponto central da questão, ou seja, ao que ela se refere. Por exemplo, na pergunta "Qual o país que mais importa soja?" o foco é "importa soja". Buscar o foco de uma questão é uma das melhores maneiras de eliminar a ambiguidade que uma pergunta pode conter como, por exemplo, na frase "Qual a cor da manga do termo do presidente dos Estados Unidos durante seu discurso presencial no ano de 2008?" a palavra "manga" pode se referir a uma fruta ou a uma parte de uma camisa. Uma das abordagens utilizadas na descoberta do foco é a busca por correspondências de padrões baseado nas informações de classificação da questão (Allam e Haggag, 2012).

A tarefa de elaboração da consulta extraí um conjunto de palavras-chave que será a base da consulta computacional. A consulta gerada é transmitida para o módulo de processamento do documento, especificamente na etapa de recuperação de documentos. Um exemplo de conversão da pergunta em consulta computacional é apresentado na Figura 2.9. As principais abordagens utilizadas na definição do conjunto das palavras-chave são a eliminação de stopwords, o reconhecimento das entidades nomeadas e um etiquetador morfossintático de textos (do inglês, Part-of-Speech Tagger). Abordagens complementares como, por exemplo, as ontologias e os dicionários de sinônimos, podem ser utilizadas na expansão do conjunto de palavras-chaves (Allam e Haggag, 2012). 


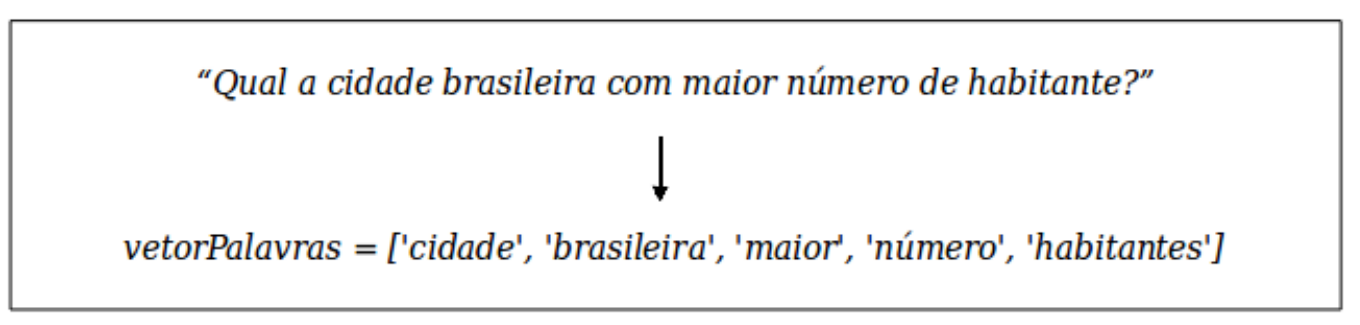

Figura 2.9: Exemplo de conversão de uma pergunta, em linguagem natural, em um vetor de palavras-chave.

\subsubsection{Processamento de Documentos}

A etapa de "Processamento do Documento" engloba as tarefas que compreendem desde a recuperação dos documentos candidatos até o tratamento e a extração das respostas candidatas. Esta etapa é dividida nas tarefas de (i) recuperação de documentos e (ii) extração das respostas candidatas. Esta etapa recebe como entrada de dados a consulta criada pela etapa de processamento da questão com base na pergunta feita pelo usuário.

A tarefa de recuperação de documentos objetiva a recuperação de documentos precisos que contenham a resposta da pergunta elaborada pelo usuário. Uma diferença entre os sistemas de RI e os módulos de recuperação de documentos em sistemas de QA é o rigor na recuperação dos documentos. A proposta dos sistemas de QA é fornecer respostas objetivas, diferente dos sistemas de RI que buscam por informações mais genéricas tornando o resultado da busca por documentos relevantes mais ampla (Monz, 2003).

Encontrar respostas em documentos não é uma tarefa simples, pois as perguntas podem apresentar diferentes níveis de complexidade. Há diferentes maneiras de analisar um documento em busca das respostas. Uma delas é utilizar as tags encontradas na etapa de análise da questão e da resposta para direcionar quais artigos científicos serão recuperados e quais são as possíveis potenciais respostas associadas a esses artigos. Outras abordagens propostas são o uso de árvores de análise sintática ou de grafos de dependência (Monz, 2003).

Caso não seja possível estabelecer uma conexão entre a questão e as respostas candidatas por meio da análise sintática, outras abordagens mais complexas podem ser utilizadas como, por exemplo, a proximidade linear. O conceito de proximidade linear é baseado na premissa de que as palavras-chave que representam a pergunta do usuário e a resposta candidata estão contidas em uma pequena quantidade $N$ de parágrafos consecutivos. Caso a premissa se concretize na análise do documento, ele é retornado, caso contrário não (Allam e Haggag, 2012; Gupta e Gupta, 2012).

\subsubsection{Processamento da Resposta}

A etapa de "Processamento da Resposta" é a última fase do processo de Question Answering. Nesta etapa, as respostas candidatas são selecionadas e ordenadas de acordo com o grau de similaridade entre a questão e as respostas candidatas. A etapa se divide entre as tarefas de (i) seleção e ordenação das respostas e (ii) validação das respostas. Como resultado desse módulo, respostsa para a pergunta inserida pelo usuário no começo do processo de QA são retornadas. Os sistemas de QA não precisam, necessariamente, retornar uma única resposta, eles podem retornar várias respostas ordenadas de acordo com o grau de relevância.

A primeira etapa do processo de seleção da resposta é a identificação das respostas candidatas. 
Várias abordagens podem ser utilizadas nesse processo. Monz (2003) propõe o uso das tags definidas nas etapas de análise da pergunta ou o uso de um etiquetador morfossintático. Allam e Haggag (2012) propõem a ordenação dos parágrafos. Esta ordenação pode ser realizada de acordo com critérios como, por exemplo, a resposta mais relevante ou a menos relevante.

Na ordenação de parágrafos, o algoritmo pode ser utilizado baseado em três critérios distintos: (i) a quantidade de palavras da questão do usuário, que são reconhecidas nas respostas candidatas na mesma ordem de posição, (ii) o número de palavras que separa as palavras-chave mais distantes entre si no parágrafo analisado ou (iii) o número de palavras incompatíveis com as palavraschave (Gupta e Gupta, 2012).

A partir da identificação das respostas candidatas, é possível definir qual resposta deve ser selecionada. Nesta etapa, a abordagem heurística é uma das mais utilizadas. Esta abordagem extrai somente as palavras mais relevantes para a resposta final por meio de medidas como, por exemplo, a distância entre palavras-chave ou a quantidade de palavras-chave coincidentes entre respostas e a questão. Caso o sistema não encontre nenhuma resposta, ele retorna para a etapa de ordenação dos parágrafos (Allam e Haggag, 2012). Monz (2003) sugere que caso tenha feito o uso de árvores de análise sintática ou grafos de dependência na etapa de análise dos documentos, essas informações devem ser analisadas e comparadas com uma árvore de análise sintática da questão na etapa de identificação da resposta, pois a posição dos elementos nestas árvores fornece informações relevantes.

Para validar as respostas recuperadas pelo sistema de QA, os autores Allam e Haggag (2012) propõem o uso de ferramentas lexicais como o WordNet $^{4}$ na validação da resposta candidata como resposta correta. Neste sentido, as respostas candidatas são submetidas às ferramentas lexicais e os resultados obtidos são comparados com a resposta correta para verificar se a resposta candidata é do mesmo tipo da resposta correta. Na Figura 2.10, um exemplo de comparação entre as estruturas gramaticais da resposta candidata e da resposta correta é apresenta. Quando as perguntas se tratam de domínios específicos, às vezes, é necessário o uso de fontes de informações específicas.

\section{Pergunta: "Qual o nome do presidente dos EUA?"}

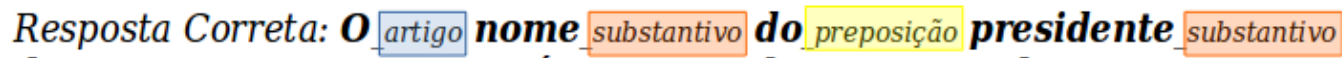
dos preposição EUA NomePróprio é verbo Barack NomePróprio Obama NomePróprio.

Resposta Candidata: $\boldsymbol{O}$ artigo nome substantivo do preposição presidente substantivo $_{\text {na }}$ dos preposição EUA NomePróprio é verbo George NomePróprio Bush NomePróprio.

Figura 2.10: Exemplo de comparação entre a estrutura gramatical da resposta candidata e da resposta correta. Neste contexto, a ordem das cores de ambas as frases devem estar alinhadas.

\subsubsection{Avaliação de Sistemas de QA}

A avaliação de sistemas de QA pode ser realizada (i) manualmente, por meio de um colaborador humano, (ii) automaticamente, por meio de scripts pré-programados ou (iii) pela combinação e comparação dos resultados obtidos nas avaliações manuais e automáticos. As comparações são realizadas por meio de medidas estatísticas de coocorrência (Bilotti e Nyberg, 2006). Uma das formas

\footnotetext{
${ }^{4}$ https://wordnet.princeton.edu/
} 
mais conhecidas de avaliação de sistemas de QA utiliza corpus compostos por tuplas de perguntas e respostas. Os corpus podem ser criados especificamente para a avaliação do sistema em questão ou disponibilizados por conferências como a TREC (Voorhees e Tice, 2000) e a CLEF (Magnini et al., 2004; Olvera-Lobo e Gutiérrez-Artacho, 2015). Informações sobre a TREC foram/são apresentadas, respectivamente, nas Seções 2.1.3 e 3.1.

A CLEF (do inglês, Conference and Labs of the Evaluation Forum), anteriormente chamada Cross-Language Evaluation Forum, é uma organização que oferece suporte à pesquisa no contexto multilíngue. A principal tarefa da CLEF é desenvolver repositórios de dados para o desenvolvimento de novas técnicas computacionais e propiciar, para os seus pesquisadores participantes, condições para a realização de experimentos de sistemas de RI e, mais recentemente, de QA. A CLEF propõe tarefas para os seus participantes e os resultados são apresentados em um fórum que acontece no mês de Setembro de cada ano. A CLEF no contexto de QA surgiu em 2003. A conferência propôs oito tarefas monolíngues e 73 tarefas multilíngues, além de disponibilizar documentos em dez tipos diferentes de idiomas para serem recuperados em nove idiomas (Magnini et al., 2004; Vallin et al., 2006).

Segundo Bilotti e Nyberg (2006), junto à utilização das coleções de referências e métricas de avaliação, os desenvolvedores de sistemas de QA estão gerando automaticamente resumos para avaliar o desempenho do sistema durante as etapas de desenvolvimento. Estas avaliações são semelhantes aos testes de regressão aplicados em outros tipos de softwares. O intuito é prevenir a inserção de erros no sistema de QA durante o processo de desenvolvimento. Os autores afirmam também que a avaliação da interface de usuário do sistema é outro tipo de avaliação realizada pelos pesquisadores, uma vez que pesquisas apontam que interfaces pouco agradáveis podem comprometer a usabilidade dos sistemas computacionais.

Um dos fatores que tem aumentado consideravelmente a complexidade do desenvolvimento e da avaliação de sistemas de QA é o tipo de pergunta inserida pelo usuário. Como mencionado anteriormente, as perguntas do tipo definição (ex. "Quem é Barack Obama?") exigem respostas complexas, muitas vezes, compostas por diferentes fragmentos de textos de diferentes documentos. A dificuldade neste tipo de pergunta é categorizar a importância que cada fragmento tem para a resposta final. Assim, a TREC adotou, como solução, o uso de "colaboradores" que categorizam manualmente os fragmentos de textos encontrados de acordo com o grau de relevância para suportar avaliações (Bilotti e Nyberg, 2006; Dang et al., 2007).

Outras formas de avaliar os sistemas de QA são propostas por Lin e Demner-Fushman (2005) e Marton e Radul (2006). Os autores sugerem o uso combinado de avaliações efetuadas pelo sistema e por um colaborador, e a comparação dos resultados. Leidner e Callison-Burch (2003) propõem o uso de FAQs (do inglês, Frequently Asked Questions). O método insere as respostas das perguntas dos sistemas FAQ em posições específicas de documentos aleatórios. Em seguida, o usuário insere no sistema de QA a pergunta referente à resposta conhecida e o sistema de QA deve retornar a resposta esperada.

As métricas utilizadas na avaliação dos sistemas de QA são: a precisão, a revocação e a $F$ measure. Os valores dessas métricas são obtidos a partir dos dados encontrados pelo sistema e das análises realizadas pelo colaborador humano (Bilotti e Nyberg, 2006; Blair, 1979). 


\section{Capítulo 3}

\section{Trabalhos Relacionados: Sistemas de QA}

Os primeiros sistemas de QA começaram a ser desenvolvidos entre as décadas de sessenta e setenta. Esses sistemas possuíam características em comum como, por exemplo, um módulo básico de conversão da pergunta feita pelo usuário em consultas de banco de dados e o fato de serem desenvolvidos para domínios específicos. No decorrer das próximas décadas houve a popularização dos sistemas de QA que resultou, por exemplo, na criação de projetos de QA para ambiente Web, em domínios de conteúdos mais genéricos, com arquiteturas mais complexas e a utilização de elementos multimídias. Neste capítulo, uma revisão bibliográfica sobre os sistemas de QA é apresentada. Inicialmente, a história dos sistemas de QA é retratada. Além disso, alguns sistemas de QA desenvolvidos atualmente nos domínios genérico e da saúde são apresentados e, por fim, os sistemas de QA desenvolvidos no Brasil são descritos.

\subsection{Histórico dos Sistemas de QA}

O primeiro sistema de QA surgiu na década de sessenta e foi chamado BASEBALL (Green et al. , 1961; Kolomiyets e Moens, 2011). Esse sistema lia e respondia questões escritas por meio de cartões perfurados sobre dados relacionados aos jogos de beisebol da liga americana. Os dados foram coletados durante o período de uma temporada. Para realizar a consulta nas informações coletadas, o sistema convertia a questão em uma consulta ao banco de dados. O SHRDLU (Winograd, 1971) foi um sistema de Inteligência Artificial capaz de fazer planos e manter conversas simples sobre um conjunto de objetos geométricos. O sistema possuía módulos para análise, planejamento, questionanswering, gestão dos diálogos, entre vários outros.

O LUNAR (Woods et al., 1972) foi um sistema de QA que utilizava, como fonte de informação, dados sobre análises geológicas de amostras de pedras recolhidas durante a missão de Apollo até a lua. Avaliações realizadas na época mostraram que o LUNAR respondeu $90 \%$ das questões propostas por pessoas que não conheciam o seu funcionamento. O sistema transformava as perguntas feitas pelo usuário em consultas de banco de dados. Além disso, o LUNAR possuía módulos de análise sintática e semântica. O MYCIN (Shortliffe, 1976) foi outro sistema de QA desenvolvido na década de 70 criado para auxiliar profissionais da área da saúde na identificação dos agentes causadores de infecções como, por exemplo, a meningite, e na recomendação de medicamentos antibióticos com doses ajustadas para o paciente em tratamento. O sistema utiliza um motor de inferência e uma base de dados de regras. As perguntas eram feitas pelo próprio sistema na forma de "consulta médica" composta por perguntas simples (sim ou não) e perguntas textuais. O MYCIN é um sistema 
especialista (sistema que simula o conhecimento de um profissional expert em um tema específico) considerado uma das raízes dos sistemas de QA na área médica pois, ele apresentava explicações sobre conceitos médicos (Kolomiyets e Moens, 2011). Após apresentado alguns dos primeiros sistemas de QA desenvolvidos, algumas semelhanças com os sistemas atuais são perceptíveis como, por exemplo, o início do processo de QA com uma pergunta feita pelo usuário em linguagem natural e a fragmentação de todo o processo em módulos (Kolomiyets e Moens, 2011).

Nas décadas seguintes a década de 70 houve a popularização dos sistemas de QA que resultou na criação de projetos mais ambiciosos. Na década de oitenta, por exemplo, a Universidade de Berkeley desenvolveu o UNIX Consultant (UC) (Wilensky et al., 1988). O UC foi um sistema que ajudou usuários inexperientes a adquirir conhecimentos sobre o sistema operacional UNIX. O sistema utilizava abordagens avançadas de PLN, uma base de conhecimento abrangente e um módulo que buscava adaptar as respostas para que um número maior de usuários consiga entender o conteúdo da resposta. Primeiramente o sistema realiza uma análise gramatical da questão inserida pelo usuário, em seguida, o UC faz uma interpretação contextual do conteúdo da pergunta seguida por uma interpretação das intenções e objetivos do usuário, depois o framework define as suas próprias metas e arquiteta como deve ser a resposta mais adequada para a pergunta inserida, por fim o UC determina a resposta adequada e retorna ao usuário (University e Company, 1995).

Nos anos noventa, o primeiro sistema de QA baseado em conteúdo Web foi desenvolvido. O sistema é conhecido como START (SynTactic Analysis using Reversible Transformations) ${ }^{1}$ (Katz , 1990, 1997) e é acessível até os dias atuais. O START responde perguntas em linguagem natural no idioma inglês e as respostas são exibidas por meio de componentes de texto e multimídias (gráficos e desenhos). O sistema utiliza abordagens de PLN e árvore de análise sintática junto à uma base de conhecimento ${ }^{2}$. No final da década de noventa, com o surgimento das conferências especializadas em áreas relacionadas ao processamento da informação, as pesquisas em QA foram impulsionadas. Em 1999, a TREC (Text Retrieval Conference) incluiu em sua competição tarefas focadas em sistemas de QA de domínio aberto (Voorhees e Tice, 2000). O objetivo da competição era responder questões em linguagem natural apoiadas em uma grande base de documentos textuais. Em 2003, a CLEF (Conference and Labs of the Evaluation Forum) incrementou as suas tarefas com Question Answering multilíngue (Magnini et al., 2004). As questões da coleção de referência eram compostas por idiomas europeus (Kolomiyets e Moens, 2011).

\subsection{Sistemas de QA Atuais}

Atualmente, os sistemas de QA estão sendo estudados e aperfeiçoados por diferentes grupos de pesquisas de diferentes partes do mundo. Além disso, os sistemas de QA ultrapassaram o ambiente acadêmico e se tornaram mundialmente conhecidos por estarem presentes nos smartphones e auxiliarem as pessoas em suas tarefas diárias. Esses sistemas são conhecidos como assistentes pessoais inteligentes, e eles podem variar de acordo com o sistema operacional do smartphone. Os assistentes mais conhecidos são o Google Now ${ }^{3}$ (para Android) e a Siri ${ }^{4}$ (para iOS). Ambos os assistentes pessoais utilizam interfaces do usuário em linguagem natural para executar tarefas como, por exemplo,

\footnotetext{
${ }^{1}$ http://start.csail.mit.edu/index.php

${ }^{2}$ http://start.csail.mit.edu/start-system.php

${ }^{3}$ https://www.google.com/intl/en/landing/now/\#whatisit

${ }^{4}$ https://support.apple.com/en-us/HT204389
} 
responder questões sobre o tempo ou fazer recomendações ao usuário sobre o melhor trajeto para chegar ao trabalho.

Desde 2005, os pesquisadores da IBM ${ }^{5}$ começaram o desenvolvimento de um supersistema de inteligência artificial que tinha como desafio responder perguntas em linguagem natural (Ferrucci et al. , 2010). O supersistema, conhecido como Watson, tinha como desafio participar de uma competição de "perguntas" de conhecimentos gerais no programa americano Jeopardy. Em 2013, três anos após ganhar a competição, o Watson começou a ser avaliado nos domínios da saúde e genética como um sistema de suporte à decisões clínicas no tratamento de câncer de pulmão no Memorial Sloan-Kettering Cancer Center (MSKCC) (IBM, 2012) e, em 2014, no auxílio ao tratamento as pessoas com tumor cerebral maligno chamado glioblastoma multiforme no New York Genome Center (EUA) (IBM, 2014). No contexto de câncer de pulmão, o Watson analisa a informação clínica do paciente e, no contexto de tumor cerebral maligno, o genoma do paciente e em ambos os contextos busca o tratamento personalizado com base em periódicos científicos especializados. Em 2014, o MSKCC anunciou que as pesquisas iniciadas com foco no câncer de pulmão haviam se expandido para mais de doze tipos diferentes de câncer como, por exemplo, cólon, próstata, bexiga, ovário, pâncreas, rim, fígado, útero, bem como os melanomas e os linfomas (MSKCC, 2014). Em Agosto de 2015, a IBM anunciou a inclusão ao Watson de artifícios para manipulação e processamento de imagens médicas. Neste sentido, a IBM pretende contribuir no auxílio à tomada de decisões no atendimento ao paciente (IBM, 2015).

Na literatura científica atual, diferentes tentativas de construção de sistemas de QA foram identificadas. Moreda et al. (2011) propõem duas abordagens baseadas em informações semânticas para o módulo de extração da resposta. A primeira abordagem propõe a extração das respostas por meio de regras semânticas e a segunda abordagem propõe, como extensão das regras semânticas encontradas na primeira abordagem, o uso das classes semânticas do WordNet. Na primeira abordagem, as regras semânticas são criadas automaticamente com o auxílio de NEs. O processo de construção é dividida em quatro etapas: Primeiramente, para cada par pergunta-resposta é definido um conjunto de condições que um documento relevante deve conter. Em seguida, trechos selecionados dos documentos são validados com base nas relações semânticas contidas nos trechos. Depois, as frases são generalizadas como padrões semânticos e, por fim, os padrões semânticos semelhantes são eliminados. Estes padrões semânticos são armazenados em uma base de dados separado de acordo com o tipo de questão.

Na segunda abordagem é proposto o uso das classes semânticas do WordNet junto com as regras semânticas construídas na primeira abordagem. Uma vez conhecida as regras semânticas extraídas na primeira abordagem e as classes semânticas do WordNet, o módulo de extração da resposta busca fragmentos de textos compatíveis com as regras semânticas e marca-os com rótulos. Depois, o WordNet busca a raiz da classe semântica de cada rótulo encontrado. Se ambos são compatíveis com as regras gramaticas do bando de dados, a frase é extraída como resposta potencial. O objetivo do trabalho é avaliar a influência das informações semânticas no processo de extração de respostas e comparar os resultados obtidos com sistemas QA que utilizam abordagem de reconhecimento de entidades nomeadas. Segundo os autores, os resultados apontam que a inclusão de informação semântica melhora consideravelmente a precisão do sistema, principalmente para as questões onde as respostas são os substantivos comuns. O resultado com a adição de informação semântica apresenta

\footnotetext{
${ }^{5}$ http://www.ibm.com/en-us/homepage-b.html
} 
$F_{\beta=1}=74.73 \%$ e o resultado da abordagem de reconhecimento de entidades nomeadas apresenta $F_{\beta=1}=12.19 \%$, cujo $\beta$ define o peso da medida da precisão no cálculo da medida $F$. Quando o $\beta$ se aproxima de 1 , a medida de revocação é favorecida. Por outro lado, se o $\beta$ se aproxima de 0 , a medida de precisão é favorecida.

Yen et al. (2013) propõem um sistema de QA baseado em abordagens de Aprendizado de Máquina para integração das etapas de classificação da questão e da seleção das respostas. O classificador categoriza a questão inserida pelo usuário e repassa essa informação para a etapa de ordenação das passagens, que reorganiza as passagens recuperadas da etapa de processamento dos documentos. Na classificação da questão, o conteúdo do vetor de características é composto pela: (i) representação específica de termos genéricos extraídos da pergunta realizada pelo usuário. Por exemplo, uma pergunta que contenha os termos "basquete" e "vôlei" pode ser representada pelo termo "esporte". Em seguida, todos os termos específicos relacionadas ao termo de contexto geral "esportes" são buscados no WordNet; e pelas (ii) palavras relacionadas e não-stopwords de cada termo que compõe a pergunta. Por exemplo, a palavra "baseball" possui como palavras relacionadas "jogo de bola" do inglês ball game, "bola" do inglês ball, e "equipamentos de baseball" do inglês baseball equipment. O classificador utilizado foi o SVM, ele prediz o tipo da pergunta mapeando as palavras encontradas na construção dos vetores de características. O sistema apresenta para o usuário, como resposta da pergunta inserida, as cinco respostas mais relevantes. O sistema apresentou acurácia de $84.4 \%$ e 85.6\% para a etapa de classificação da questão com e sem o apoio de classes de palavras.

Ryu et al. (2014) propõem o uso da Wikipédia ${ }^{6}$ como fonte de conhecimento para um sistema de QA. A arquitetura do sistema é composta por vários módulos de extração da resposta baseado no tipo de informação semiestruturada como, por exemplo, conteúdo de artigos, definições ou artigos estruturados. A Wikipédia fornece informações amplas e semiestruturadas construída por meio de um esforço colaborativo entre voluntários. Ela forma uma rede de conhecimento baseada nos conceitos de taxonomia, ou seja, conhecimentos similares ocupam posições próximas entre si, e de categorias. Neste contexto, as categorias representam descrições gerais de um artigo e elas podem responder questões do tipo lista. Por exemplo, segundo o autor, os artigos do tipo lista associados a Arnold Schwarzenegger são: "Pessoas que migraram da Áustria para os Estados Unidos" e "Atores-políticos americanos", portanto perguntas do tipo "Quem são os políticos americanos que migraram da Áustria?" podem ser respondidas. Nas perguntas do tipo definição, os artigos da Wikipédia, principalmente o título e o primeiro parágrafo, são utilizados como fonte de informações. Além disso, os autores utilizam a Wikipédia também para mapear as principais informações da em estruturas na forma de tripla <título do artigo, propriedade, valor $>$. Por exemplo, $<$ "Barack Obama","predecessor", "George W. Bush">. Segundo os autores, o sistema apresentou 87.1\% de precisão, $52.7 \%$ de revocação e $65.6 \%$ de F-measure.

Suresh kumar e Zayaraz (2015) propõem um framework de QA para domínios genéricos que utiliza um algoritmo interativo para extrair ontologias ou seja, extrair os atributos de um domínio e os seus relacionamentos, de um conjunto de documentos relevantes baseado no conceito de semente apoiado em regras de padrões e árvores binárias de decisão. A construção de uma ontologia é iniciada por meio de uma questão inserida pelo usuário em linguagem natural e, a cada questão inserida a ontologia é atualizada e integrada no framework de QA. Para cada sentença dos documentos relevantes é gerada uma árvore binária de decisão utilizando, como ferramenta com-

\footnotetext{
${ }^{6}$ https://www.wikipedia.org/
} 
putacional, o parser de dependência de Stanford (De Marneffe e Manning, 2008). Em seguida, as árvores de decisões binárias são aplicadas junto com parsers de padrões de dependência construídos manualmente por meio de análises empíricas. O resultado do processo são um conjunto de triplas $<$ palavra-chave candidata (conceito semente), relacionamento, conceito associado $>$. Este conjunto de triplas é utilizado no treinamento de um classificador Naive Bayes de maximização de expectativas. O classificador é utilizado para predizer se existe associação entre o conceito semente e o conceito associado. Neste contexto, a ontologia com os conceitos mais relevantes é construída. Os autores afirmam que o framework de QA alcançou resultados de revocação $=99 \%$ e precisão $96 \%$.

Hartawan e Suhartono (2015) propõem um sistema de QA baseado no Modelo do Espaço Vetorial para representar o conhecimento e recuperar a resposta para o usuário. Nesse sentido, a consulta realizada pelo usuário, em linguagem natural, é comparada com a base de conhecimento por meio de medidas de similaridade. O sistema apresentou resultados de 0.662 de revocação, 0.548 de precisão e 0.580 da F-Measure. Por outro lado, segundo os autores, o tempo de processamento do sistema para retornar a resposta é em torno de 29 segundos por questão.

\subsubsection{Sistemas de QA nos Domínios da Saúde}

Além do Watson da IBM, nos domínios da saúde e medicina, alguns sistemas de QA médicos foram encontrados na literatura. Cao et al. (2011) desenvolveram um sistema de QA clínico chamado AskHERMES. O sistema possui um robusto processamento semântico de questões complexas e, como saída, o sistema retorna fragmentos de resumos. O processamento das questões complexas é dividida em etapas: Primeiramente, as questões são classificadas entre 12 tópicos utilizados para a anotação do banco de perguntas. Os tópicos utilizados são: dispositivo, diagnóstico, epidemiologia, etiologia, história, gestão, farmacologia, achado físico, procedimento, prognóstico, teste e tratamento e prevenção. Além disso, são extraídos as palavras-chave de cada pergunta que podem ser usadas na extração das respostas. A classificação das perguntas e a extração das palavras-chaves são feitas por meio de métodos de aprendizado de máquina supervisionado. Vários algoritmos foram avaliados, porém, o que apresentou o melhor desempenho foi a SVM. Na identificação automática das palavras-chaves foi utilizado o método campos aleatórios condicionais (CRFs) (Lafferty, 2001) que é um modelo estocástico utilizado na extração de informações em documentos. Além das análises semântica (por exemplo, bigrama e trigrama) e sintática (POS-tag), os autores acrescentaram ferramenta lexical baseada no MetaMap (Aronson, 2001) que integra UMLS na busca por conceitos utilizados na expansão dos termos da consulta do usuário e na tarefa de classificação. O sistema indexa documentos de várias fontes de informação como, por exemplo, o MEDLINE, o PubMed, o eMedicine e a Wikipédia. Segundo os autores, o sistema apresentou uma boa habilidade na solução de questões longas e complexas.

Ben Abacha e Zweigenbaum (2015) desenvolveram um sistema de QA chamado MEANS. O MEANS é apoiado por abordagens semânticas compostas por técnicas de PLN e Web Semântica. As técnicas de PLN são utilizadas na construção de anotações RDFs dos documentos utilizados na busca pelas respostas e as técnicas de Web Semântica na recuperação desses dados por meio de consultas do tipo SPARQL, que é uma linguagem de programação utilizada para fazer consultas em fontes de dados RDF. O sistema realiza análise dos dados em dois níveis de complexidade. O primeiro busca por entidades médicas como, por exemplo, drogas, sintomas e doenças. A segunda análise é realizada em nível de relacionamento como, por exemplo, tratamentos, prevenções e causas. 
As questões são focadas nos tipos factuais e booleanas. Segundo os autores, o MEANS apresentou $60 \%$ de precisão para as perguntas do tipo booleanas para as questões booleanas e $85.71 \%$ para as perguntas factuais.

\subsection{Sistemas de QA no Brasil}

No Brasil, o desenvolvimento de sistemas de QA é pouco explorado. Machado Junior et al. (2009) desenvolveram um sistema de QA chamado SQAS (Shallow Question Answering System) nos domínios de textos jornalísticos do idioma português. A arquitetura do sistema é composta pelos módulos de (i) busca de textos e parágrafos candidatos e (ii) filtragem das respostas segundo padrões (expressões regulares) criados para cada modelo de pergunta. O sistema apresentou resultados precisos na busca pelos parágrafos candidatos à resposta e na filtragem de alguns modelos de perguntas.

Wilkens et al. (2010) desenvolveram um sistema de QA por voz para o idioma português (brasileiro) chamado COMUNICA. O sistema possui a capacidade de buscar informações em banco de dados estruturados e não-estruturados. Um dos principais objetivos do sistema é promover a inclusão digital permitindo ao usuário uma nova maneira de acesso à informações escritas. O sistema é composto por módulos de reconhecimento e sintetização da fala, um módulo de processamento de texto, um módulo administrador responsável por gerenciar os demais módulos e um módulo de acesso aos bancos de dados. De acordo com os autores, os módulos de apoio à fala ainda estão em construção. O sistema utiliza técnicas de PLN e ontologias nos módulos de processamento textual.

Amorim et al. (2012) criaram um sistema de QA genérico, com uma arquitetura flexível, que independe do domínio da pergunta inserida. Para que o sistema suporte esta abrangência, os autores utilizaram um banco de ontologias junto a uma gama de softwares de apoio. Neste sentido, os softwares são ativados de acordo com as necessidades do sistema. Quando uma pergunta é realizada, o sistema resolve problemas de sinonímia com o apoio do WordNet. Em seguida, a pergunta é utilizada para recuperar documentos em um banco de dados AIML (Artificial Intelligence Markup Language $)^{7}$. Caso a resposta não seja encontrada nesse banco de dados, o sistema busca a resposta na Web. Nesse sentido, um crawler, ou seja, são programas computacionais que navegam pela Web de forma automática e metódica buscando tipos específicos de informação, é utilizado para buscar páginas web de conteúdo específico da pergunta feita pelo usuário.

Prestes (2011) realizou um trabalho de comparação entre sistemas de QA distintos com foco no módulo de processamento da resposta, sendo eles: (i) um para o idioma português, (ii) um para o idioma inglês e (iii) um em idioma português, porém estendido para o inglês. O objetivo do trabalho foi comparar a eficiência dos diferentes sistemas de QA levando em consideração a complexidade da linguagem a qual foram criados. Os autores concluíram que os melhores métodos para extração de respostas são modelagem usando "bag-of-words" e o cálculo de similaridade pela distância entre palavras-chaves. O framework criado pelos autores é composto por regras e técnicas PLN.

Arrigo et al. (2014) desenvolveram um sistema de QA que utiliza a Web para criar um corpus anotado de informações no idioma Português. Este corpus foi dividido em seis domínios de informação distintos com, pelo menos, duas perguntas distintas por domínio. Estas perguntas e suas

\footnotetext{
${ }^{7}$ O AIML é uma linguagem baseada em XML utilizada na criação de diálogos, pelo computador, que simulam um diálogo em linguagem natural entre humanos (Wallace, 2003).
} 
respostas são etiquetadas por meio de palavras-chave. Em seguida, um algoritmo foi desenvolvido para fazer download apenas do conteúdo textual dos cem primeiros resultados encontrados pelo buscador web a partir de uma pergunta inserida pelo usuário. Toda a informação é etiquetada e analisada. Caso as etiquetas das informações correspondam à uma etiqueta padrão < pergunta, resposta >, está informação é separada e ordenada. Ao final do processo, os cinco padrões de respostas mais frequentes são exibidos pelo sistema. O idioma utilizado neste projeto é o Português. Após a implementação, o sistema será avaliado para verificação do seu desempenho e validação do método proposto.

\subsection{Comparativo dos Sistemas de QA}

A Tabela 3.1 apresenta uma sistematização tabular dos sistemas de QA apresentados neste capítulo e suas respectivas abordagens, artefatos linguísticos e domínios da informação. Neste sentido, o termo abordagem refere-se ao conjunto de técnicas computacionais e tecnologias utilizadas na construção de cada trabalho de QA, o domínio de informação refere-se a que tema e tipo de informação os sistemas foram avaliados e os artefatos linguísticos refere-se se os sistemas foram apoiados por ferramentas externas de linguagem como, por exemplo, as ontologias e a UMLS.

Os sistemas de QA evoluíram consideravelmente com o passar do tempo. As abordagens para construção desses sistemas se estendem desde a construção de uma simples consulta a um banco de dados até abordagens mais complexas empregando artifícios semânticos e Aprendizado de Máquina. Dentre todos os trabalhos apresentados neste capítulo, os trabalhos de Cao et al. (2011) e Ben Abacha e Zweigenbaum (2015) são os que mais se aproximam da proposta do QASF, pois, ambos foram desenvolvidos para um ambiente tão complexo e específico como é o ambiente médico. Outro trabalho interessante foi o desenvolvido por Yen et al. (2013) que utiliza SVM na integração entre as etapas de classificação na questão e seleção da resposta. Com os mesmos objetivos desses sistemas, o desenvolvimento do QASF foi apoiado, em partes, por abordagens apresentadas nesses trabalhos.

O QASF quando comparado com os demais sistemas de informação do tipo QA possui alguns diferenciais. Inicialmente o QASF foi projetado para atuar no domínio médico, cuja a busca por informações clínicas relevantes pode ser mais complexa quando comparada a outros domínios da informação. Por essa razão, o módulo de recuperação de documentos foi construído baseado em um framework especialista em recuperação de informações médicas, o SisViDAS. A arquitetura do sistema QASF é ampla e pode ser estendida para vários outros domínios de informação, variando apenas os artefatos linguísticos como, por exemplo, as ontologias e a UMLS. Outro diferencial é que o sistema está sendo desenvolvido para processar perguntas com diferentes níveis de complexidade, ou seja, perguntas que exigem diferentes níveis de processamento do QASF para encontrar a resposta mais adequada. Um exemplo de pergunta simples é "O que são doenças crônicas?" e de pergunta complexa é "Por que ela é hipoglicêmica? Não há histórico de diabetes e os testes relacionados ao açúcar do sangue, feitos em casa, estão entre 50 e $60 . "$ 
Tabela 3.1: Sistematização de alguns sistemas de $Q A$ da literatura e suas respectivas abordagens.

\begin{tabular}{|c|c|c|c|}
\hline Sistemas & $\begin{array}{l}\text { Domínio de } \\
\text { Informação }\end{array}$ & $\begin{array}{c}\text { Artefatos } \\
\text { Linguísticos }\end{array}$ & Abordagens \\
\hline QASF & Saúde & Sim & SVM, RI, EI e NLP \\
\hline $\begin{array}{c}\text { BASEBALL } \\
\text { (Green et al., 1961) }\end{array}$ & $\begin{array}{l}\text { Jogos de } \\
\text { Beisebol }\end{array}$ & Não & $\begin{array}{l}\text { Conversão da questão em } \\
\text { uma consulta ao banco } \\
\text { de dados das informações } \\
\text { coletadas. }\end{array}$ \\
\hline $\begin{array}{c}\text { SHRDLU } \\
\text { (Winograd, 1971) }\end{array}$ & $\begin{array}{l}\text { Análise } \\
\text { Geométrica }\end{array}$ & Não & $\begin{array}{l}\text { O sistema possuía módulos } \\
\text { para análise, planejamento, } \\
\text { QA, gestão dos diálogos, } \\
\text { entre vários outros. }\end{array}$ \\
\hline $\begin{array}{c}\text { LUNAR } \\
\text { (Woods et al., 1972) }\end{array}$ & $\begin{array}{l}\text { Análise } \\
\text { Geológica }\end{array}$ & Não & $\begin{array}{l}\text { Transformação das perguntas } \\
\text { feitas pelo usuário em } \\
\text { consultas de banco de dados. } \\
\text { Além disso, o sistema } \\
\text { possuía módulos de } \\
\text { análise sintática e semântica. }\end{array}$ \\
\hline $\begin{array}{c}\text { MYCIN } \\
\text { (Shortliffe, 1976) }\end{array}$ & Saúde & Não & $\begin{array}{c}\text { Utiliza um motor de } \\
\text { inferência e uma base } \\
\text { de dados de regras. }\end{array}$ \\
\hline $\begin{array}{l}\text { UNIX Consultant (UC) } \\
\text { (Wilensky et al., 1988) }\end{array}$ & $\begin{array}{c}\text { Sistema } \\
\text { Operacional } \\
\text { UNIX }\end{array}$ & Não & $\begin{array}{c}\text { Técnicas de PLN, } \\
\text { uma base de conhecimento } \\
\text { abrangente e um módulo } \\
\text { que buscava parafrasear } \\
\text { as respostas para } \\
\text { cada tipo de usuário. }\end{array}$ \\
\hline $\begin{array}{c}\text { START } \\
(\text { Katz, 1990, 1997) }\end{array}$ & Genérico & Não & $\begin{array}{c}\text { Uso de PLN e } \\
\text { árvore de análise } \\
\text { sintática junto a uma } \\
\text { base de conhecimento. }\end{array}$ \\
\hline (Moreda et al., 2011) & Genérico & Sim & $\begin{array}{c}\text { Utiliza informações } \\
\text { semânticas para } \\
\text { o módulo de extração } \\
\text { da resposta. }\end{array}$ \\
\hline (Yen et al., 2013) & Genérico & Não & $\begin{array}{c}\text { Técnicas de AM para } \\
\text { integração das etapas } \\
\text { de classificação da } \\
\text { questão e na seleção } \\
\text { das respostas }\end{array}$ \\
\hline (Ryu et al., 2014) & Genérico & Não & $\begin{array}{l}\text { Uso da Wikipédia como } \\
\text { fonte de conhecimento }\end{array}$ \\
\hline Suresh kumar e Zayaraz (2015) & Genérico & Sim & $\begin{array}{l}\text { Utiliza regras de Padrões } \\
\text { e árvores binárias }\end{array}$ \\
\hline Hartawan e Suhartono (2015) & Genérico & Não & $\begin{array}{c}\text { Modelo de } \\
\text { Espaço Vetorial }\end{array}$ \\
\hline $\begin{array}{c}\text { AskHERMES } \\
(\text { Cao et al., 2011) }\end{array}$ & Saúde & Sim & UMLS, NLP, RI e EI \\
\hline $\begin{array}{c}\text { MEANS } \\
\text { (Ben Abacha e Zweigenbaum, 2015) }\end{array}$ & Saúde & Sim & $\begin{array}{c}\text { Utiliza Informações } \\
\text { semânticas compostas } \\
\text { por técnicas de } \\
\text { PLN e Web Semântica }\end{array}$ \\
\hline $\begin{array}{c}\text { SQAS } \\
\text { (Machado Junior et al., 2009) }\end{array}$ & $\begin{array}{c}\text { Textos } \\
\text { Jornalísticos }\end{array}$ & Não & $\begin{array}{l}\text { Composta por Expressões } \\
\text { Regulares e NLP }\end{array}$ \\
\hline $\begin{array}{c}\text { COMUNICA } \\
\text { (Wilkens et al., 2010) }\end{array}$ & Genérico & Sim & $\begin{array}{l}\text { O sistema utiliza técnicas } \\
\text { de PLN e ontologias nos } \\
\text { módulos de processamento } \\
\text { textual. }\end{array}$ \\
\hline (Amorim et al., 2012) & Genérico & Sim & $\begin{array}{c}\text { Uso de ontologias } \\
\text { com softwares de apoio. }\end{array}$ \\
\hline (Prestes, 2011) & Genérico & Sim & Utiliza regras e técnicas PLN. \\
\hline (Arrigo et al., 2014) & Genérico & Não & $\begin{array}{c}\text { Criar um corpus Web em } \\
\text { Português. Faz uma } \\
\text { análise semântica da } \\
\text { pergunta e utiliza AM } \\
\text { para classificação. }\end{array}$ \\
\hline
\end{tabular}




\section{Capítulo 4}

\section{Trabalhos de Suporte}

Os trabalhos de suporte apresentados neste capítulo são dois frameworks desenvolvidos anteriormente pelo grupo de pesquisa desta mestranda. O SisViDAS é um framework que relaciona artigos científicos a fatores de risco descritos em prontuários médicos do paciente e alerta profissionais da área da saúde sobre problemas no desenvolvimento humano (Macedo et al., 2015; Pollettini et al., 2012, 2014). O framework FREDS associa informações textuais de laudos de exames com imagens de diagnóstico de Punção Aspirativa por Agulha Fina por meio de mapeamentos conceituais (Macedo et al., 2016; Pessotti, 2012). Esses dois frameworks são utilizados no módulo de processamento de documentos do framework de QA apresentado.

No QASF, os frameworks SisViDAS e FREDS processam informações de diferentes tipos de documentos. Neste contexto, o SisViDAS processa informações de artigos científicos e prontuário médico do paciente e o FREDS processa informações textuais de laudos de exames de diagnósticos médicos e imagens de diagnóstico por imagem. Esses documentos são usados como fonte de informação para as consultas realizadas pelo usuário ao sistema de QA. Assim, os frameworks possibilitam a expansão das entradas de dados para consulta, ou seja, possibilitam a consulta a diferentes fontes de informações para obter as respostas. Neste primeiro momento, o QASF está utilizando apenas informações de abstracts de artigos científicos recuperados pelo SisViDAS. Seções 4.1 e 4.2, as arquiteturas do SisViDAS e do FREDS são apresentadas respectivamente. Essas arquiteturas ilustram os componentes e o funcionamento de cada um dos dois frameworks de suporte do QASF.

\subsection{Framework para Sistema de Vigilância para Doenças Crônicas (SisViDAS)}

Estudos em medicina genômica sugerem que seres humanos expostos a fatores de risco no início da vida como, por exemplo, a escassez de alimentos, podem sofrer influências na expressão do gene e, como resultado, na vida adulta desenvolverem doenças crônicas (Barker, 2001). As doenças crônicas são enfermidades causadas por diferentes fatores como, por exemplo, o genético e o estilo de vida. Algumas das doenças crônicas mais conhecidas são as doenças cardiovasculares (OMS, 2009a), a diabetes tipo 2 (OMS, 2009b) e a obesidade (OMS, 2009c). A maioria dessas doenças são incuráveis por medicação. Por outro lado, com mudanças nos hábitos diários é possível prevenir, amenizar e até curar em alguns casos essas enfermidades (Barker, 2001; Verma et al., 2009). As doenças crônicas e suas consequências têm sido fortemente pesquisadas por profissionais da área da 
saúde. Os resultados mais importantes são frequente e abundantemente publicados em repositórios online de informações científicas como o PubMed.

O Sistema de Vigilância para Doenças Crônicas (Macedo et al., 2015; Pollettini et al., 2012, 2014) e suas versões originaram o framework SisViDAS para o desenvolvimento de sistemas de vigilância que alertam profissionais da saúde sobre problemas no desenvolvimento humano relacionados as seguintes doenças crônicas: doenças cardiovasculares, a diabetes tipo 2 e a obesidade. Os alertas são feitos, por meio de relacionamentos entre informações sobre doenças crônicas contidas em artigos científicos e fatores de riscos descritos em registros clínicos do paciente (Pollettini et al., 2014). O SisViDAS foi desenvolvido para atender as seguintes funcionalidades: (i) atualização da coleção de artigos científicos, (ii) recuperação de artigos científicos relevantes para um registro clínico, (iii) classificação de pacientes em grupos de risco para doenças crônicas, (iv) expansão da ontologia de doenças crônicas e (v) validação do framework. A Figura 4.1 ilustra a infraestrutura do SisViDAS.

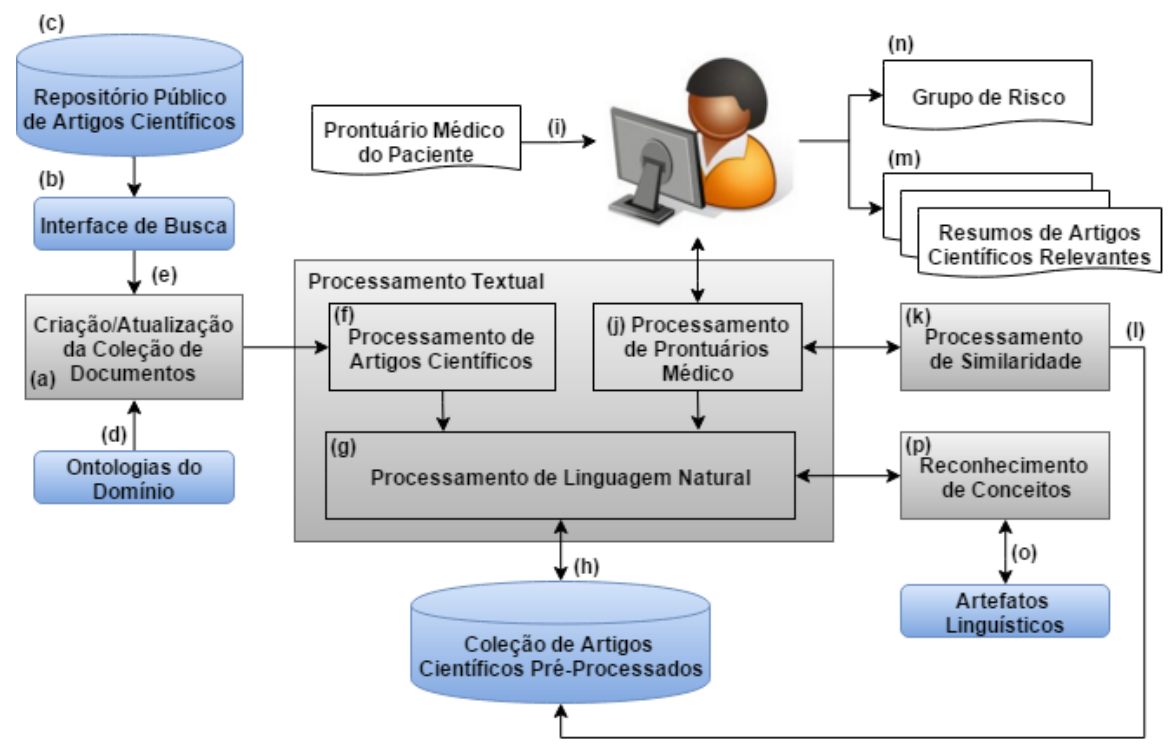

Figura 4.1: Estrutura do framework SisViDAS: (a) Módulo para criação e atualização da coleção de artigos. (b) Interface de busca. (c) Coleção online de artigos científicos. (d) Ontologias do domínio. (e) Recuperação de artigos científicos de repositórios online. (f-g-j) Processamento textual dos artigos recuperados dos repositórios online e dos prontuários inseridos, apoiados pelo módulo base do processamento textual composto pelas técnicas de Processamento de Linguagem Natural. (h) Database local com a coleção já processada. (i-n-m) Interface com o usuário, recebe como entrada prontuários médicos do paciente e retorna grupos de risco e os abstracts de artigos científicos mais relevantes. (k) Módulo que mede a similaridade entre prontuário médico do paciente e artigos cientificos. (l) Processo de acesso aos artigos pré-processados e retorna os que tem os maiores graus de similaridade. (o) Artefatos linguísticos, como, por exemplo, UMLS. (p) Reconhecimento de conceitos. BASEADO EM (Pollettini et al., 2014).

Para buscar artigos científicos em repositórios públicos, e, posteriormente, transferi-los para um repositório local no computador, o sistema possui um módulo de interação e recuperação de artigos em repositórios públicos apoiado por conceitos obtidos em ontologias do domínio (Figura 4.1 (a), (b), (c), (d), (e)). As ontologia do domínio utilizada no SisViDAS é a Ontologia de Doenças Crônicas (em tradução livre do inglês Chronic Disease Ontology - CDO) (Verma et al., 2009). A CDO possui informações sobre as (i) doenças crônicas (obesidade, doenças crônicas e diabetes tipo 2), (ii) genes e suas mutações relacionadas e (iii) informações sobre histórico de vida, saúde e nutrição. A CDO é dividida em cinco domínios principais: do organismo, molecular, médico, nutricional e mapa de informática biomédica. Além do CDO, o SisViDAS é apoiado por recursos da Entrez Programming 
Utilities (E-utilities) (NCBI, 2010), pelo Biopython ${ }^{1}$ (Cock et al., 2009) e pela UMLS. Para buscar os conceitos UMLS, duas abordagens foram investigadas. A primeira abordagem foi o uso da UTS Web Service API, a qual utiliza n-grams para interagir com a $A P I$ e buscar os conceitos. A segunda abordagem considerava a ferramenta MetaMap² (Figura 4.1 (p) e (o)). Os artigos são processados pelo módulo de processamento textual (Figura 4.1 (f)) que compreende as atividades de remoção de stopwords, processamento de n-grams, identificação de conceitos do domínio da saúde e cálculo da importância ("peso") de cada conceito em relação ao documento. As atividades são suportadas pelo pacote python Natural Language Toolkit (NLTK) (Bird, 2006). Além disso, as listas de stopwords utilizadas no projeto são dos idiomas inglês e português e elas pertencem ao projeto Snowball ${ }^{3}$ (Figura 4.1 (g)). Para finalizar o processamento da coleção a ser relacionada aos prontuários médicos, o resultado obtido do processamento de NLP é armazenado em um banco de dados na forma de uma nova coleção de informação (Figura 4.1 (h)).

Quando um usuário deseja recuperar artigos similares a um prontuário médico do paciente e descobrir os grupos de risco (Figura 4.1 (i), (m) e (n)), a primeira etapa é realizar o processamento desse prontuário de forma semelhante ao processamento textual realizado nos artigos científicos. Neste sentido, primeiramente, os termos são identificados e comparados com dicionários de sinônimos (Figura 4.1 (j), (g) e (p)). Em seguida, consultas compostas pelos termos identificados são construídas (Figura 4.1 (g)). E, por fim, a similaridade entre a consulta que representa o prontuário médico do paciente e os artigos é calculada e os artigos com maior grau de similaridade são retornados para visualização do usuário (Figura 4.1 (k) e (l)). Além disso, visando potencializar a recuperação de documentos, o trabalho analisou três abordagens distintas para a expansão das consultas (Macedo et al., 2015). Na primeira abordagem as meta-informações dos artigos recuperados das bases de dados científicas são consideradas como termos a expandir a consulta do usuário (o registro médico). Nessa primeira abordagem, as meta-informações do artigo são os termos MESH. Na segunda abordagem, n-grams são extraídos dos documentos processados. E, por fim, a última abordagem considera como meta-informações o campo "Publication Type" dos artigos anexados pelo PubMed. O SisViDAS foi experimentado no contexto de fatores de risco genéticos e epigenéticos para doenças crônicas. Os resultados obtidos demonstram que a abordagem de reconhecimento de conceitos utilizando a ferramenta MetaMap apresentou melhor resultado quando comparada com as demais (Macedo et al., 2015).

Esse framework foi desenvolvido em parceria com pesquisadores do Instituto da Criança da Faculdade de Medicina da USP. Os pesquisadores contribuíram na elaboração dos prontuários para a experimentação do framework. Nesse sentido, os profissionais prepararam uma lista de termos e expressões mais frequentes nos registros clínicos dos pacientes além de fornecerem um prontuário de atendimento não preenchido do centro de saúde-escola utilizado para acompanhamento de saúde das crianças. Devido às questões éticas que envolvem a manipulação de dados reais de pacientes, as desenvolvedoras do SisViDAS optaram em gerar uma simulação dos dados do prontuário de atendimento. Neste sentido, os campos utilizados na simulação foram: idade do paciente, sexo, diagnóstico nutricional, crescimento, desenvolvimento (DNPM), vacinação, alimentação, cotidiano infantil, familiograma, ambiente emocional, condições ambientais, condições sócio-econômico-culturais, fatores de risco (riscos e proteção familiares relacionados à saúde), fatores de proteção (riscos e proteção

\footnotetext{
${ }^{1}$ http://biopython.org/wiki/Main_Page

${ }^{2}$ http://metamap.nlm.nih.gov/

${ }^{3} \mathrm{http}: / /$ snowball.tartarus.org/
} 
familiares relacionados à saúde), doenças atuais, doenças anteriores ou crônicas e antecedentes familiares (Pollettini et al., 2012). Os dados dos campos dos prontuários foram gerados no formato de uma matriz atributo versus prontuário, cujos valores de cada célula da matriz foram sorteados como números aleatórios com o auxílio do software "Mathematica", versão 8.0.0. Ao todo, sessenta prontuários foram simulados e por fim, destes sessenta prontuários, trinta foram selecionados por meio da exclusão dos casos incoerentes (Pollettini et al., 2012).

Para a tarefa de classificação do paciente em um dos grupos de risco de doenças crônicas (doenças cardiovasculares, diabetes mellitus ou obesidade), o software dispôs de um classificador previamente treinado em uma base de referência de registros clínicos. Para esta tarefa foram avaliados três classificadores distintos, sendo eles: (i) Relevance Feedback RFCat (Pollettini et al., 2009; Pollettini, 2008) desenvolvido em trabalhos anteriores da autora; (ii) Instance Based Learner (IBK) (Learning , 2016) e (iii) Multilayer Perceptron (Kollias, 2006), sendo os dois últimos pertencentes ao pacote WEKA $^{4}$.

A interface gráfica do usuário do SisViDAS foi desenvolvida para auxiliar e facilitar aos pesquisadores e médicos pediatras o relacionamento entre os fatores de risco e as doenças crônicas. Neste sentido, a interface foi desenvolvida para receber e processar consultas curtas com fatores de riscos potenciais e consultas longas que são uma forma de representação dos registros clínicos. As interfaces gráficas do usuário são apresentadas na Figura 4.2. Na Figura 4.2 (a), a interface do usuário principal é apresentada. No campo "Registro" é inserido os dados do prontuário médico que serão utilizados na pesquisa dos artigos científicos. Na Figura 4.2 (b), o resultado da busca de artigos científicos para o termo de fator de risco "obesidade" é apresentado.

Ao realizar uma comparação de resultados de buscas entre o SisViDAS e algumas ferramentas de buscas online ((i) Google; (ii) Google Acadêmico e (iii) Pubmed) com base em buscas por expressões (palavras-chave digitadas nas ferramentas de busca), observou-se que o SisViDAS recupera com mais precisão os artigos científicos relacionados à fatores de risco e epigenética quando comparado com as demais ferramentas (Pollettini et al., 2014). O SisViDAS é um framework que efetiva a transformação dos resultados de pesquisas biomédicas em conhecimento possível de ser utilizado para aprimorar a saúde pública, portanto, os desenvolvedores do SisViDAS acreditam que este framework contribui na área de bioinformática translacional ${ }^{5}$.

\subsection{Framework para Redução da Descontinuidade Semântica em Imagens Médicas (FREDS)}

As desordens da tireoide estão se tornando cada vez mais frequentes e uma das mais conhecidas é o câncer de tireoide. Segundo informações do Instituto Nacional do Câncer e da publicação "Cancer Incidence in Five Continents", durante o período compreendido entre 1973 e 2002, a taxa de incidência dessa enfermidade aumentou mais de cinco vezes (INCA, 2014; Parkin et al., 2005). Por outro lado, a taxa de mortalidade para este tipo de câncer apresentou uma queda contínua. Algumas das justificativas para esta queda é a melhoria no tratamento desta enfermidade e nos

\footnotetext{
${ }^{4}$ WEKA (do inglês Waikato Environment for Knowledge Analysis) é um pacote de algoritmos de aprendizado de máquina.

${ }^{5}$ Segundo a Associação Americana de Informática Médica (do inglês American Medical Informatics Association - AMIA), bioinformática translacional compreende o desenvolvimento de métodos de otimização para transformar dados biomédicos em conhecimento proativo, preditivo, preventivo e participativo na área da saúde (Butte, 2008).
} 


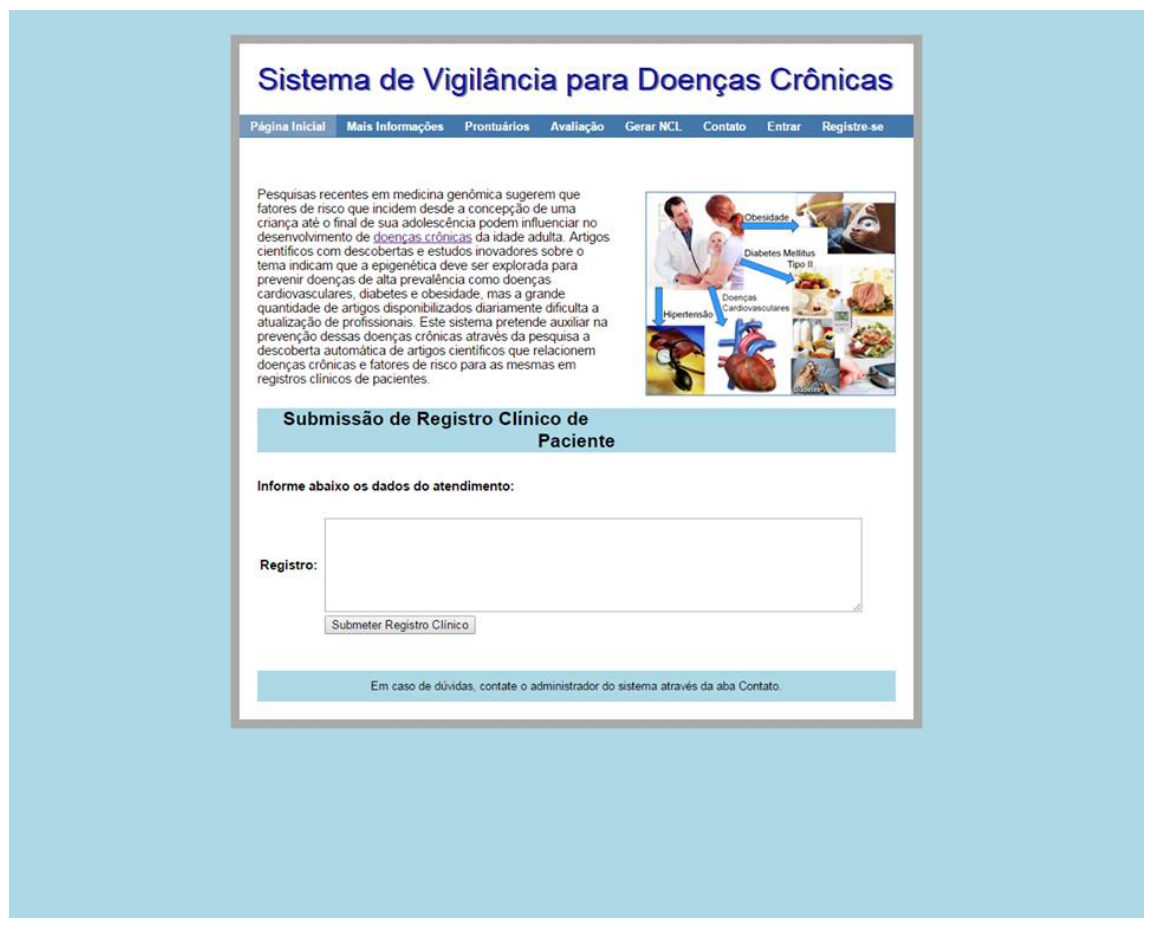

(a)

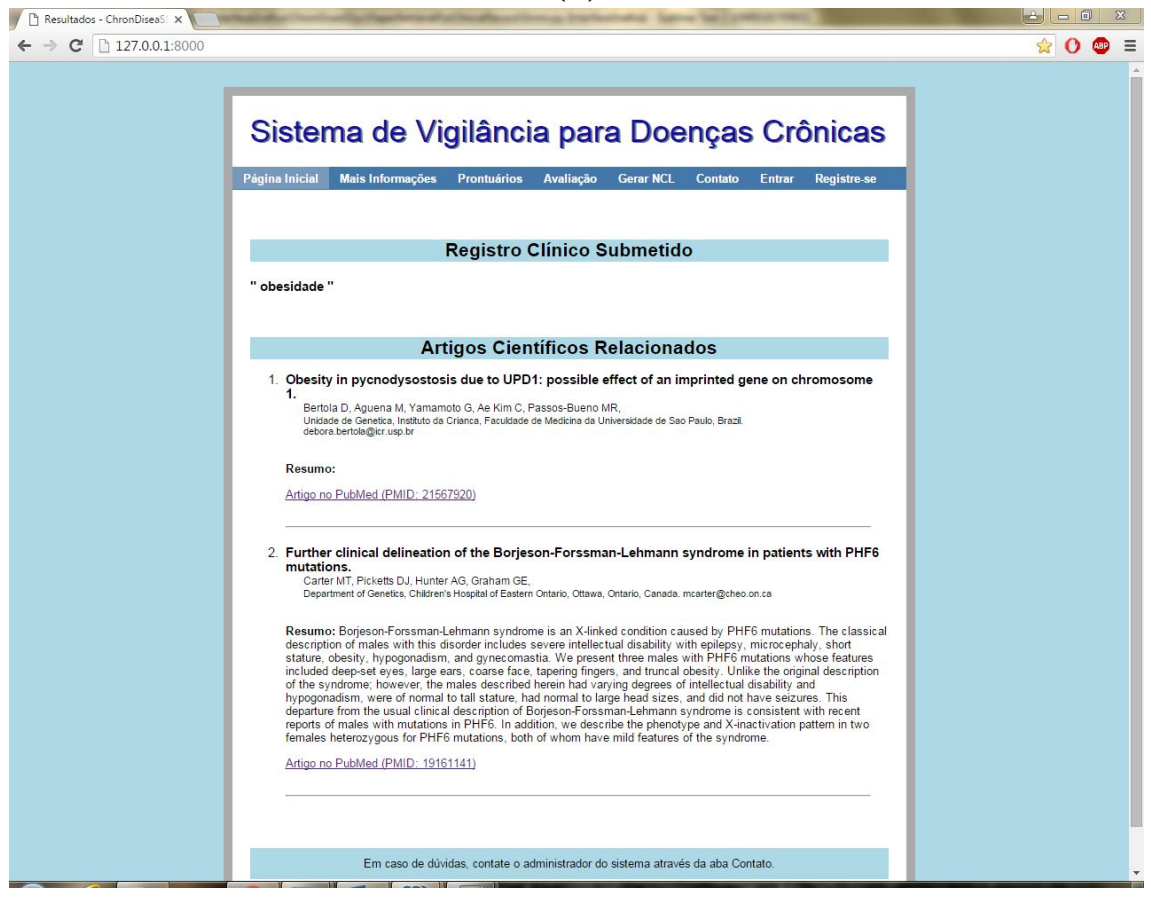

(b)

Figura 4.2: Interfaces do usuário do Sis ViDAS (Pollettini, 2011). 
exames de diagnóstico (INCA, 2014). Um dos exames mais utilizados no diagnóstico inicial de nódulos na tireoide é a Punção Aspirativa com Agulha Fina (do inglês, Fine Needle Aspiration Biopsy - FNBA). As principais vantagens deste tipo de exame é a relação entre o custo e benefício, a facilidade da execução do procedimento e a seleção de pacientes para cirurgia. Em contrapartida, para que o diagnóstico seja preciso são necessárias amostras adequadas de material de tireoide e a experiência do patologista que realiza o diagnóstico (Murussi et al., 2001).

Atualmente, é notável o crescente uso de sistemas computacionais de auxílio ao diagnóstico (do inglês, Computer Aided Diagnosis - CAD) que auxiliem patologistas em diagnósticos. A principal proposta de um CAD é fornecer informações adicionais como, por exemplo, dados morfológicos extraídos de imagens de diagnóstico por imagens, recuperação de imagens de exames similares ao caso estudado ou informações textuais resgatadas de uma base de laudos de diagnósticos. Nesse sentido, o framework intitulado FREDS (Framework para Redução da Descontinuidade Semântica em Imagens Médicas) e um sistema CAD para validar o framework foram desenvolvidos. O principal objetivo foi gerar conhecimento por meio de mapeamentos conceituais entre o conteúdo da imagem de FNBA e as informações textuais presentes no exame, com o intuito de diminuir o gap semântico gerado pelo processo que compreende desde a recuperação computadorizada de imagens médicas até a interpretação humana do seu conteúdo (Pessotti, 2012).

As principais funções do FREDS são: (i) permitir ao especialista submeter imagens patológicas adquiridas; (ii) identificar regiões de interesse nas imagens; (iii) realizar e exibir cálculos morfométricos; (iv) devolver laudos similares às expressões de buscas obtidas por meio de rótulos das imagens; (v) obter e agrupar diagnósticos de um conjunto de laudos; e (vi) obter os termos mais frequentes de um conjunto de diagnósticos. Na Figura 4.3, a arquitetura do FREDS é apresentada.

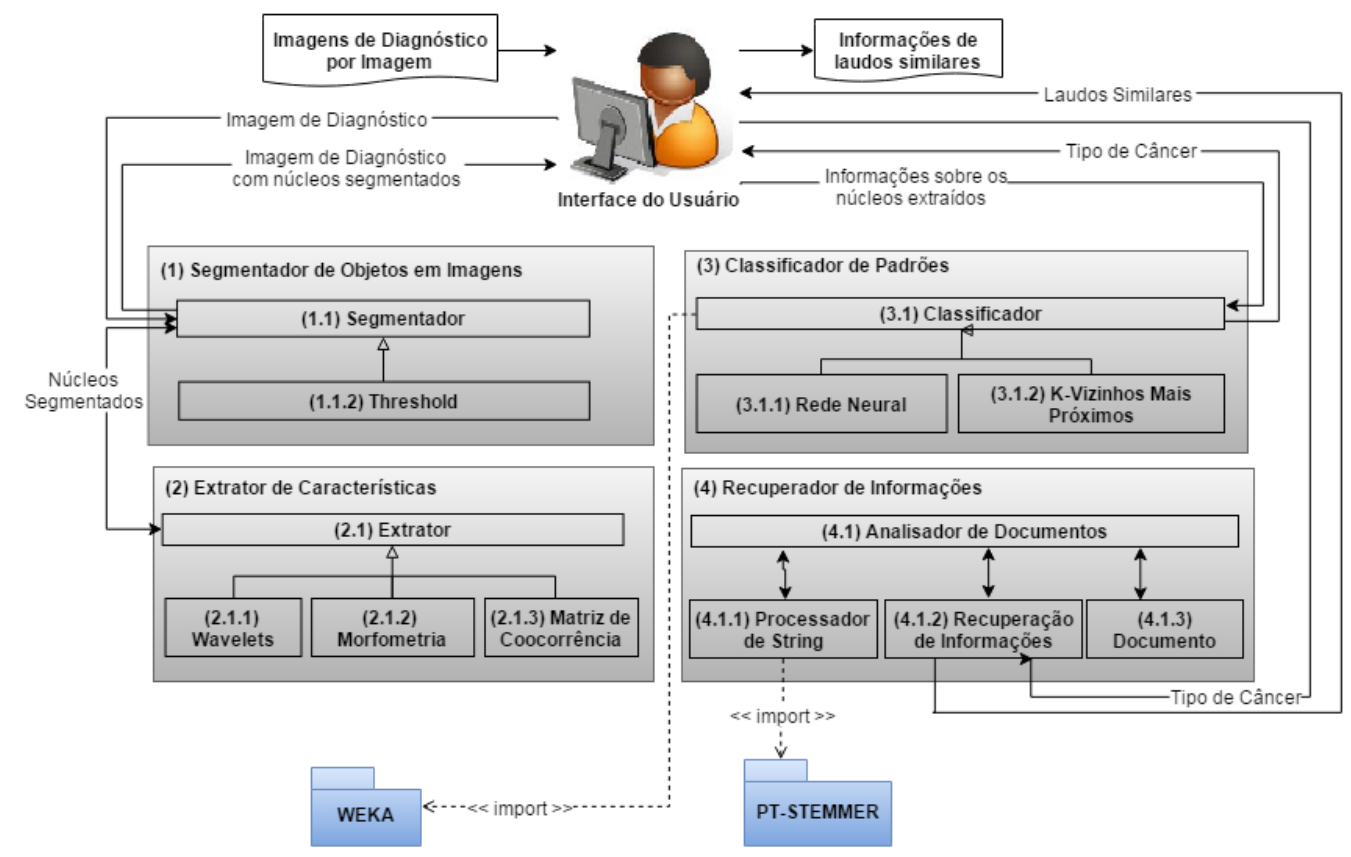

Figura 4.3: Estrutura do framework FREDS. BASEADO EM: (Pessotti, 2012).

O componente "Segmentador de Objetos em Imagens" (Figura 4.3 (1)) é composto por métodos que segmentam as estruturas relevantes das imagens, ou seja, os núcleos das células em FNBA. Para esta etapa foi utilizada a técnica de limiarização ou threshold Otsu (Otsu, 1975). A técnica de 
limiarização consiste em criar um histograma, ou seja, uma representação da quantidade de pixels por tonalidade da escala de tons cinzas. Em seguida, o método de Otsu é utilizado para selecionar o melhor ponto de corte que é a maior variância entre o fundo da imagem e a região de interesse. Por fim, uma máscara binária é gerada para mostrar, na imagem, somente as regiões de interesse.

O "Extrator de Características" (Figura 4.3 (2)) é formado por classes responsáveis por representar as informações segmentadas como vetores de características. Nessa etapa, as técnicas de extração de características Matriz de Coocorrência (COOC), Transformada Discreta de Wavelets (DWT) e Morfometria (MORPHO) foram utilizadas. A Matriz de Cooccorrência (Figura 4.3 (2.1.3)) é uma abordagem estatística utilizada na extração de padrões de textura (Albregtsen, 2008). O método cria uma matriz que considera a distribuição dos pixels e os seus relacionamentos. Quando varia o vetor usado na representação da matriz é possível calcular a Energia, o Contraste, a Correlação, a Entropia e a Homogeneidade (Haralick et al., 1973).

A Transformada Discreta de Wavelets (Figura 4.3 (2.1.1)) é uma abordagem espectral que decompõe sinais em componentes menores, permitindo a análise dos dados em domínios de frequências distintos com a aplicação de escala de resolução para cada componente (Daubechies, 1992). A Morfometria (Figura 4.3 (2.1.2)) é um método quantitativo utilizado na caracterização de estruturas celulares individuais por meio de medidas como, por exemplo, o raio, o perímetro e a área (Priya e Sundaram, 2011). No FREDS foram utilizados o raio médio, o perímetro, a área, o índice de contorno nuclear e a razão maior e a menor do raio (Macedo et al., 2016). Os parâmetros morfométricos foram incluídos no FREDS porque são uma das principais características do auxílio ao diagnóstico de doenças com achados patológicos em imagens. Essas medidas podem detectar alterações morfológicas relevantes nas células. Assim, a morfometria pode ser uma importante fonte de informação semântica na tarefa de classificação de nódulos (Padovani Jr et al., 2007).

O "Classificador de Padrões" contém as técnicas de Aprendizado de Máquina que classificam os vetores de características em classes pré-definidas que são: Câncer, Bócio e Não-Câncer. Os métodos de classificação experimentados no framework foram k-Vizinhos mais Próximos (do inglês $k$-Nearest Neighbor - KNN) e as Redes Neurais do tipo Multilayer Perceptron (MLP)(Figura 4.3 (3.1.1) e (3.1.2)). O intuito da aplicação de classificadores no FREDS é a automatização do processo de rotulação, ou seja, atribuir nomes automaticamente as estruturas descobertas na imagem. No FREDS, esse processo pode ser realizado de duas maneiras distintas: (i) automática e (ii) semiautomática com o auxílio de um patologista. Na primeira maneira, técnicas de Processamento Digital de Imagens, Recuperação de Imagens Baseado no Conteúdo e Aprendizado de Máquina são utilizadas. Previamente, uma base de dados rotulada é necessária para que os classificadores conheçam as características específicas das células que compõem cada classe. Quando um exemplo desconhecido é inserido, o exemplo é segmentado, depois o vetor de características é criado e, por fim, ele é classificado e rotulado de acordo com sua similaridade com os exemplos das classes conhecidas pelo classificador. No modelo semiautomático, as estruturas de interesse são identificadas e classificadas pelo CAD manualmente pelo especialista.

O "Recuperador de Informações" (Figura 4.3 (4)) busca laudos de exames médicos que correspondam à classe indicada na etapa de Classificação. Durante o processo de recuperação da informação, os documentos que contenham descrições de achados patológicos similares aos encontrados na imagem são buscados na base de laudos. Quando a imagem está classificada/rotulada, os rótulos são utilizados na formação de consultas de usuários para buscar laudos similares. Na construção das 
consultas, a expansão de termos por meio do uso de thesauri foi utilizada junto com a combinação de operadores lógicos (AND e OR). Os prontuários são recuperados por meio do cálculo da similaridade dos cossenos.

O framework FREDS foi desenvolvido com a linguagem de programação o JAVA. Na Figura 4.4, as interfaces do usuário do FREDS são apresentadas. Nas Figuras 4.4(a) e 4.4(c), a transformação visual que acontece na imagem durante o processo de segmentação/classificação é demonstrada. Nas Figuras 4.4(a) e 4.4(c), a interface do usuário e a sequência de processos a serem executados são apresentados. Por fim, na Figura 4.4(e), os processos de recuperação de laudos similares à imagem classificada são apresentados.

Após a imagem ser inserida no FREDS, a primeira etapa é a segmentação automática ou semiautomática. Caso o usuário escolha a segmentação semiautomática, o primeiro passo é criar os ROIs (do inglês Region Of Interest), ou seja, selecionar áreas de interesse da imagem que, nesse caso, são os núcleos. Para realizar esta tarefa na interface, quadros na cor amarela são criados na imagem pressionando o botão "create ROI" (Figura 4.4(b)1). Em seguida, o usuário posiciona manualmente esses quadros em torno dos núcleos de interesse. O número de quadros a serem criados e posicionados é ilimitado, para cada novo quadro, o botão "create ROI" deve ser pressionado novamente. Caso o usuário deseja segmentar a imagem automaticamente, o primeiro passo é pressionar o botão "Automatic Segmentation" (Figura 4.4(b)1). Quase instantaneamente os núcleos da imagem são contornados por uma linha preta (Figura 4.4(a)). O limiar do threshold pode ser ajustado manualmente (Figura 4.4(b)1) para que o núcleo seja contornado corretamente, pois, muitas vezes, o contorno automático do framework pode ignorar detalhes importantes do núcleo das células.

Após a imagem ser segmentada, o usuário pode escolher entre: (1) classificar manualmente os núcleos e salvar as informações no banco de dados que, posteriormente, será utilizado para atualizar a informação dos extratores de características e no treinamento e feedback da classificação automática; ou (2) classificar automaticamente à imagem. Caso o usuário selecione a opção (1), o rótulo do núcleo deve ser selecionado, ou seja, deve ser escolhido qual tipo de conteúdo a imagem representa (Câncer, Bócio e Não-Câncer.) (Figura 4.4(b)3). Em seguida, a informação dos extratores pode ser atualizada escolhendo o extrator ou a combinação de extratores e pressionando o botão "Rebuild database" (Figura 4.4(b)4). Se a opção (2) for escolhida, ou seja, o usuário deseja classificar automaticamente os núcleos da imagem e encontrar qual o tipo principal da imagem (Câncer, Bócio e Não-Câncer.), a aba "Pattern Classification" deve ser selecionada (Figura 4.4(b)2).

Para classificar automaticamente os núcleos segmentados da imagem, o usuário deve selecionar o extrator ou a combinação de extratores e o classificador a serem utilizados e, por fim pressionar o botão "Run Classifier" (Figura 4.4(d)1). Em seguida, cada núcleo da imagem será classificado dentre uma das três classes disponibilizadas pelo framework (Câncer, Bócio e Não-Câncer.). Cada núcleo classificado é pintado com uma a cor específica da classe encontrada pelo classificador (Não-Câncer é representado pela cor vermelha, Bócio pela cor azul e Câncer pela cor verde). Todas as classes encontradas na imagem são descritas na caixa "Celular Description" (Figura 4.4(d)2). Por fim, a classe que mais se repete na imagem (classe majoritária) é exibida para o usuário (Figure 4.4(d)3).

Após a imagem ser classificada, os laudos similares aos resultados obtidos na classificação da imagem são buscados. Na Figura 4.4(e), a interface de recuperação de laudos médicos é apresentada. Nesse sentido, o FREDS utiliza as informações descritas na caixa "Celular Description" (Figura 4.4(d)2) junto com o uso de ontologias do domínio e thesaurus para criar uma consulta 


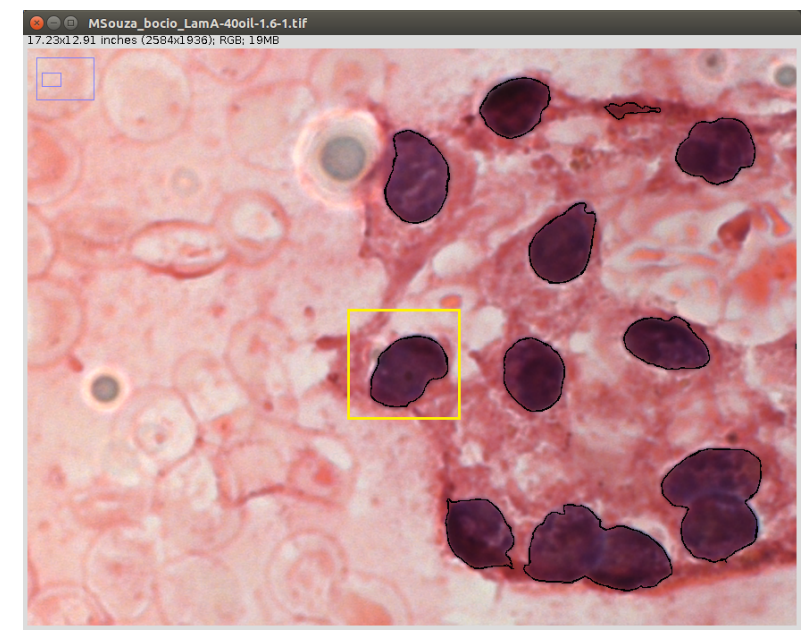

(a)

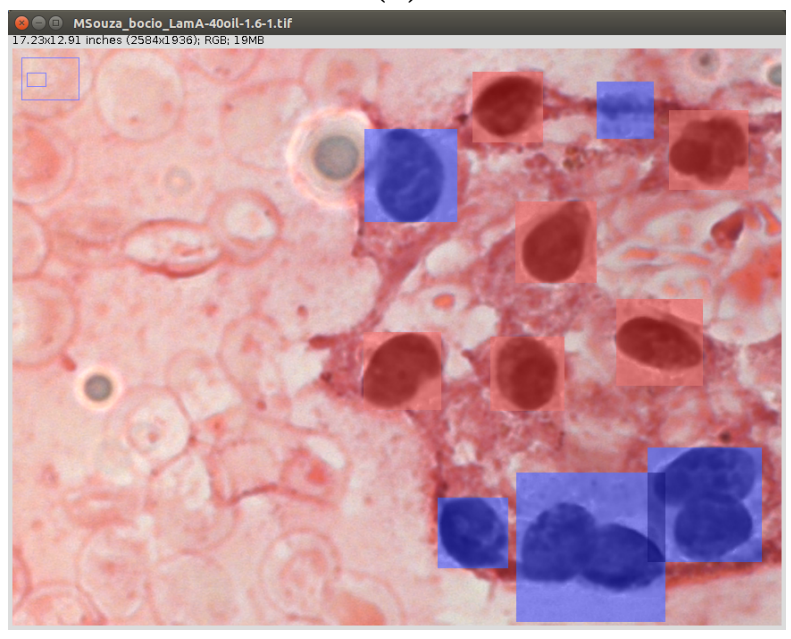

(c)

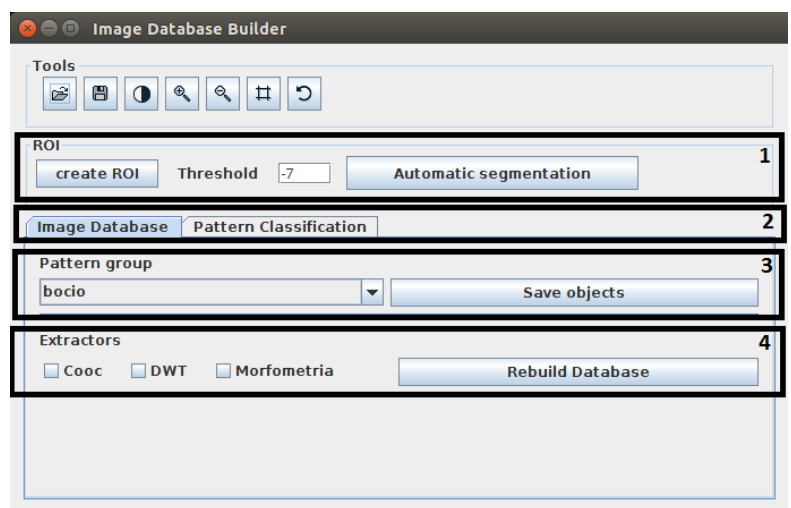

(b)

(FREDS) 38 
com expansão de termos. Os resultados são apresentados para o usuário na forma de uma lista de termos mais relevantes encontrados nos laudos e os principais diagnósticos.

A avaliação do FREDS foi realizada analisando a taxa de acerto dos classificadores (KNN e MLP) (Pessotti, 2012). Inicialmente, três cenários de avaliação foram definidos com todas as combinações possíveis entre os extratores: (i) extratores avaliados separadamente; (ii) em pares; (iii) todos juntos. Os experimentos foram executados em função de cada classificador e depois comparados entre si. No primeiro cenário, a melhor taxa de acerto foi $81.2 \%$ para a COOC com o classificador KNN. No segundo cenário, as melhores combinações foram COOC e MORPHO e classificador MLP, com taxa de acerto em 84.6\%. E no último cenário (todos os extratores juntos), o melhor classificador foi o MLP com $85.7 \%$.

Os frameworks SisViDAS e FREDS compõem parte da etapa de Processamento de Documentos como apresentado na Figura 5.10. Eles serão responsáveis pelas tarefas de busca de documentos relevantes (artigos científicos, prontuários médico do paciente e laudos de exames de diagnóstico) que possam conter respostas de interesse ao usuário do sistema. Contudo, para que esta etapa esteja completada, o desenvolvimento de funções para busca e segmentação de parágrafos candidatos nos documentos retornados pelo SisViDAS e FREDS foram criadas. Durante a construção do FREDS, houve dificuldades em obter a análises patológicas mais apuradas sobre as imagens captadas pelo especialista, estas imagens iriam ser utilizadas na validação do FREDS. Portanto, uma das atividades realizadas por esta mestranda foi a realização de novas avaliações para a uma validação mais apurada do FREDS. Neste sentido, a solução encontrada foi a criação de uma nova coleção de referência, desta vez curada por um patologista, e a realização de novas avaliações. Os resultados estão descritos no próximo capítulo e detalhados em Macedo et al. (2016). 


\section{Capítulo 5}

\section{Question Answering Surveillance Framework (QASF)}

Nos últimos anos, a tarefa de buscar e ler artigos científicos de interesse tem se tornado uma tarefa cansativa e complexa para o usuário em geral. Alguns dos principais problemas são o aumento substancial na quantidade de artigos publicados em repositórios da Web, o idioma em que o artigo está escrito, muitas vezes diferente do idioma nativo do usuário, e a dificuldade na formulação de consultas usando linguagens diferente da linguagem natural. Para os profissionais da saúde, a tarefa de busca por informação é ainda mais complexa e cansativa, uma vez que além dos problemas citados, os profissionais possuem uma rotina de trabalho estressante e ainda enfrentam problemas como a rápida atualização das informações sobre tratamentos, medicações e procedimentos (ABS, 2005; Shortliffe e Cimino, 2013). Os sistemas de QA surgiram como uma atualização dos sistemas de RI e com o objetivo de fornecer informações diretas e precisas sobre uma pergunta proposta pelo usuário. Para realizar esta tarefa, estes sistemas utilizam técnicas computacionais, principalmente, das áreas de Extração de Informação, Mineração de Texto e Recuperação de Informação (Allam e Haggag, 2012).

Conforme apresentado no Capítulo 2, os sistemas clássicos de QA possuem três módulos principais: (i) processamento da questão, (ii) processamento do documento e (iii) processamento da resposta. Neste capítulo é apresentada a construção do Question Answering Surveillance Framework (QASF) suportado (i) pelas classes e módulos dos frameworks FREDS e SisViDAS estendidos por novas classes propostas pela mestranda para a etapa de processamento de documentos e (ii) por novas classes e módulos para as etapas de processamento da questão e de seleção da resposta. Na Seção 5.1, uma visão geral do QASF é apresentada. Nas Subseções 5.1.1, 5.1.2 e 5.1.3, os detalhes de construção de cada módulo são descritos. Por fim, nas Seções 5.2 e 5.3, a modelagem do QASF e as interfaces do usuário do QASF são apresentadas respectivamente.

\subsection{Arquitetura do QASF}

O QASF é um framework ${ }^{1}$ do tipo Question Answering que tem como objetivo auxiliar profissionais da área da saúde respondendo questões do domínio da epigenética e doenças crônicas. O

\footnotetext{
${ }^{1}$ Frameworks são modelos de sistemas reutilizáveis representado por um conjunto de classes abstratas de forma que elas colaboram entre si (Roberts e Johnson, 1996).
} 
QASF é composto por três módulos principais: (i) processamento da questão, (ii) processamento do documento e (iii) processamento da resposta. A arquitetura do QASF é apresentada na Figura 5.1.

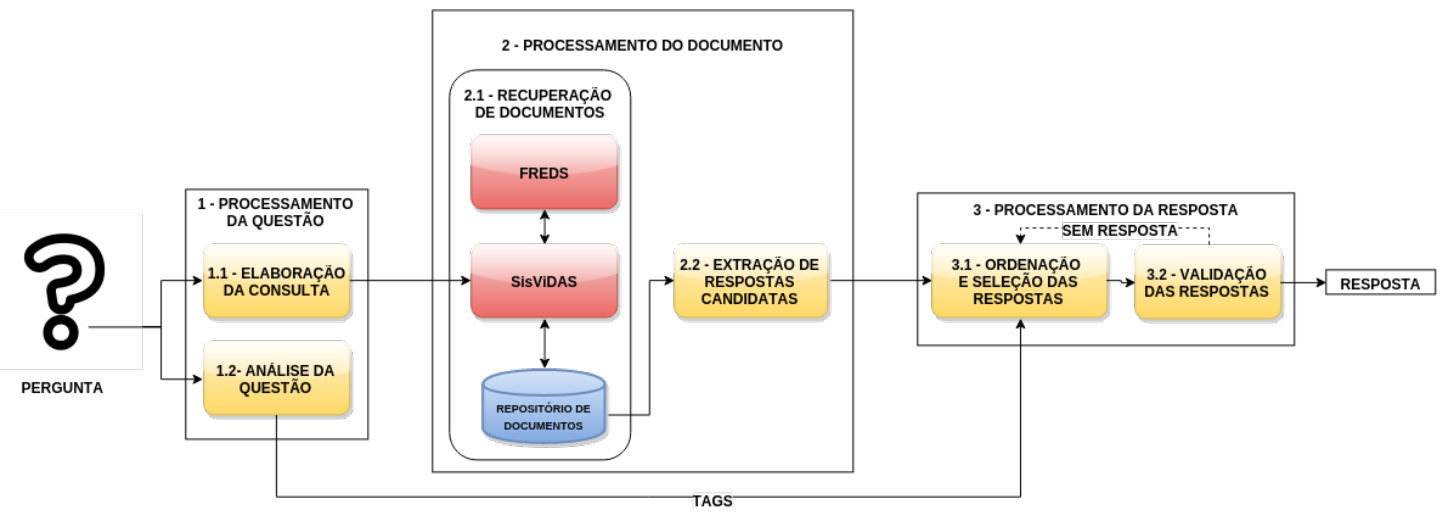

Figura 5.1: Arquitetura da proposta do $Q A S F$.

O módulo de "1 - Processamento da Questão" é composto pelas tarefas de "Elaboração da Consulta" e "Análise da Questão". A tarefa "1.1 - Elaboração da Consulta" utiliza as técnicas de Processamento de Linguagem Natural para a eliminação de stopwords e a extração das palavras de maior relevância contidas na pergunta do usuário para manipular as consultas. Na tarefa de "1.2 Análise da Questão", as técnicas de AM juntamente com uma base de questões para treinamento e técnicas de análise de correspondência de padrões são utilizadas.

O módulo de "2 - Processamento do Documento" é composto pelas tarefas de "Recuperação de Documentos" e "Extração das Respostas Candidatas". A tarefa de "2.1 - Recuperação de Documentos" é realizada pelos frameworks FREDS e SisViDAS. O SisViDAS retorna os artigos científicos e/ou prontuários médico do paciente de maior interesse e o FREDS retorna laudos de exames médico. Neste trabalho de mestrado, somente a experimentação com o SisViDAS é realizada. A "2.2 Extração das Respostas Candidatas" é feita nos abstracts dos artigos retornados, nas informações do prontuário médico e dos laudos de exames por meio da técnica de proximidade linear.

O módulo de "3 - Processamento da Resposta" é composto pelas tarefas de "Ordenação e Seleção das Respostas" e "Validação das Respostas". Para a tarefa de "3.1 - Ordenação e Seleção das Respostas" utilizou-se o cálculo da similaridade por cosseno e na "(3.2) Validação da Resposta", o QASF utiliza uma coleção de referência chamada EDRMrSa. Esta coleção de referência é apresentada na Subseção 6.1.3.

\subsubsection{Processamento da Questão}

O módulo de "Processamento da Questão" objetiva extrair informações da questão realizada pelo usuário em linguagem natural. As informações extraídas são fundamentais na seleção das respostas candidatas e para converter a questão em uma consulta em linguagem computacional. A consulta computacional é utilizada, posteriormente, no módulo de "Processamento dos Documentos" para a recuperação dos artigos que possivelmente contenham a resposta para a pergunta do usuário. A etapa de "Processamento da Questão" é dividida em dois submódulos: "Análise da Questão" e "Elaboração da Consulta".

$\mathrm{Na}$ literatura, foram encontradas algumas abordagens para o submódulo de "Análise da Questão": correspondência de padrões (Er e Cicekli, 2013), Máquina de Vetores de Suporte (do inglês, 
Support Vector Machine - SVM) e análise morfossintática (Monz, 2003; Zhang e Lee, 2003). O QASF é suportado por abordagens de Aprendizado de Máquina, especificamente por técnicas de SVM e Naive Bayes, e por abordagens de correspondência de padrões. Na abordagem de Aprendizado de Máquina, os classificadores foram construídos e validados utilizando um conjunto de perguntas separado de acordo com o tema da pergunta (classes ou tags). Em seguida, esse conjunto é analisado pelo framework para que quando o usuário inserir uma pergunta, não analisada anteriormente, o framework seja capaz de classificar corretamente esta pergunta. Os resultados obtidos com os classificadores são apresentados e comparados entre si na Subseção 6.2.1.

No QASF, a abordagem de correspondência de padrões é utilizada para analisar perguntas do tipo definição (Exemplo: What is cancer?). Perguntas desse tipo possuem uma construção gramatical conhecida, composta por: Pronome Interrogativo ("Whats") + Verbo + Sujeito + Pontuação. Tendo isso em vista, o QASF primeiramente analisa o pronome interrogativo da questão, caso seja "What", o framework busca pelo sujeito da frase e o envia para um banco de dados lexical (dicionário), neste caso o WordNet ${ }^{2}$. Em seguida, o WordNet retorna a definição do sujeito. Na Figura 5.2, um modelo visual de como a análise da questão por correspondência de padrões é realizada é apresentado. Os demais tipos de questões (how, where, who, etc) são avaliadas somente pelas técnicas de AM.

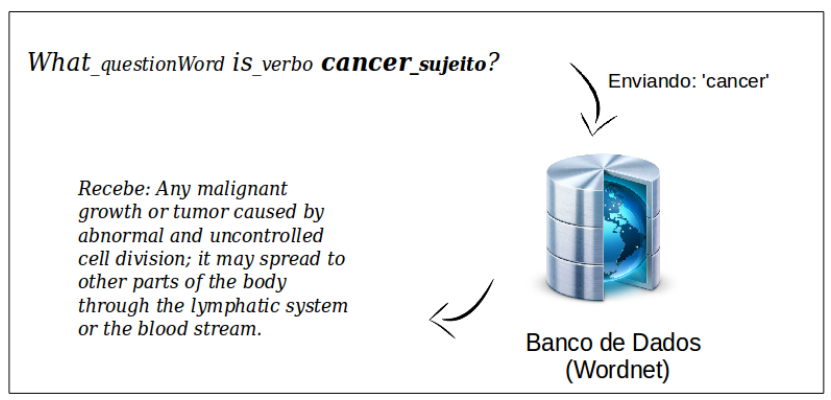

Figura 5.2: Análise da questão por correspondência de padrões. Primeiramente, a pergunta é analisada afim de descobrir os elementos gramaticais que à compõe. Em seguida, o sujeito da questão é enviado para o banco de dados WordNet e, por fim, a definição do sujeito é recebida pelo QASF.

O outro elemento que compõe o módulo de "Processamento da Questão" é o submódulo de "Elaboração da Consulta". Neste submódulo, um conjunto de palavras-chave é extraído, o qual será a base da consulta computacional de uma pergunta inserida pelo usuário em linguagem natural. A representação da consulta no formato de um vetor de palavras é transmitida para o módulo de "Processamento de Documentos" especificamente para o submódulo de "Recuperação de Documentos".

No QASF, a construção do vetor de palavras é feita em duas etapas. Na primeira etapa, os elementos que não possuem relevância para compor um conjunto de palavras-chave significativo são desconsiderados. Na segunda etapa, o foco é na adição de elementos sinônimos à cada elemento do vetor resultante da primeira etapa e na extração do radical de todas essas palavras que compõem o vetor de palavras-chave. Essas tarefas da segunda etapa são necessárias pois na construção de textos $^{3}$ e suas unidades menores como, por exemplo, a frase (pergunta), é comum haver flexão

\footnotetext{
${ }^{2}$ https://wordnet.princeton.edu/

3"Texto é unidade linguística comunicativa fundamental, produto de uma atividade verbal humana, que possui sempre caráter social, está caracterizado por seu campo semântico e comunicativo, assim por sua coerência profunda e superficial, devida à intenção (comunicativa) do falante criar um texto íntegro, e à sua estruturação mediante os
} 
nas palavras para que elas expressem categorias gramaticais adequadas à construção de um texto coerente. Essas flexões são realizadas, geralmente, por meio da inserção de prefixos e sufixos. Na Figura 2.4 da Subseção 2.2.1, exemplos de flexões de uma palavra por meio da adição de sufixos distintos foi demonstrado. Durante a busca e a recuperação computacional de informações textuais, estas flexões gramaticais podem dificultar a busca por textos e ou frases candidatas. Por exemplo, caso um framework de recuperação textual esteja procurando a palavra "computacional" e nos textos do conjunto de busca contenham apenas os termos "computacionalmente" e/ou "computadores" há grandes possibilidades do framework não retornar esses textos como candidatos à resposta correta porque o framework busca apenas pelo termo em questão e não pelos termos similares. Percebendo esta dificuldade, técnicas de stemming ${ }^{4}$ e lematização ${ }^{5}$ foram aplicadas para finalizar a segunda fase de construção do vetor de palavras do QASF.

No QASF, a primeira etapa da construção do vetor de palavras é feita desconsiderando os pronomes interrogativos, as "stopwords" e as pontuações. Considerando que os pronomes interrogativos têm grande importância na fase de "Análise da Questão", para definir o tipo de pergunta inserida pelo usuário, eles são retirados da consulta, mas armazenadas separadamente no QASF. Na Figura 5.3, a primeira etapa da construção da consulta computacional, a partir de uma pergunta inserida pelo usuário é apresentada. Para iniciar o processo de construção da consulta, o usuário insere uma pergunta e como resultado final é construído a primeira parte do vetor com as palavraschave da pergunta. Nesta etapa, os pronomes interrogativos do inglês são desconsideradas da frase inserida pelo usuário. Em seguida, as "stopwords" e as pontuações da frase são eliminadas. Por fim, o resultado é um vetor de palavras que será inserido como entrada de dados na segunda etapa de construção do vetor final de palavras.

\section{"Wy.at is carcinoma of tye thyroid $\mathbf{X}$ "}

$$
\text { vetorPalavras }=[\text { 'is', 'carcinoma', 'thyroid' }]
$$

Figura 5.3: Primeira etapa de construção do vetor de palavras-chaves do QASF. Primeiramente, o QASF elimina os pronomes interrogativos (' $X$ ' na cor vermelha), em seguida, as stopwords são eliminadas (' $X$ ' na tonalidade alaranjada) e por fim, as pontuações são eliminadas (' $X$ ' na tonalidade azul).

A segunda etapa de construção do vetor de palavras-chave inicia-se com a busca de termos sinônimos aos termos resultante da primeira. O QASF envia termo pôr termo para o banco de dados lexical WordNet e, como resultado, um conjunto de palavras sinônimas é recebido. Caso o WordNet não encontre palavras sinônimas para um termo enviado, o QASF solicita ao mesmo a busca de termos hiperônimos, ou seja, termos que pertencem ao mesmo domínio semântico porém com significado mais amplo. A partir desse momento, o vetor de palavras é composto pelos elementos resultantes da primeira etapa e seus sinônimos e hiperônimos. Na Figura 5.4, um exemplo de busca

conjuntos de regras: as próprias de nível textual e as do sistema da língua." (Sanchís, 1982)

${ }^{4} \mathrm{O}$ stemming é o processo de reduzir o termo ao seu radical, por meio da remoção de elementos das palavra como, por exemplo, os afixos e as vogais temáticas (Bird et al., 2009).

${ }^{5} \mathrm{~A}$ lematização é o processo de desflexionar uma palavra, trazendo-a, geralmente, para a sua forma infinitiva (Galisson e Coste, 1983). 
por sinônimos e hiperônimos com o auxílio do WordNet é apresentado. Na figura, os sinônimos dos elementos do vetor de palavras são buscados individualmente no WordNet. O termo "carcinoma" não possui palavras sinônimas segundo o WordNet, então o QASF solicita ao WordNet os termos hiperônimos que, no caso da palavra "carcinoma", são "cancer" e "malignant neoplastic disease".

vetorPalavras $=$ ['is', 'carcinoma', 'thyroid']
Sinônimos:
'is': ['represent', 'equal', 'constitute' ...]
$\frac{\text { carcinoma: [ ??? ] (não há sinônimos) }}{\text { thyroid: ['thyroidal', 'thyroid gland'] }}$
Hiperônimo:
carcinoma: ['cancer', 'malignant neoplastic disease']

Figura 5.4: Segunda etapa de construção do vetor de palavras-chaves do QASF. Primeiramente, o QASF envia as palavras do vetor para o WordNet retornar seus sinônimos. Caso não haja sinônimos, o QASF solicita que o WordNet busque pelos termos hiperônimos do termo que está sendo avaliado.

Para finalizar a segunda etapa de construção do vetor de palavras-chave do QASF, as técnicas de stemming e lematização foram aplicadas nas palavras do vetor para que todas fossem reduzidas apenas ao radical. A técnica de lematização aplicada no QASF é apoiada por um corpus do WordNet para a transformação dos verbos flexionados para a forma infinitiva. A técnica de stemming foi empregada no QASF na extração do radical das palavras do vetor de palavras-chave, apoiada pela biblioteca de processamento de linguagem natural NLTK em parceria com Snowball. Um exemplo de stemming e lematização é apresentado na Figura 5.5. Na figura, o verbo destacado na tonalidade vermelha representa o processo de lematização, enquanto que as palavras na tonalidade azul representam a extração do radical das palavras do vetor por meio da técnica de stemming. Quando os radicais são extraídos e são iguais, eles são convertidos à um único elemento do vetor como, por exemplo, o radical "thyroid", extraído das palavras "thyroid" e "thyroidal", apresentado pela tonalidade verde.

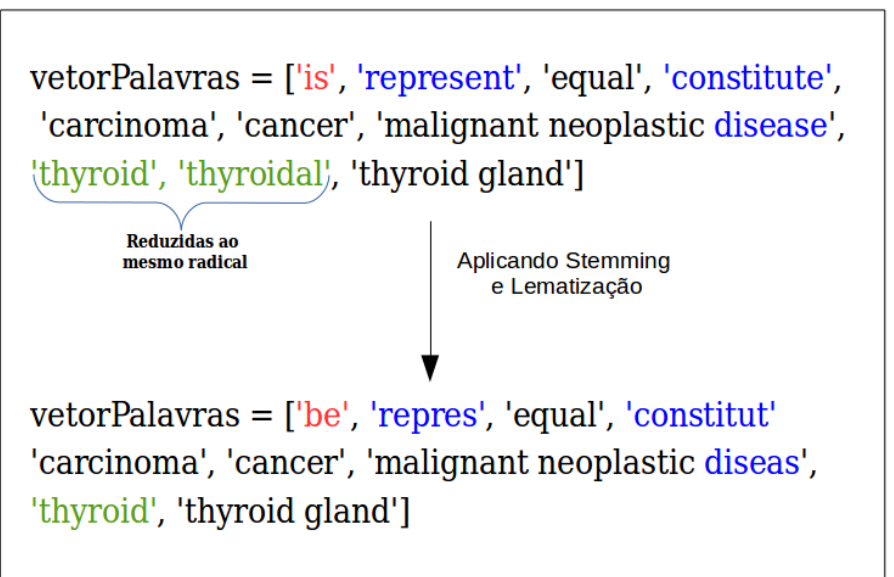

Figura 5.5: Final da segunda etapa de construção do vetor de palavras-chaves do QASF. O processo de lematização é representado pela tonalidade vermelha. A aplicação da técnica de stemming é apresentada nas tonalidades azul e verde. Contudo, a tonalidade verde representa também a redução de duas palavras que possuem o mesmo radical a um único elemento no vetor de palavras-chave final. 


\subsubsection{Processamento dos Documentos}

O módulo de "Processamento dos Documentos" engloba os submódulos de "Recuperação dos Documentos" candidatos e de "Extração das Respostas Candidatas". A tarefa de "Recuperação de Documentos" objetiva a recuperação de documentos que contenham as possíveis respostas para a pergunta elaborada pelo usuário. Como entrada de dados desta etapa, o vetor de palavras, baseado na pergunta feita pelo usuário na etapa anterior de "Processamento da Questão", é inserido. O submódulo de "Extração de Respostas Candidatas" é responsável por analisar os textos recuperados e localizar possíveis frases candidatas.

O submódulo de "Recuperação de Documentos" é sustentado pelos trabalhos de suporte, apresentados no Capítulo 4, que são o SisViDAS e o FREDS. Esse submódulo foi projetado com reuso das classes dos frameworks com o intuito de ampliar o leque das informações manipuladas para a busca de frases candidatas relevantes no contexto de um sistema de QA especializado em domínios médicos para obter mais precisão das respostas retornadas ao usuário. Nesse sentido, o SisViDAS compreende os processos de busca da informação em artigos científicos e prontuários médico do paciente nos domínios de epigenética e doenças crônicas e o framework FREDS associa informações textuais entre laudos de exames e de imagens de diagnóstico por meio de mapeamentos conceituais (Macedo et al., 2016; Pessotti, 2012). Nesta dissertação, somente a recuperação de informação realizada pelo SisViDAS é avaliada. Esta decisão foi tomada devido à complexidade na elaboração de avaliações para ambos os frameworks em contrapartida ao restante tempo de mestrado disponível. A modelagem deste módulo é apresentada na Seção 5.2 e outras informações sobre o SisViDAS podem ser visualizadas na Seção 4.1.

O submódulo de "Extração das Respostas Candidatas" é um dos mais complexos, pois o usuário pode fazer perguntas em diferentes níveis de complexidade. Esses níveis de complexidade das perguntas influenciam no conjunto de técnicas a ser utilizado na extração das respostas candidatas. $\mathrm{Na}$ literatura, vários autores propõem diferentes abordagens como, por exemplo, utilizar as tags encontradas no submódulo de "Análise da Questão", o uso de árvores de análise sintática ou de grafos de dependência (Monz, 2003) e a proximidade linear (Allam e Haggag, 2012; Gupta e Gupta , 2012). No QASF, o processo de extração de respostas candidatas utiliza os abstracts dos artigos recuperados pelo submódulo de "Recuperação de Documentos" e os analisa um a um. Esse processo de análise é detalhado em duas etapas.

$\mathrm{Na}$ primeira etapa, após os abstracts dos artigos serem recuperados pelo submódulo anterior, o conteúdo dos abstracts de cada artigo é convertido para apenas letras minúsculas. Esta conversão é necessária para que o framework não diferencie palavras idênticas com tamanhos de letras distintos. Por exemplo, "Chronic Disease" e "chronic disease" são termos idênticos com tamanhos distintos de letras. Caso não haja este tratamento, o framework pode considerar ambos os termos como termos diferentes. Em seguida, os abstracts são segmentados em parágrafos. Uma vez que no módulo de "Processamento da Pergunta" as palavras-chave que compõem o vetor foram reduzidas apenas à seus radicais por meio das técnicas de lematização e stemming (ver final da Subseção 5.1.1), o mesmo deve ser realizado com as palavras que compõem os parágrafos dos abstracts candidatos para que haja uma correspondência de padrões entre os radicais da pergunta e os radicais dos parágrafos candidatos.

Após a redução aos radicais das palavras dos parágrafos candidatos, uma comparação entre o vetor de palavras-chave, que representa a pergunta inserida pelo usuário, e cada parágrafo candi- 
dato segmentado é realizada. No processo de comparação, as palavras-chave contidas no vetor são buscadas uma a uma no parágrafo candidato. Caso a quantidade de palavras-chave encontradas no parágrafo seja igual ou maior a um liminar $l$, definido manualmente, o parágrafo é selecionado como resposta candidato. A Figura 5.6 apresenta um exemplo de parágrafo onde algumas palavras foram reduzidas à seus radicais e comparadas com o vetor de palavras-chave. Primeiro, as palavras em letras maiúsculas da "Frase Normal" são convertidas em minúsculas para evitar que o framework considere palavras iguais como distintas (ver a palavra "the", em negrito, na "Frase normal" e na "Frase modificada".). Em seguida, as técnicas de lematização e stemming são aplicadas. Os termos sublinhados demonstram o processo de lematização (ex. o is da "Frase normal" é lematizado para o termo "be" na "Frase modificada") e de stemming (ex. do termo "located" na "Frase normal" é extraído o radical "locat" da "Frase modificada") dos parágrafos candidatos. Por fim, os termos "vetorPalavras" e "Frase modificada" são comparados. Se houver um valor $l$ de correspondências (ver na figura correspondências entre os termos destacados com a mesma cor), a frase é considerada uma frase candidata.

vetorPalavras $=[$ 'be', 'repres', 'equal', 'constitut' 'carcinoma', 'cancer', 'malignant neoplastic diseas', 'thyroid', 'thyroid gland']

Frase normal: "The thyroid gland is shaped like a butterfly and is located in the front of your neck."

Frase modificada: "the thyroid gland be shape like a butterfli and be locat in the front of your neck."

Figura 5.6: Exemplo do processo de preparação dos parágrafos dos abstracts que serão analisados pelo QASF. A letra " $t$ " da palavra "the" (em negrito) foi convertida para minúscula uma vez que ela representa inicio de frase. Em seguida, as palavras sublinhadas na "Frase normal" e na "Frase modificada" mostram o processo de transformação por meio das técnicas de stemming e lematização. Em seguida, o "vetorPalavras" (criado no módulo anterior) e a "Frase modificada" (frase candidata modificada) são comparadas entre si na busca por padrões de correspondência. Estes padrões podem ser visualizados nas palavras destacadas em tonalidades vermelha e rosa. Caso o limiar l seja 2, por exemplo, esta frase pode ser considerada uma frase candidata.

\subsubsection{Processamento da Resposta}

O módulo de "Processamento da Resposta" é a última etapa do processo de Question Answering. Neste módulo, as respostas candidatas são selecionadas e ordenadas de acordo com o grau de similaridade entre a questão e as respostas candidatas. A etapa se divide entre os submódulos de "Seleção e Ordenação das Respostas" e "Validação das Respostas". Como resultado deste módulo, as respostas para a pergunta inserida pelo usuário no início do processo de QA são retornadas. Os sistemas de QA não precisam, necessariamente, retornar uma única resposta, eles podem retornar várias respostas ordenadas de acordo com o grau de relevância. Atualmente, o QASF tem retornado as dez respostas mais similares à pergunta inserida pelo usuário, contudo esse valor pode ser reajustado.

O submódulo de "Ordenação e Seleção das Respostas" realiza a ordenação das respostas can- 
didatas por meio de medidas de similaridade e apresenta ao usuário um número $n$ de respostas mais semelhantes. Na ordenação das respostas candidatas, alguns critérios podem ser adotados: (i) a quantidade de palavras da questão do usuário que é reconhecida nas respostas candidatas na mesma ordem de posição, (ii) o número de palavras que separa as palavras-chave mais distantes entre si no parágrafo analisado ou (iii) o número de palavras incompatíveis com as palavraschave (Allam e Haggag, 2012; Gupta e Gupta, 2012).

No QASF, o submódulo de "Ordenação e Seleção das Respostas" pode realizar o cálculo da similaridade do cosseno de dois métodos distintos. No primeiro método, o QASF aplica as técnicas de lematização e stemming na pergunta inserida pelo usuário e utiliza as frases candidatas modificadas por essas mesmas técnicas na etapa anterior de "Processamento do Documento" para que ambos, pergunta e respostas candidatas, possuam o mesmo tipo de construção gramatical. Outro diferencial deste método é a utilização dos sinônimos encontrados na etapa de "Processamento da Questão" para criar um dicionário de sinônimos e transcrever as palavras sinônimas para uma única palavra-chave. A Figura 5.7 apresenta um passo a passo de como é calculado à similaridade por este método. O primeiro passo deste método é a recuperação do dicionário de sinônimos das palavraschave que representam a questão feita pelo usuário. Em seguida, o QASF busca pelas palavras sinônimas nas frases candidatas e quando as encontram, o framework as substituem pela palavrachave. Por exemplo, as palavras "cancer" e "malignant neoplastic disease" são palavras sinônimas à palavra-chave "carcinoma". Quando o QASF encontrar as palavras "cancer" e "malignant neoplastic disease" nas frases candidatas, o framework substituirá essas duas palavras pela palavra-chave "carcinoma". O mesmo se repete, no exemplo da figura, as palavras sinônimos "thyroidal" e "thyroid gland são substituídas pela palavra-chave "thyroid quando encontrados nas frases candidatas. Essas modificações são apresentadas na Figura 6.8a nas "Frase original" e "Frase Modificada". Em seguida, os radicais das palavras que compõem a pergunta e as respostas candidatas são extraídas por meio de técnicas de stemming e lematização (ver Figura 6.8b). Por fim, o cálculo da similaridade entre a pergunta e as frases candidatas modificadas é realizado. Ambos, pergunta e respostas candidatas, são transformadas em vetores no espaço vetorial e a similaridade é calculada por meio do cosseno do ângulo dos vetores que representam a questão e cada resposta candidata (ver Figura 5.7c). 
Questão: What is carcinoma of the thyroid?

Dicionário de Sinônimos:

'is': ['represent', 'equal', 'constitute' ...]

'carcinoma': ['cancer', 'malignant neoplastic disease']

'thyroid': ['thyroidal', 'thyroid gland']

Frase original: Pappilary carcinoma of the thyroid is the most common cancer of the thyroid gland. Frase modificada: Pappilary carcinoma of the thyroid is the most common carcinoma of the thyroid.

(a)

\begin{tabular}{|ll|}
\hline $\begin{array}{l}\text { Pergunta original: } \\
\text { What is carcinoma of the thyroid? }\end{array}$ & $\begin{array}{l}\text { Frases candidatas originais: } \\
\text { Papillary carcinoma of the thyroid is the most common cancer } \\
\text { of the thyroid gland') } \\
\text { Thyroid cancer is an uncommon type of cancer } \\
\begin{array}{l}\text { Pergunta modificada: } \\
\text { what be carcinoma of the thyroid? }\end{array}\end{array} \quad \begin{array}{l}\text { Frases candidatas modificadas: } \\
\text { pappilary carcinoma of the thyroid is the most common } \\
\text { carcinoma of the thyroid. } \\
\text { thyroid carcinoma be an uncommon type of carcinoma. }\end{array}$ \\
\hline
\end{tabular}

(b)

Pergunta modificada:
what be carcinoma of the thyroid?
the most common carcinoma of the
thyroid.
thyroid carcinoma be an uncommon
type of carcinoma.
Resultado do cálculo do cosseno:
(0.816496580927726, 'papillary carcinoma of the thyroid is the most common cancer of the thyroid gland')
$(0.6454972243679029, '$ 'thyroid cancer is an uncommon type of cancer')
(0.5940885257860046, ' the thyroid gland is located inside the front of the lower neck')

(c)

Figura 5.7: Apresentação do primeiro método de cálculo da similaridade. O primeiro passo, o QASF busca pelas palavras sinônimas nas frases candidatas as substituem pela palavra-chave. Quando o QASF encontrar as palavras "cancer" e "malignant neoplastic disease" nas frases candidatas, o framework substituirá essas duas palavras pela palavra-chave "carcinoma". Em seguida, os radicais das palavras que compõem a pergunta e as respostas candidatas são extraídas por meio de técnicas de stemming e lematização e, por fim, o cálculo da similaridade por meio do cosseno do ângulo entre a pergunta e as frases candidatas modificadas é realizado.

O segundo método de calcular a similaridade considera a pergunta e as respostas candidatas em suas formas gramaticais originais. Para o cálculo da similaridade, a pergunta feita pelo usuário e as respostas candidatas são convertidas para o espaço vetorial e o cosseno do ângulo dos vetores que representam a pergunta do usuário e cada resposta candidata é calculada. Em ambos os métodos, as respostas são ordenadas de acordo com o valor da similaridade e um número $n$ de respostas mais similares são retornadas para o usuário. Este número $n$ pode ser ajustado manualmente pelo usuário. O QASF exibe ao usuário as dez respostas mais similares. A avaliação dos dois métodos de cálculo da similaridade foi realizado com o intuito de analisar qual método apresenta melhores resultados. Na Figura 5.8, um exemplo do cálculo da similaridade por este método é apresentado. 


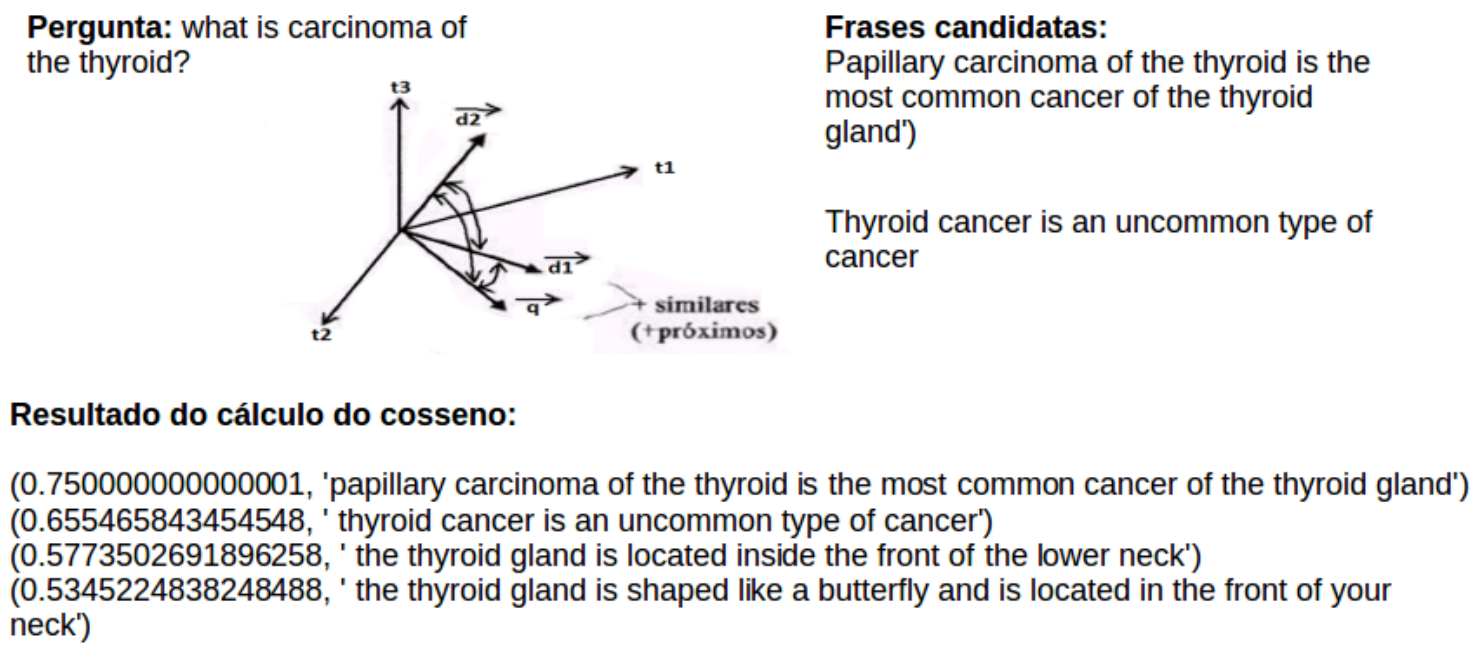

Frases candidatas:

Papillary carcinoma of the thyroid is the most common cancer of the thyroid gland')

Thyroid cancer is an uncommon type of cancer

\section{Resultado do cálculo do cosseno:}

( 0.750000000000001 , 'papillary carcinoma of the thyroid is the most common cancer of the thyroid gland') ( 0.655465843454548, ' thyroid cancer is an uncommon type of cancer')

( 0.5773502691896258, ' the thyroid gland is located inside the front of the lower neck')

$(0.5345224838248488, '$ the thyroid gland is shaped like a butterfly and is located in the front of your neck')

Figura 5.8: Apresentação do segundo método de cálculo da similaridade. Neste modelo, a questão e as frases candidatas permanecem no formato original e a similaridade é calculada por meio do cosseno do ângulo entre a pergunta do usuário e cada resposta candidata.

\subsection{Modelagem do QASF}

O QASF foi modelado em três diferentes níveis de abstração e o resultado é apresentado por meio de diagramas UML. O primeiro diagrama é o diagrama de Caso de Uso. Este diagrama reflete a interação das funcionalidades do QASF e os seus relacionamentos com os usuários do sistema. O segundo diagrama apresentado é o Diagrama de Atividades que apresenta as etapas necessárias para responder uma questão e como estas etapas se relacionam entre si. O terceiro diagrama é o Diagrama de Classe. Este diagrama apresenta o relacionamento entre as classes de processamento do QASF e o relacionamento entre as classes do QASF e as classes dos frameworks FREDS e SisViDAS, que compõem o módulo de Processamento de Documentos.

Na Figuras 5.9, o diagrama de caso de uso é apresentado. Os atores que interagem com o sistema são: o "Usuário" e os "Profissionais da Área da Saúde", ambos são as "Pessoas" envolvidas na interação com a proposta. Especificamente, os "Profissionais da Área da Saúde" são as pessoas que detêm alguma relação com a área da saúde como, por exemplo, os médicos, os enfermeiros, os nutricionistas, entre outros profissionais. O ator "Usuário" abrange as pessoas sem conhecimentos científicos sobre qualquer área da saúde. Esses usuários podem ser pacientes que estão realizando o tratamento de alguma enfermidade e possuem dúvidas ou apenas usuários sadios buscando por informações específicas. Ambos os atores, "Usuário" e "Profissionais da Área da Saúde" são uma especialização do ator "Pessoas". Esta especialização é necessária, pois existe diferença nas bases de informação utilizadas no processo de busca de documentos. Quando a pergunta é realizada por um "Usuário", os documentos que contenham informações de interesse são buscados apenas em artigos científicos. Caso a pergunta seja feita por "Profissionais da Área da Saúde", as informações de interesse podem ser buscadas em artigos científicos, prontuários médico do paciente e em laudos de exames de diagnóstico. Esta especialização foi necessária devido ao fato dos prontuários médico do paciente e laudos de exames que possuem informações sigilosas não acessíveis às pessoas fora do ambiente médico. Portanto, os "Profissionais da Área da Saúde" necessitam realizar "Login" no fra- 
mework, ao contrário dos demais "Usuário"s que podem "Fazer Pergunta" diretamente. Após "Fazer a Pergunta", o QASF realiza o "Processamento da Pergunta", o "Processamento dos Documentos" e o "Processamento das Respostas". Caso a pessoa que esteja interagindo com o QASF seja um "Usuário", o framework realiza um "Filtro" nos documentos a serem utilizados na busca pelas respostas candidatas, ou seja, o QASF só busca as respostas candidatas nos artigos científicos. Por fim, o QASF "Apresenta as Respostas" à "Pessoa" que comunica-se com o framework.

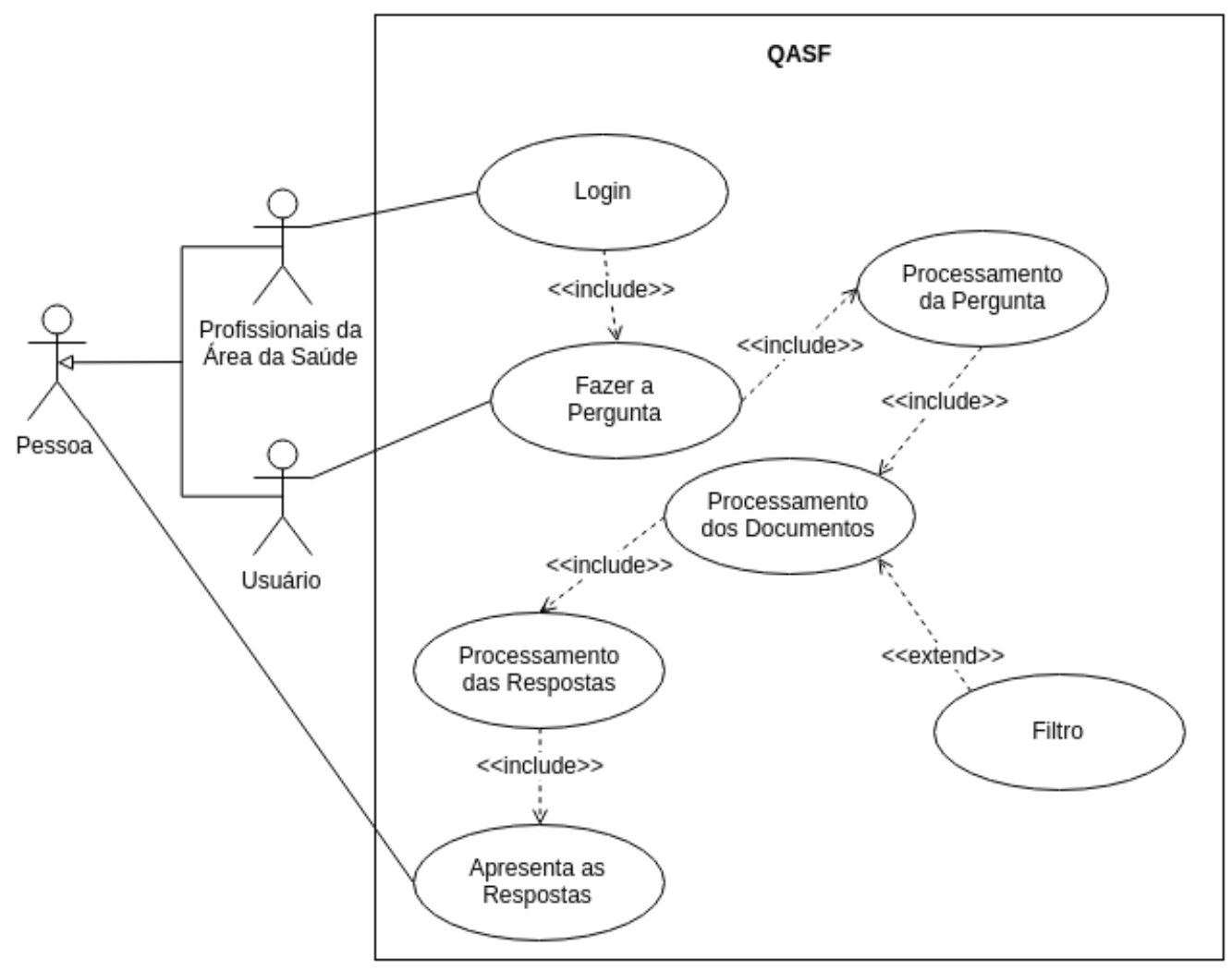

Figura 5.9: Diagrama de caso de uso do QASF.

Na Figura 5.10, o diagrama de atividades do QASF é apresentado. Este diagrama está modelando as etapas a serem realizadas para responder uma questão. 


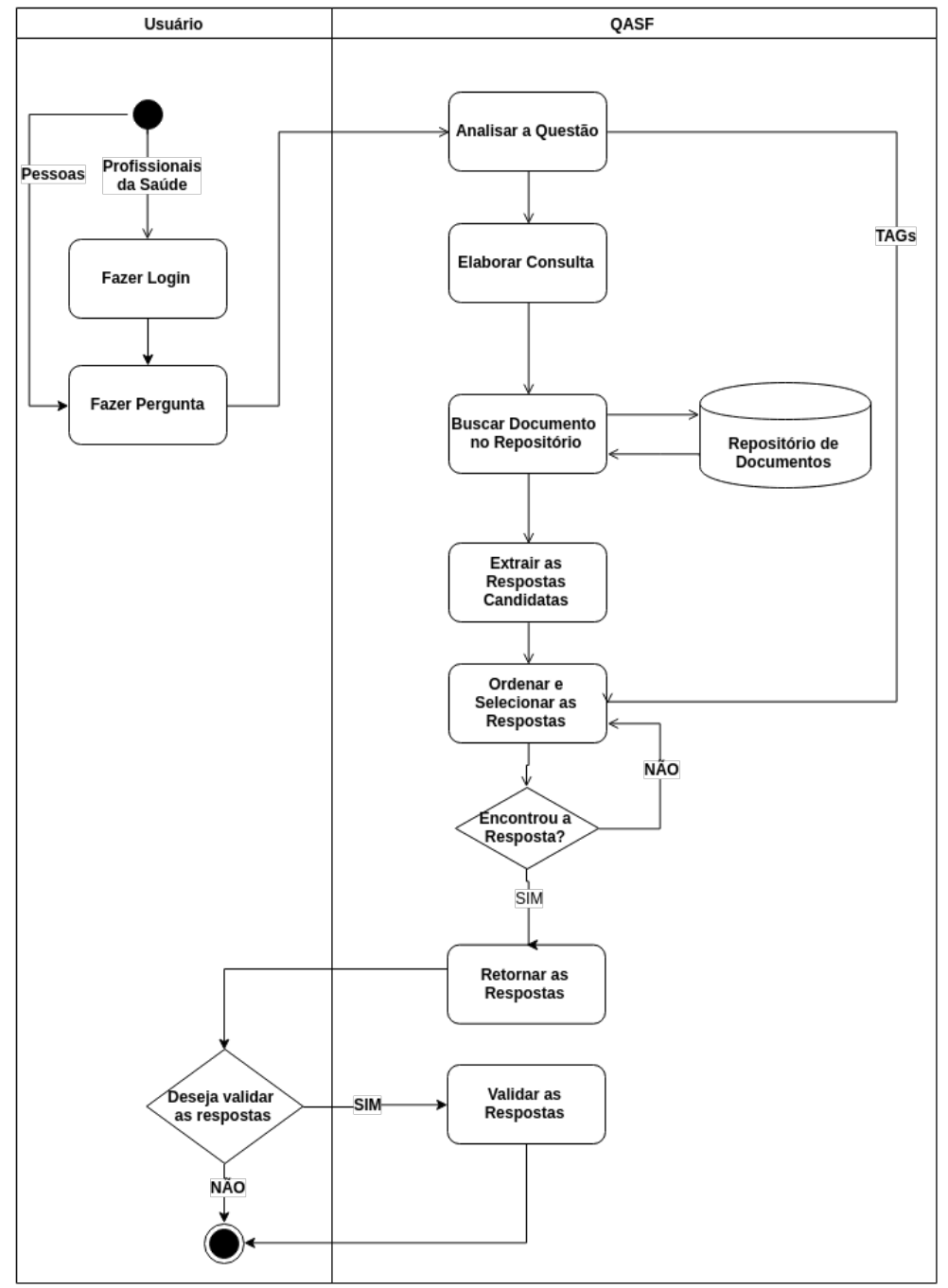

Figura 5.10: Diagrama de atividades do $Q A S F$.

O fluxo de atividades começa no "Usuário". Se o "Usuário" for "Profissionais da Saúde", a primeira atividade é "Fazer Login", caso contrário, o processo é iniciado ao "Fazer Pergunta" em linguagem natural. Em seguida, as tarefas de "Analisar a Questão" e "Elaborar Consulta" são iniciadas. A primeira tarefa analisa a questão em busca de informações relevantes e envia estas informações para a etapa de "Ordenar e Selecionar as Respostas". A tarefa "Elaborar Consulta" transforma a pergunta inserida pelo usuário em uma consulta para buscar os documentos que contenham a resposta de interesse. A próxima etapa "Buscar Documento no Repositório" recebe a consulta e a envia para que os frameworks de RI (SisViDAS e FREDS) busquem os documentos em suas bases de documentos. Se o usuário está logado no framework, o "Repositório de Documentos" é representado por artigos científicos, prontuários médico do paciente e laudos de exame, caso contrário, apenas por artigos científicos.

Na próxima etapa "Extrair as Respostas Candidatas", os documentos recuperados são analisados e os parágrafos candidatos são extraídos. A "Ordenar e Selecionar as Respostas" ordena os parágrafos, por meio de alguma métrica de similaridade, e retorna uma quantidade $n$ de parágrafos definidas nas configurações do sistema. Se o QASF encontrou respostas, ele "Retornar as Respostas" ao usuário, caso não tenha encontrado, o QASF retrocede à etapa de "Ordenar e Selecionar as Respostas" e procura por novas alternativas. A próxima atividade é "Avaliar as Respostas" retornadas 
pelo framework. Esta atividade é realizada apenas se o usuário for um "Profissional da Saúde". Nesse sentido, o profissional avalia se a resposta retornada pelo QASF está correta.

O último diagrama da modelagem é o diagrama de classes. Este diagrama apresenta a estrutura e o relacionamento entre as classes do framwork. A Figura 5.11 apresentada o Diagrama de Classes que ilustra as classes contidas na integração dos frameworks FREDS, SisViDAS e QASF e como elas se relacionam entre si. Este diagrama de classe foi projetado pela mestranda com base nos diagramas de classes dos frameworks SisViDAS (Macedo et al., 2015; Pollettini et al., 2012, 2014) e FREDS (Macedo et al., 2016; Pessotti, 2012).

De acordo com o diagrama apresentado, estruturalmente, o QASF é composto por classes próprias apresentadas na área na tonalidade alaranjada e mais dois frameworks: o SisViDAS e o FREDS (responsáveis pela recuperação dos documentos a serem utilizados na busca das respostas para as perguntas do usuário). Estes dois frameworks estão representados respectivamente pelas classes dentro das áreas em tonalidades vermelho e azul.

Dentro de cada área colorida que representa cada framework, as classes pertencentes a cada módulo são retratadas em cores distintas. De acordo com a legenda de cores, para o framework FREDS os módulos nas tonalidades verde, roxo e abóbora, respectivamente, representam as classes: "Object Segmentation", "Pattern Image Classification" e "Image Feature Extraction". Estas classes desempenham as tarefas de processamento de imagens, especificamente as funções de segmentação, extração de características e classificação de objetos. De acordo com a legenda de cores da Figura 5.11, no framework SisViDAS as classes em azul são responsáveis pela criação e manutenção da coleção de artigos científicos, enquanto que as classes em tons de alaranjado representam o processamento textual variando a tonalidade para diferenciar o processamento de artigo, prontuário médico do paciente. O módulo em tonalidade roxa escura representa a classe de avaliação da similaridade. Além disso, as classes em tonalidade amarela representam as classes de processamento de linguagem natural e as em vermelho os módulos externos de reconhecimento de conceitos. Em tom lilás claro está representado o pacote externo de funções de aprendizado de máquina WEKA, aplicado na classificação dos pacientes em grupos de risco de doenças crônicas e na classificação de objetos extraídos de imagens médicas.

A integração entre o FREDS e o SisViDAS é realizada, internamente, entre as classes de classificação de padrões da imagem (no diagrama a classe é chamada "Classificador" e está apresentada na tonalidade abóbora, indicado na legenda de cores como "Classificador de imagens") e o módulo de recuperação de artigos científicos (no diagrama a classe é chamado "PaperRetrieval" e está apresentada na cor branca, indicado na legenda de cores como "Interface"). Para o framework QASF, as classes são representadas pela tonalidade azul escuro. A classe "Natural Language Processing" representa o processamento textual das demais classes do QASF: "Question Processing", "Document Processing" e "Answer Processing". A classe "Question Processing" possui os métodos de "buscarSinonimos", "responderPerguntasWordnet", "encontraHiperonimos" e os métodos para conversão da pergunta em vetor de palavras-chave "trataPerguntaParte1" e "trataPerguntaParte2". O primeiro método chama os métodos da classe "NaturalLanguageProcessing" para eliminação das stopwords, dos pronomes interrogativos e das pontuações e o segundo método chama os métodos para busca dos sinônimos e hiperônimos e a aplicação das técnicas de lematização e stemming. A classe "Document Processing" possui os métodos "RecuperaDocumentos" que faz conexão com as classes do SisViDAS e do FREDS para recuperação dos documentos a serem buscados as respostas candidatas, "Prepa- 
raAbstract" que, no caso dos artigos científicos, separa somente o abstract das demais informações do artigo, "BuscarRespostaCandidatas" que compara o vetor de palavras-chave com os parágrafos segmentados dos abstracts e, por fim, "TratarParagrafo" que prepara o parágrafo com técnicas de lematização e stemming. A classe "Answer Processing" possui os dois métodos para o cálculo da similaridade por meio do cosseno "CossenoSimilaridadeSimples" e "CossenoSimilaridade". O primeiro método calcula a similaridade entre perguntas e frases candidatas com a gramática original e o segundo método aplica as técnicas de stemming e lematização antes do cálculo do cosseno. 


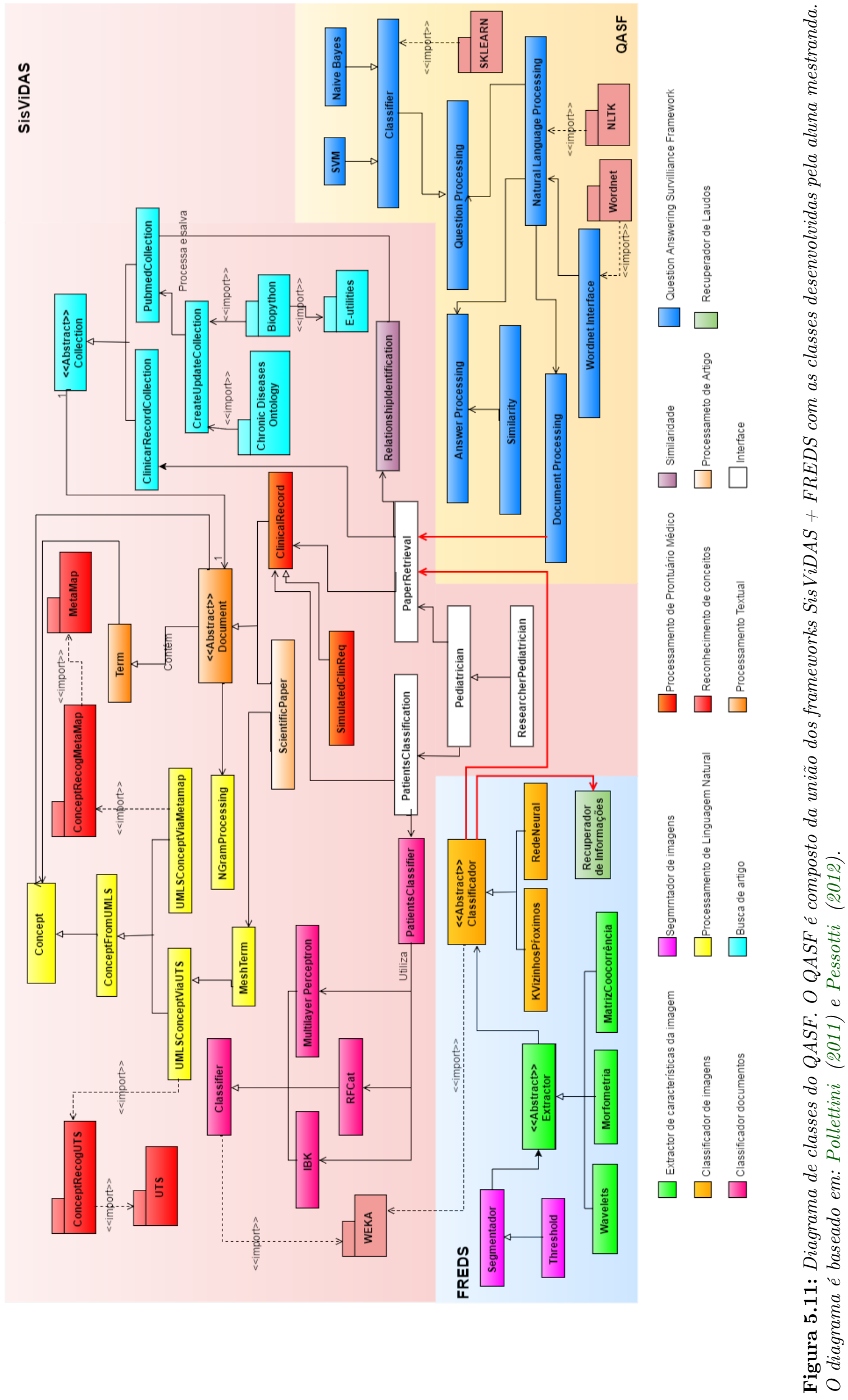




\subsection{Interfaces do QASF}

As interfaces de usuário do QASF foram desenvolvidas para permitir que os usuários insiram uma consulta em linguagem natural e recebam um conjunto de dez respostas mais similares à consulta inserida. Essas interfaces foram desenvolvidas para a web por meio de framework Django ${ }^{6}$. O Django foi escolhido para desenvolver as interfaces do QASF porque ambos utilizam o Python como linguagem de programação, portanto, a interação entre um e outro é mais fácil. Na Figura 5.12, as interfaces do QASF são apresentadas. A Figura 5.12a apresenta a interface principal do QASF. Usando o campo texto no centro da interface, o usuário pode inserir uma pergunta. As respostas são apresentadas por ordem de relevância na Figura 5.12b. Ao clicar sobre a resposta, o usuário é direcionado para a página do Pubmed com o resumo do artigo.

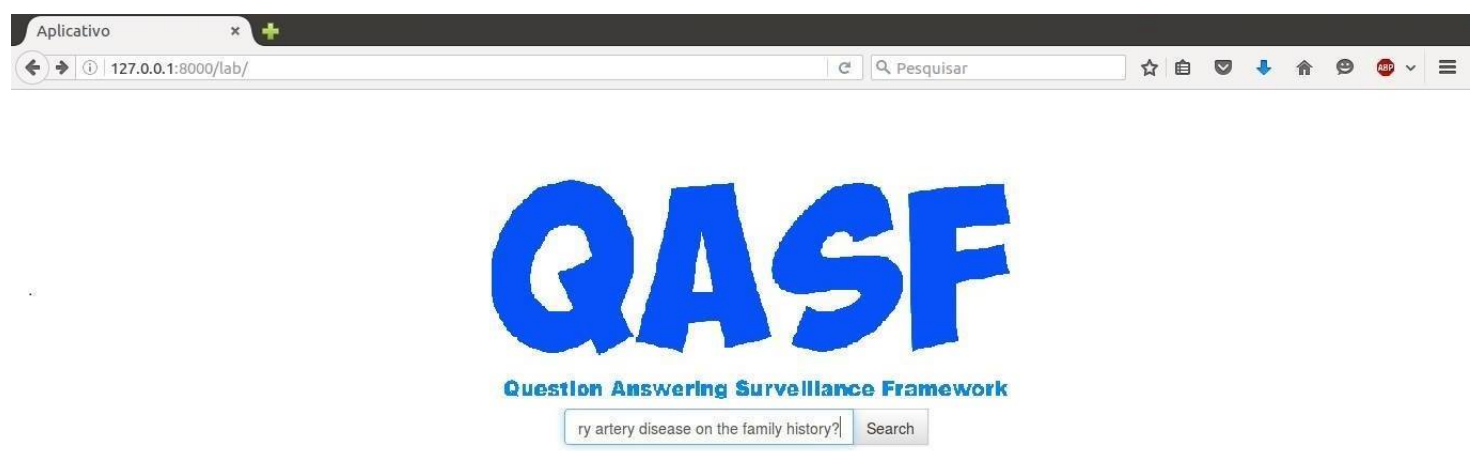

(a)

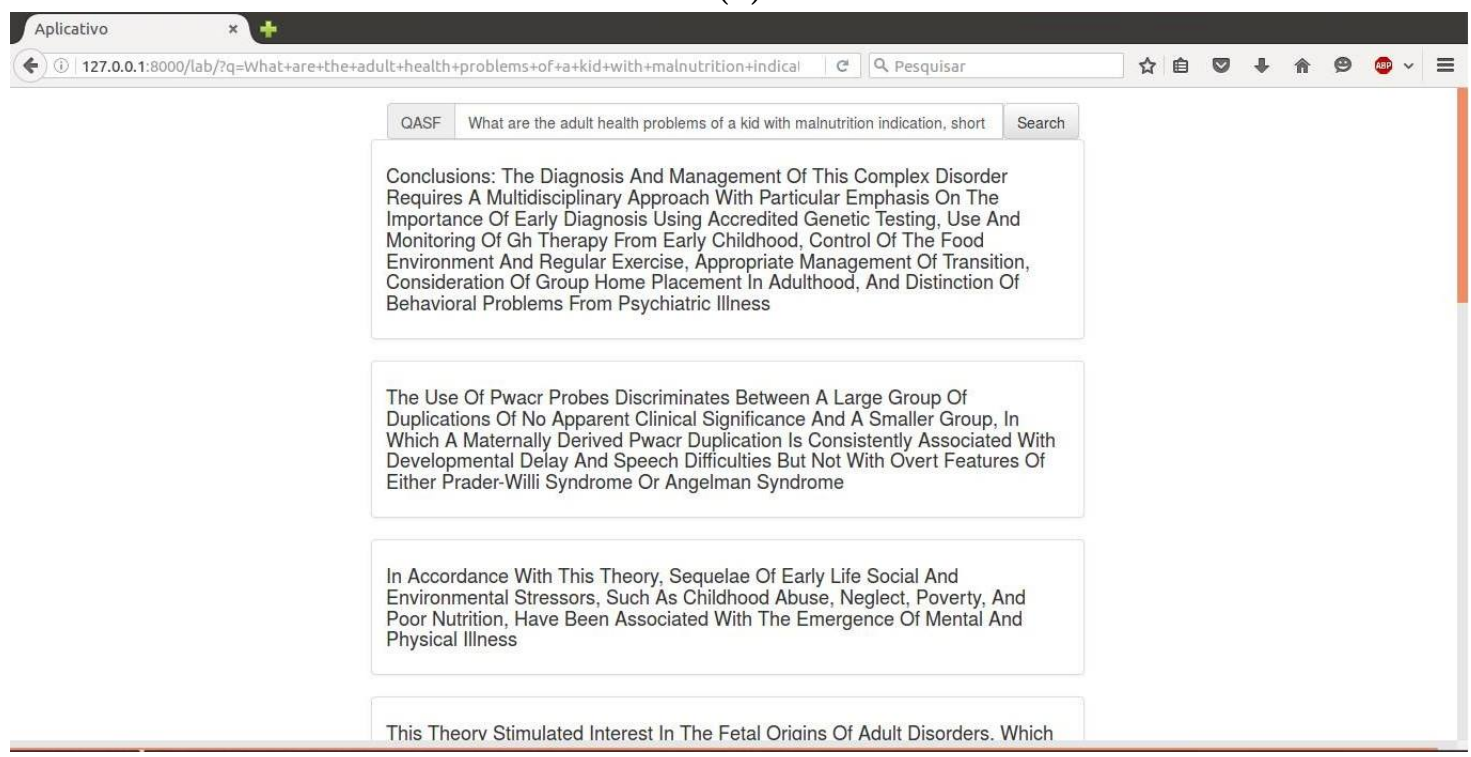

(b)

Figura 5.12: Interfaces do usuário do QASF.

\footnotetext{
${ }^{6}$ Segundo o site oficial "Django é um framework web de alto nivel escrito em Python que estimula o desenvolvimento rápido e limpo." (https://www.djangoproject.com/)
} 


\section{Capítulo 6}

\section{Avaliação do QASF}

Uma das formas mais conhecidas de avaliação dos sistemas de QA utiliza corpora compostas por tuplas de perguntas e respostas. As corpora podem ser criadas especificamente para a avaliação do sistema em questão ou disponibilizadas por conferências como a TREC (Voorhees e Tice, 2000) e a CLEF (Magnini et al., 2004; Olvera-Lobo e Gutiérrez-Artacho, 2015). Junto à utilização das coleções de referências, as métricas de avaliações têm sido utilizadas também na avaliação desses sistemas, sendo as principais: a precisão, a revocação e a F-measure. Os valores dessas métricas são obtidos a partir da comparação das informações retornados pelo sistema e das informações analisadas pelo colaborador humano (Bilotti e Nyberg, 2006; Blair, 1979).

No QASF, a avaliação foi realizada por meio das métricas de desempenho juntamente com algumas coleções de referências. A primeira coleção é a AskHERMES. Esta coleção foi utilizada na avaliação do módulo de "Análise da Questão". A segunda é a FnATI que foi criada pelo próprio grupo de pesquisa da mestranda e utilizada na avaliação do FREDS, e a terceira coleção é a EDRMrSa. Esta última coleção foi utilizada na maioria das avaliações realizadas neste framework.

As avaliações do QASF foram divididas por módulos. No módulo de "Processamento da Questão", as coleções AskHERMES e a EDRMrSa foram utilizadas. Nos demais módulos do QASF somente a EDRMrSa foi utilizada. A seguir, cada coleção de referência, as avaliações e os resultados obtidos na avaliação dos módulos do QASF são apresentados. Este capítulo está estruturado da seguinte maneira: a Seção 6.1 apresenta a descrição de todas as coleções de referências utilizadas no QASF e a Seção 6.2 apresenta a avaliação e os resultados obtidos em cada módulo do QASF.

\subsection{Coleções de Referência}

Durante as etapas de construção e de avaliação do QASF, surgiu a necessidade de utilizar coleções de referências diversificadas que atendessem as necessidades de cada etapa analisada. A primeira coleção, chamada AskHERMES (Cao et al., 2011), foi utilizada na avaliação das técnicas de Aprendizado de Máquina na etapa de análise da questão. Uma vez que o objetivo desta etapa é encontrar a categoria a qual uma pergunta pertence, essa coleção foi utilizada por conter as perguntas subdivididas em categorias. A segunda coleção, chamada FnATI (do inglês Fine-needle Aspiration Thyroid Images), foi utilizada na avaliação do FREDS, que compõe a etapa de "Processamento de Documentos" especificamente na recuperação dos documentos, pois o FREDS é um framework CAD que avalia imagens médicas e devido a necessidade de avaliações mais apuradas do framework, uma coleção de imagens curadas por um patologista foi necessária. A terceira coleção de 
referências, chamada EDRMrSa (do inglês, Epigenetic Data Related between Medical Records and Scientific Articles), foi utilizada na avaliação de todos os demais módulos do QASF. Essa coleção é composta por prontuários médicos do paciente no idioma português transcritos para o formato de perguntas complexas no idioma inglês que se relacionam a uma coleção que artigos científicos curada por especialistas por meio de critérios de relevância. Nas subseções seguintes, as informações detalhadas sobre cada coleção de referência são apresentadas.

\subsubsection{AskHERMES}

Uma das coleções de referência usada para avaliar o QASF foi construída primordialmente por Cao et al. (2011) para avaliação do sistema AskHERMES e disponibilizada pelos autores para download na web. A coleção de perguntas é composta por 4654 questões médicas sobre doenças crônicas. As questões são separadas nos doze seguintes tópicos (classes ou tags): dispositivo, diagnóstico, epidemiologia, etiologia, história, gestão, farmacologia, achado físico, procedimento, prognóstico, teste e tratamento e prevenção. As perguntas foram classificadas pelos próprios clínicos do projeto AskHERMES. Os tópicos não possuem a mesma quantidade de perguntas. Alguns exemplos de perguntas são: "What is the protein you can test to see if someone has type 1 or type 2?" que é do tipo teste. Outro exemplo é "Is diabetes a risk factor for carpal tunnel syndrome?" do tipo diagnóstico.

\subsubsection{FnATI (Fine-needle Aspiration Thyroid Images)}

A FnATI é uma coleção referência de imagens extraídas das lâminas de Punção Aspirativa por Agulha Fina (PAAF) de tecido tiroidiano cedidos pela Profa. Dra. Edna Teruko Kimura do Instituto de Ciências Biomédicas da USP de São Paulo. A coleção foi criada e validada pelo próprio grupo de pesquisa da mestranda. As imagens foram captadas a partir das lâminas no Laboratório de Neurologia Aplicada e Experimental da FMRP-USP, utilizando um microscópio Zeiss Axio Imager M1 (Carl Zeiss AG) com câmera AxioCam Mrc5 (Carl Zeiss AG, lentes objetivas EC Plan-Neofluar 40x 1.3 Oil e 1.6x Optovar). As imagens foram captadas no formato TIFF (do inglês Tagged Image FIle Format) com 2584 pixels de largura e 1936 pixels de altura utilizando o padrão de cores RGB. A FnATI é composta por 48 imagens de câncer de tireoide do tipo papilífero, 56 do tipo bócio e 71 do tipo não câncer.

As fotos foram analisadas por uma patologista e classificadas de acordo com o protocolo Bethesda. Este protocolo foi criado para facilitar a comunicação entre profissionais da área da saúde e pesquisadores no diagnóstico de doenças da tireoide (Cibas e Ali, 2009). Ele é composto por seis categorias, sendo elas: (i) amostra não diagnosticada; (ii) benigno; (iii) atipias de significado indeterminado; (iv) suspeito de neoplasia folicular; (v) suspeito de malignidade; e (iv) maligno (Cibas e Ali, 2009). A coleção de referência desenvolvida foi utilizada nas tarefas de classificação e validação dos resultados obtidos pelo FREDS.

\subsubsection{EDRMrSa (Epigenetic Data Related between Medical Records and Scien- tific Articles)}

A coleção de referência EDRMrSa foi desenvolvida durante a construção e avaliação do framework SisViDAS (Macedo et al., 2015; Pollettini et al., 2012, 2014). Esta coleção foi criada em 
parceria com pesquisadores especialistas no domínio de origens fetais para a saúde e doença do Instituto da Criança (ICr) da Faculdade de Medicina da USP (FM-USP). Os pesquisadores realizaram um estudo com aproximadamente duas mil crianças com o objetivo de identificar perfis de risco para prevenir doenças na fase adulta iniciadas em estágios precoces da vida. $\mathrm{O}$ estudo incluiu uma análise detalhada do histórico de três gerações antecedentes de cada uma das crianças. Paralelamente, estes pesquisadores colaboraram prepararam uma lista de termos e expressões mais frequentes nos registros clínicos dos pacientes avaliados e forneceram um modelo de prontuário de atendimento (não preenchido) do centro de saúde-escola utilizado para acompanhamento de saúde das crianças. Estas colaborações dos pesquisadores do ICr auxiliaram os pesquisadores do SisViDAS na construção de uma coleção de referência composta por relacionamentos entre casos clínicos e artigos científicos e na avaliação do SisViDAS.

Para a criação da EDRMrSa, a primeira etapa foi a simulação computacional de prontuários do paciente. Essas simulações foram uma maneira de solucionar os problemas éticos que os prontuários reais poderiam ocasionar. Neste sentido, matrizes contendo números aleatórios correspondentes à lista de termos e expressões mais frequentes nos registros clínicos foram relacionadas aos valores sorteados para cada um dos atributos do prontuário resultando em 60 casos simulados. Destes casos simulados, os casos inconsistentes foram excluídos resultando em 30 casos consistentes. Em seguida, os profissionais do ICr estabeleceram o relacionamento entre seis casos simulados e os 455 artigos científicos disponíveis relacionados ao domínio de fatores epigenéticos. Nesse sentido, o SisViDAS foi preparado para comportar a avaliação de cinco usuários especialistas distintos. Para cada usuário, os casos clínicos simulados foram exibidos no formato de lista e o framework alterava a ordem a qual os casos eram exibidos.

Para facilitar a avaliação feita pelos profissionais do ICr dos relacionamentos de cada caso clínico com os 455 artigos científicos disponíveis, um limiar de similaridade foi utilizado como critério de seleção dos artigos a serem avaliados. Para cada caso clínico simulado pelos profissionais do ICr, em média, foram classificados por categoria: 53 artigos como "Fortemente relevantes"; 19 como "Relevantes", 25 como de "Baixa relevância" e 129 como "Totalmente Irrelevantes" gerando um total de 226 artigos classificados por prontuário. Na Figura 6.1, um dos prontuários médico simulado e analisado pelos pesquisadores do ICr é apresentado. Os demais prontuários estão anexados no Apêndice A. 
\begin{tabular}{|l|}
\hline Paciente: 2 \\
Diagnóstico nutricional: Com indício desnutrição \\
Crescimento: Baixa estatura \\
Desenvolvimento (DNPM): Adequado \\
Vacinação: Atualizada \\
Alimentação: Com baixo teor de fibras \\
Cotidiano infantil: Adequado \\
Familiograma: Seqüelas de Doenças Crônicas \\
Ambiente emocional: Violência \\
Condições ambientais: Casa em área de enchentes \\
Condições sócio-econômico-culturais: Falta de lazer familiar \\
Fatores de Risco: Distúrbios do comportamento/ vínculo \\
Fatores de proteção: Cultura de exercícios \\
Doenças atuais: Asma \\
Doenças anteriores ou crônicas: Pós-termo de 42 semanas completas \\
Antecedentes familiares: Doença arterial coronariana
\end{tabular}

Figura 6.1: Prontuário simulado do Paciente 2 da EDRMrSa.

Como o QASF é um sistema do tipo QA, o processo de busca e seleção das respostas é iniciado por meio de uma questão. Considerando que a EDRMrSa é composta por prontuários relacionados a artigos científicos e que o SisViDAS foi avaliado no contexto multilíngue, ou seja, prontuários e artigos científicos em idiomas distintos, a solução encontrada para validar o QASF que é um framework de QA que realiza todo o seu processamento baseado no idioma Inglês, foi transcrever os prontuários do idioma Português para perguntas no idioma Inglês. Na Figura 6.2, a pergunta resultante do processo de transcrição do prontuário médico do paciente para uma pergunta de usuário é apresentada

"What are the adult health problems of a kid with malnutrition indication, short
stature, neuropsychomotor development appropriate, updated vaccines, low fiber
diet, an appropriate childhood routine, some family members who have chronic
illness, violent emotional environment, lives in a flood area, with a lack of family
entertainment, with risk of behavioral disorders, with physical exercises practice,
with asthma, with pre-term of 35 completed weeks and coronary artery disease on
the family history?"

Figura 6.2: Questão criada a partir do prontuário simulado do Paciente 2 da EDRMrSa.

\subsection{Avaliação dos Módulos do QASF}

A avaliação do QASF foi dividida de acordo com os módulos do framework (processamento da questão, dos documentos e das respostas) e realizada principalmente com a coleção de referência EDRMrSa. Somente no módulo de "Processamento da Questão", especificamente o submódulo de "Análise da Questão" foi avaliado com o auxílio da coleção de referência AskHERMES. As subseções estão organizadas da seguinte maneira: a Subseção 6.2.1, os resultados dos experimentos do módulo 
de "Processamento da Questão" são apresentados. Na Subseção 6.2.2, a avaliação e os resultados do módulo de "Processamento dos Documentos" são apresentados. Por fim, na Subseção 6.2.3, a avaliação e os resultados do módulo de "Processamento das Respostas" são apresentados.

\subsubsection{Processamento da Questão}

A etapa de processamento da questão objetiva extrair informações da questão feita pelo usuário em linguagem natural e utilizar essas informações na busca e seleção das respostas candidatas. Essa etapa é dividida em dois submódulos: "Análise da Questão" e "Elaboração da Consulta". A seguir, as avaliações dos dois submódulos serão apresentadas.

\section{Análise da Questão}

O módulo de "Análise da Questão" foi construído apoiado por técnicas de correspondência de padrões para análise das perguntas do tipo definição, ou seja, que começam com o pronome interrogativo What do idioma inglês, e por técnicas de Aprendizado de Máquina (AM) SVM e Naive Bayes para análise e classificação das questões iniciadas pelos demais pronomes interrogativos do idioma inglês. Para a construção e avaliação dos classificadores de AM, uma coleção de referência que contenha a estrutura < pergunta, categoria > é necessária. Dado que a coleção de referência EDRMrSa não possui perguntas classificadas em categorias, a solução encontrada foi utilizar a coleção de referência apresentada por Cao et al. (2011) em seu trabalho, a AskHERMES. Essa coleção possui a estrutura do tipo $<$ pergunta, categoria $>$.

$\mathrm{Na}$ avaliação dos classificadores do QASF, a coleção de referência AskHERMES foi organizada em dois cenários distintos. No primeiro, toda a coleção de referência é utilizada para avaliar os classificadores. No segundo cenário, as categorias que continham menos de cem perguntas foram desconsideradas a fim de buscar um balanceamento entre as classes. Consequentemente, a coleção de referência foi reduzida a 4258 questões distribuídas nas seguintes sete classes: diagnóstico (475 perguntas), teste (578 perguntas), tratamento e prevenção (319 perguntas), achados patológicos (189 perguntas), etiologia (172 perguntas), gestão (1.380 perguntas) e farmacologia (1.145 perguntas).

$\mathrm{Na}$ Tabela 6.1, os resultados dos experimentos são apresentados. Os resultados foram obtidos com o auxílio da ténica de validação cruzada (do inglês $k$-fold), cujo $k$ é igual à 10 . Na tabela, as duas primeiras colunas compõem o primeiro cenário, cuja coleção de referência completa é utilizada na tarefa de classificação, e as duas últimas colunas o segundo cenário, cujas classes com menos de 100 perguntas foram desconsideradas. A tarefa de classificação é avaliada a partir da execução dos dois algoritmos de AM, SVM e Naive Bayes.

Tabela 6.1: Classificação de uma coleção de referência em classes pelo QASF. Os valores foram obtidos com o auxílio da técnica de validação cruzada ( $k$-fold), cujo $k=10$.

\begin{tabular}{|c|c|c|c|c|}
\hline \multirow{2}{*}{} & \multicolumn{2}{|c|}{ Corpus Completo } & \multicolumn{2}{c|}{4265 perguntas - 7 classes } \\
\cline { 2 - 5 } & Naive Bayes & SVM & Naive Bayes & SVM \\
\hline Precisão & 0.48 & 0.51 & 0.48 & 0.59 \\
Revocação & 0.42 & 0.53 & 0.46 & 0.58 \\
F-Measure & 0.32 & 0.51 & 0.38 & 0.56 \\
Acurácia & $0.43 \pm 0.04$ & $0.55 \pm 0.04$ & $0.47 \pm 0.02$ & $0.59 \pm 0.03$ \\
\hline
\end{tabular}

Em ambos os cenários, o QASF com o classificador SVM apresentou melhor desempenho com 
valores acima de 0.50 para as medidas de Precisão, de Revocação, de F-Measure e de Acurácia. Especificamente no segundo cenário, os valores da precisão e da acurácia alcançaram valores próximos a 0.6. Como já apresentado em (Almansa e Macedo, 2016), o classificador SVM apresentou melhor desempenho na classificação de questões. Além disso, as pesquisadoras perceberam que no QASF, quando as classes possuem um balanceamento, a tarefa de classificação da questão apresenta resultados melhores. Esta avaliação apresentou uma performance moderada do QASF. Contudo, um ponto a ser destacado é que as perguntas foram classificadas em seu formato original sem a aplicação de etapas de tratamento da questão como, por exemplo, a eliminação das stopwords ou a adição de termos similares por meio da UMLS, por exemplo. Se estas técnicas fossem aplicadas no QASF, talvez o desempenho dos classificadores melhoraria. Um desempenho moderado do QASF na análise das questões pode sobrecarregar ou até atrapalhar os demais módulos do framework, uma vez que as informações deste módulo auxiliam na escolha das respostas candidatas.

No QASF, a abordagem de correspondência de padrões analisa especificamente as questões do tipo definição, em busca do sujeito da questão e o envia para o banco de dados lexical (dicionário) WordNet. Em seguida, o WordNet retorna a definição do sujeito. Para avaliar esta funcionalidade do QASF, as palavras que compõem os dados dos pacientes nas perguntas em inglês da EDRMrSa foram utilizadas para formar termos compostos por uma, duas, três e quatro palavras distintas ${ }^{1}$. Esses termos foram enviados para que o WordNet retornasse a sua definição. Os resultados são apresentados na Tabela 6.2. As colunas com o título "Total" representam o número total de termos considerados a partir dos prontuários de cada paciente. As colunas nomeadas com "Resp." apresentam a quantidade de termos que obtiveram alguma resposta do WordNet em relação a quantidade total de termos da coluna "Total".

Tabela 6.2: Número de termos que obtiveram respostas retornadas pelo WordNet em função da quantidade total de termos criados por prontuário. Na tabela, cada linha representa um prontuário distinto. A coluna "Total" apresenta a quantidade total de termos gerados por prontuário e a coluna "Resp" apresenta a quantidade de termos que obtiveram algum retorno do WordNet. Ambas as colunas variam em função do número de palavras que compõem o termo ("Uma", "Duas", "Três" ou "Quatro").

\begin{tabular}{|c|c|c|c|c|c|c|c|c|}
\hline \multirow{2}{*}{ Paciente } & \multicolumn{2}{|c|}{ Uma } & \multicolumn{2}{c|}{ Duas } & \multicolumn{2}{c|}{ Três } & \multicolumn{2}{c|}{ Quatro } \\
\cline { 2 - 9 } & Total & Resp. & Total & Resp. & Total & Resp. & Total & Resp. \\
\hline p2 & $\mathbf{5 0}$ & $\mathbf{4 8}$ & 49 & 0 & 48 & 0 & 47 & 0 \\
\hline p3 & $\mathbf{5 5}$ & $\mathbf{5 4}$ & 54 & 0 & 53 & 0 & 52 & 0 \\
\hline p18 & $\mathbf{7 1}$ & $\mathbf{6 7}$ & 70 & 0 & 69 & 0 & 68 & 0 \\
\hline $\mathbf{p 1 9}$ & $\mathbf{7 2}$ & $\mathbf{6 7}$ & 71 & 0 & 70 & 0 & 69 & 0 \\
\hline p24 & $\mathbf{7 3}$ & $\mathbf{7 0}$ & 72 & 0 & 71 & 0 & 70 & 0 \\
\hline p28 & $\mathbf{1 1 0}$ & $\mathbf{1 0 5}$ & 109 & 0 & 108 & 0 & 107 & 0 \\
\hline
\end{tabular}

Na tabela é possível perceber que somente os pacientes com termos compostos por uma única palavra obtiveram respostas. Desses termos, $93 \%$ ou mais foram respondidos. Na Figura 6.3, algumas respostas retornadas pelo WordNet para o Paciente 2 são apresentadas.

\footnotetext{
${ }^{1} \mathrm{O}$ QASF considera como termo, as palavras que estão entre o verbo to be e o ponto de interrogação. Por exemplo na questão What is chronic disease?, o termo é chronic disease que é composto por duas palavras distintas.
} 
are: a unit of surface area equal to 100 square meters

adult: a fully developed person from maturity onward

health: a healthy state of wellbeing free from disease

problems: a state of difficulty that needs to be resolved

kid: a young person of either sex

malnutrition: a state of poor nutrition; can result from insufficient or excessive or unba-

lanced diet or from inability to absorb foods

indication: something that serves to indicate or suggest

short: the location on a baseball field where the shortstop is stationed

stature: high level of respect gained by impressive development or achievement

development: act of improving by expanding or enlarging or refining

appropriate: give or assign a resource to a particular person or cause

updated: modernize or bring up to date

vaccination: taking a vaccine as a precaution against contracting a disease

low: an air mass of lower pressure; often brings precipitation

fiber: a slender and greatly elongated substance capable of being spun into yarn

diet: a prescribed selection of foods

appropriate: give or assign a resource to a particular person or cause

childhood: the time of person's life when they are a child

routine: an unvarying or habitual method or procedure

family: a social unit living together

Figura 6.3: Respostas retornadas pelo WordNet para o vetor de palavras do Paciente 2.

Da análise da Tabela 6.2, pode-se confirmar que o WordNet não é um dicionário específico para a área médica, portanto, algumas respostas retornadas possuem um significado mais genérico em vez de um significado específico para a área médica. Por exemplo, o significado da palavra low apresentado pelo WordNet é an air mass of lower pressure; often brings precipitation. Esta definição não se relaciona com conceitos da área médica. Contudo, algumas definições se relacionam com o contexto médico como, por exemplo, o termo malnutrition com a definição a state of poor nutrition; can result from insufficient or excessive or unbalanced diet or from inability to absorb foods retornada pelo WordNet. Segundo o site MedlinePlus ${ }^{2}$, a definição de malnutrition é Malnutrition is the condition that occurs when your body does not get enough nutrients. There are many types of malnutrition, and they have different causes. Some causes include: Poor diet; Starvation due to food not being available; Eating disorders; Problems with digesting food or absorbing nutrients from food; Certain medical conditions that make a person unable to eat; You may develop malnutrition if you lack a single vitamin in your diet. Lacking a vitamin or other nutrient is called a deficiency. Ambas as definições possuem pontos em comum. Uma maneira de aprimorar os resultados deste submódulo seria avaliar dicionários da área médica presentes na UMLS ou mesmo em uma ontologia como a CDO (Verma et al., 2009). Dessa maneira, a atribuição de tags por termos de definição da questão deveria ser mais efetiva. Afinal, esse é o principal objetivo do módulo de "Análise da Questão".

\section{Elaboração da Consulta}

A "Elaboração da Consulta" extraí um conjunto de palavras-chave da pergunta feita pelo usuário. Este conjunto de palavras será transmitido para o módulo de "Processamento do Documento",

\footnotetext{
${ }^{2}$ O MedlinePlus ((https://www.nlm.nih.gov/medlineplus/)) é um site mantido pela Biblioteca Nacional de Medicina dos Estados Unidos que fornece informações confiáveis sobre temas da área médica.
} 
especificamente na etapa de "Recuperação de Documentos". No QASF, a construção do vetor de palavras é feita em duas etapas. Na primeira, os pronomes interrogativos, as "stopwords" e as pontuações são desconsiderados. Na Figura 6.4, o resultado do QASF da primeira etapa de construção do vetor de palavras-chave do Paciente 2 (das Figuras 6.1 e 6.2) é apresentado. Na figura é possível perceber a ausência dos pronomes interrogativos, das pontuações e das stopwords. A grande maioria das palavras que compõem o vetor são os substantivos e alguns verbos.

"are adult health problems kid malnutrition indication short stature neuropsy-
chomotor development appropriate updated vaccination low fiber diet appropriate
childhood routine family members have chronic illness violent emotional environ-
mental lives flood area lack family entertainment risk behavioral disorders physical
exercises practice asthma pos-term 42 completed weeks coronary artery disease fa-
mily history"

Figura 6.4: Vetor de palavras resultante da primeira etapa de criação do vetor final de palavras-chaves do QASF do Paciente 2.

A segunda etapa de construção do vetor de palavras-chave inicia com a busca de termos sinônimos e hiperônimos aos termos resultante da primeira etapa de construção do vetor no banco de dados lexical WordNet. Em seguida, as técnicas de stemming ${ }^{3}$ e lematização ${ }^{4}$ são aplicadas no vetor de palavras para que todas as palavras sejam reduzidas apenas ao radical. Na Figura 6.5, o vetor final de palavras e seus sinônimos reduzidos ao seus radicais realizado pelo QASF são apresentados. Na figura, os sete primeiros termos do vetor total são apresentados.

[ ['be', 'cost', 'repres', 'make up', 'equal', 'constitut', 'exist', 'personifi', 'embodi',
'follow', 'compris'], ['grown', 'full grown', 'big', 'adult', 'grownup', 'fully grown'],
['well', 'health'], ['problem', 'troubl', 'job'], ['tiddler', 'thomas kyd', 'chaff', 'pull
the leg of', 'nipper', 'banter', 'josh', 'tyke', 'jolli', 'kyd', 'kidskin', 'small fri',
'nestl', 'thomas kid', 'youngster', 'child', 'fri', 'shaver', 'tike', 'minor', 'kid'], ['de-
ficiency diseas', 'malnutrit', 'denot', 'read', 'indic', 'meter read', 'curt', 'sudden',
'inadequ', 'dead', 'unretent', 'brusk', 'short chang', 'littl', 'shortstop', 'short cir-
cuit', 'scant', 'poor', 'forget', 'unawar', 'unforesight', 'abrupt', 'short', 'brusqu',
'light', 'myopic', 'shortsight'], ['height', 'statur'], ...]

Figura 6.5: Vetor final de palavras-chave resultante da primeira etapa de criação do vetor palavras-chaves do QASF do Paciente 2. O vetor apresenta os termos sinônimos e hiperônimos dos sete primeiro termos do vetor final completo.

Na Tabela 6.3, o número de termos que compõem os vetores de palavras-chave de cada questão do paciente experimentada no QASF é apresentado. Na coluna "Consulta Simples", a quantidade dos termos encontrados da primeira etapa de construção do vetor de palavras-chave é apresentada e na coluna "Consulta c/ Sinônimos, a quantidade total de termos contabilizando a quantidade de termos da "Consulta Simples" mais os termos sinônimos e hiperônimos é apresentada.

\footnotetext{
${ }^{3} \mathrm{O}$ stemming é o processo de reduzir o termo ao seu radical, por meio da remoção de elementos das palavra como, por exemplo, os afixos e as vogais temáticas (Bird et al., 2009).

${ }^{4}$ A lematização é o processo de desflexionar uma palavra, trazendo-a, geralmente, para a sua forma infinitiva (Galisson e Coste, 1983).
} 
Tabela 6.3: Número de palavras que compõem o vetor de palavras-chave de cada questão processada pelo $Q A S F$.

\begin{tabular}{|c|c|c|}
\hline Pacientes & Consulta Simples & Consulta c/ Sinônimos \\
\hline p2 & 50 & 449 \\
\hline p3 & 55 & 450 \\
\hline p18 & 71 & 630 \\
\hline p19 & 72 & 554 \\
\hline p24 & 73 & 586 \\
\hline p28 & 110 & 800 \\
\hline
\end{tabular}

Na tabela é possível perceber que mesmo alguns pacientes apresentando um número parecido de termos que compõem a "Consulta Simples", como é o caso dos pacientes "p18", "p19", "p24", as "Consulta c/ Sinônimos" desses pacientes apresentam valores bem distintos. O paciente "p28" é o paciente com maior número de termos e os pacientes que possuem os menores números de termos são o "p2" e o "p3". Essa expansão de termos da consulta ocasionará o aumento no número de termos a serem buscados nos parágrafos analisados pelo QASF e, como consequência, a possibilidade de um parágrafo ter algum relacionamento com a pergunta do usuário aumenta.

\subsubsection{Processamento de Documentos}

O módulo de "Processamento de Documentos" é responsável por recuperar e buscar as respostas candidatas. Esse módulo engloba os submódulos de "Recuperação dos Documentos" candidatos e de "Extração das Respostas Candidatas". A seguir, as experimentações do módulo de "Recuperação de Documentos" composto pelo FREDS e o SisViDAS e do módulo de "Extração das Respostas Candidatas" do QASF são apresentadas.

\section{Recuperação dos Documentos}

A tarefa de "Recuperação de Documentos" é retornar os documentos que contenham possíveis respostas para a pergunta elaborada pelo usuário. No QASF, o submódulo de "Recuperação de Documentos" foi projetado a partir do SisViDAS (Pollettini et al., 2014) e FREDS (Macedo et al. , 2016). O submódulo de "Extração das Respostas Candidatas" busca por possíveis respostas nos documentos retornados pelo submódulo anterior.

No QASF, dois pontos poderiam prejudicar o seu desempenho na recuperação dos documentos para a busca das respostas candidatas. O primeiro é o fato do FREDS ter sido pouco avaliado, quando ele estava em desenvolvimento, e o outro ponto é o fato do SisViDAS ter sido avaliado somente no contexto de recuperação de artigos científicos no idioma inglês baseado em prontuários no idioma português (o QASF envia perguntas no idioma inglês e espera por documentos recuperados neste mesmo idioma). Portanto, a mestranda e sua orientadora optaram por realizar também experimentos no FREDS e no SisViDAS junto com o QASF. A avaliação isolada do SisViDAS está publicada em Pollettini et al. (2014).

\section{Avaliação do FREDS}

Durante o desenvolvimento do FREDS, uma das limitações encontradas foi a dificuldade em obter análises mais apuradas sobre o framework. Desse modo, as análises realizadas tiveram como 
objetivo avaliar o desempenho do FREDS de modo mais detalhado. Para resolver esta limitação, a solução encontrada foi a criação de uma nova coleção de referência curada por um patologista e a realização de novos experimentos.

A etapa de avaliação do FREDS compreende os resultados das tarefas de (i) construção de uma nova coleção de referência de imagens extraídas de lâminas de Punção Aspirativa por Agulha Fina (PAAF) de tecido tiroidiano cedidos pela Profa. Dra. Edna Teruko Kimura, para a (ii) expansão dos experimentos de desempenho do framework FREDS. O experimento realizado no FREDS pela mestranda Luciana F. Almansa em 2015 buscou expandir as avaliações realizadas durante o trabalho de mestrado do aluno Hugo Pessotti (Pessotti, 2012), antes de integrá-lo ao QASF. Os resultados foram descritos no artigo "Morphometric Information Reducing Semantic Gap on the Characterization of Microscopic Images of Thyroid Nodules" e publicado no journal Computer Methods and Programs in Biomedicine (Macedo et al., 2016).

O FREDS é um framework composto por técnicas de diferentes abordagens de extração de características (COOC - abordagem estatística, DWT - abordagem espectral e MORPHO - abordagem quantitativa) e duas técnicas com paradigmas de aprendizado distintos para classificação (MLP - conexionista e KNN - lazy learning). O objetivo era verificar como os atributos, derivados do uso de cada extrator, podem cooperar entre si na tarefa de classificar os núcleos da imagem no contexto de cada paradigma de AM. Além disso, a abordagem morfométrica ainda é pouco explorada para as lesões de tireoide devido à alta subjetividade das informações obtidas. Portanto, outro objetivo era avaliar o uso da informação morfológica.

Os experimentos foram realizados utilizando a rotulação automática do framework FREDS. Para o experimento, 10 imagens de cada classe foram escolhidas aleatoriamente. Ao serem segmentadas (separação dos núcleos), as imagens geraram 600 exemplos para as classes Papilífero e Bócio, e 400 exemplos para a classe Não-Câncer. Para as tarefas de treinamento e avaliação, o método crossvalidation $k$-fold com $\mathrm{k}=10$ foi utilizado. Como resultado, a acurácia (verdadeiros positivos) dos algoritmos de classificação foi medida em função das combinações possíveis dos extratores, ou seja, separadamente, em pares e todos juntos. Os resultados são apresentados na Tabela 6.4.

\begin{tabular}{c|cc}
\hline & KNN & MLP \\
\hline COOC & $61 \%$ & $\mathbf{6 2 \%}$ \\
DWT & $54 \%$ & $49 \%$ \\
MORPHO & $55 \%$ & $61 \%$ \\
COOC + DWT & $60 \%$ & $\mathbf{6 5 \%}$ \\
COOC + MORPHO & $64 \%$ & $\mathbf{6 5 \%}$ \\
DWT+MORPHO & $57 \%$ & $60 \%$ \\
COOC+DWT+MORPHO & $64 \%$ & $\mathbf{6 5 \%}$ \\
\hline
\end{tabular}

Tabela 6.4: Acurácia alcançada pelos extratores de características em função dos classificadores avaliados. Os valores dos extratores que apresentaram melhorar desempenho foram destacados em negrito.

Os extratores que apresentaram melhor desempenho (destacados em negrito na Tabela 6.4) foram o COOC (dentre os extratores unitários), o (COOC+DWT) e o (COOC+MORPHO) (entre os extratores em pares) e a união completa de todos os extratores. Todos as combinações de extratores que apresentaram bons resultados foram associados ao classificador MLP.

Em seguida, os autores avaliaram a interação do extrator morfológico junto aos demais extratores. Nesse sentido, os percentuais de mudança entre os extratores (e/ou combinação de extratores) 
com e sem morfologia foram calculados e apresentados na Tabela 6.5.

\begin{tabular}{c|cc}
\hline & KNN & MLP \\
\hline COOC + MORPHO & $5 \%$ & $4 \%$ \\
DWT + MORPHO & $4 \%$ & $\mathbf{2 2} \%$ \\
COOC + DWT + MORPHO & $6 \%$ & $0 \%$ \\
\hline
\end{tabular}

Tabela 6.5: Percentual de mudança com a agregação da morfologia.

Com base nos resultados apresentados na Tabela 6.5, a agregação de informações morfológicas contribuíram para a melhora da acurácia da maioria das combinações de extratores avaliados. O extrator que foi mais beneficiado foi o DWT com o classificador MLP, com uma melhora de $22 \%$ nos resultados obtidos.

Após avaliar os resultados da medida de precisão de todos os cenários avaliados, a combinação entre os extratores (COOC+DWT+MORPHO) e o classificador MLP apresentou baixa precisão. Para verificar a causa da baixa precisão, a matriz de confusão do pior cenário foi gerada. A Tabela 6.6 apresenta a matriz de confusão. As linhas da tabela representam a classe real e as colunas as classes preditas pelo classificador. Ao todo, de 1600 núcleos classificados, 1092 foram classificados corretamente.

\begin{tabular}{|c|ccc|}
\hline & Bócio & Não Câncer & Câncer \\
\hline Bócio & 370 & 102 & 128 \\
Não Câncer & 111 & 202 & 87 \\
Câncer & 100 & 40 & 406 \\
\hline
\end{tabular}

Tabela 6.6: Matriz de confusão do pior caso $(D W T+C O O C+M O R P H O$ e $M L P)$. As linhas representam as classes reais e as colunas as classes preditas. As células representam a quantidade de núcleos classificada em relação a classe real e a classe predita pelo FREDS.

Os autores do FREDS acreditam que a rotulação de imagem constitui uma maneira de criar relacionamentos entre informação extraídas de imagens e informações textuais. O uso de dados morfométricos como informação complementar durante o processo de classificação auxiliam no aumento da taxa de acerto dos algoritmos de classificação, além de ajudar o especialista na interpretação dos resultados, visto que informações técnicas sobre os núcleos das células são profundamente conhecidas pelo profissional da saúde. Após a experimentação do FREDS com bons resultados, este foi incorporado ao QASF.

\section{Avaliação do SisViDAS e do QASF}

A recuperação de artigos científicos no QASF foi realizada com o auxílio das classes de recuperação de informação desenvolvidas para o framework SisViDAS. Nesse sentido, a mestranda desenvolveu no QASF métodos computacionais que interagem com o SisViDAS solicitando, por meio do vetor de palavras-chave, os artigos para que o QASF busque as respostas candidatas.

As classes de recuperação de informação do SisViDAS não foram avaliadas no contexto de enviar e receber informações no mesmo idioma, ou seja, enviar pergunta e receber respostas no idioma inglês, mas somente em idiomas distintos, ou seja, enviar o prontuário no idioma português e receber artigos científicos no idioma inglês. Portanto, o objetivo dessa avaliação é observar a interação do QASF com o SisViDAS e também o comportamento do SisViDAS quando exposto a 
informações do mesmo idioma. Na Figura 6.6, o gráfico de precisão versus revocação da recuperação de documentos para extração das respostas candidatas é apresentado. O gráfico apresenta a precisão e a revocação média, contabilizada a partir dos seis prontuários utilizados na avaliação do QASF, variando a quantidade máxima de artigos a ser recuperada pelo SisViDAS.

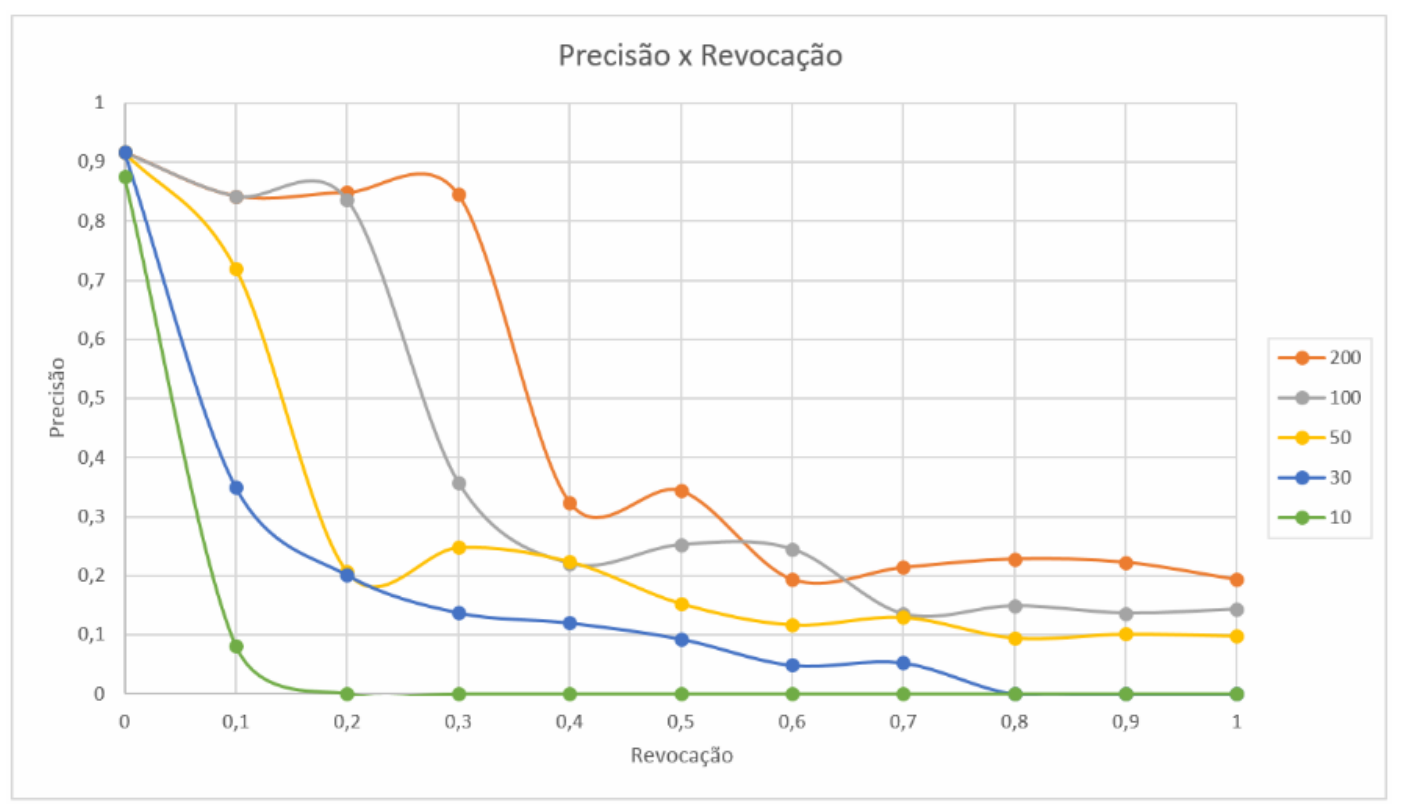

Figura 6.6: Precisão $x$ Revocação média na recuperação de artigos científicos variando a quantidade máxima de artigos a serem recuperados.

No gráfico, a quantidade máxima de artigos a serem recuperados influência diretamente no desempenho do QASF. Para a quantidade 200 (linha alaranjada), quando a precisão alcança valores de quase 0,9 a revocação é aproximadamente 0,3 . Porém, com a precisão entre 0,2 e 0,3 e revocação 0, 6 há uma inversão entre os conjuntos de 100 e de 200 artigos recuperados, onde a precisão para 100 artigos recuperados é maior que a precisão para 200 artigos recuperados.

\section{Extração das Respostas Candidatas}

A extração das respostas candidatas no QASF utiliza os artigos científicos recuperados pelo SisViDAS. Em seguida, cada palavra dos parágrafos dos resumos dos artigos científicos retornados é comparada com o vetor de palavras-chave. Caso a quantidade de palavras seja igual ou maior a um liminar $l$, o parágrafo é considerado um parágrafo candidato. Após exaustivas avaliações no QASF, a mestranda definiu o valor $l$ por meio de uma fórmula demonstrada na Equação 6.1.

$$
l \geq\left\lfloor\text { QtdPalavrasQuestaoProcessada }-\left(\frac{\text { QtdPalavrasQuestaoProcessada }}{10}\right)\right\rfloor
$$

cujo, o limiar $l$ é maior ou igual à parte inteira da QtdPalavrasQuestaoProcessada que representa a quantidade de palavras vetor de palavras-chave da primeira etapa de construção do vetor, menos o próprio valor da variável QtdPalavrasQuestaoProcessada dividido por dez. Por exemplo, utilizando os valores do paciente "p2" apresentados na Tabela 6.3, cujo valor 50 é atribuído à variável QtdPalavrasQuestaoProcessada, o resultado do limiar $l$ será maior ou igual à 45, ou seja, para uma resposta ser considerada como resposta candidata ela necessita ter 45 ou mais termos 
iguais ou similares ao vetor de palavras-chave que representa a questão feita pelo usuário. Na Figura 6.7, exemplos de respostas candidatas extraídas por meio da questão sobre o Paciente 2 são apresentados.

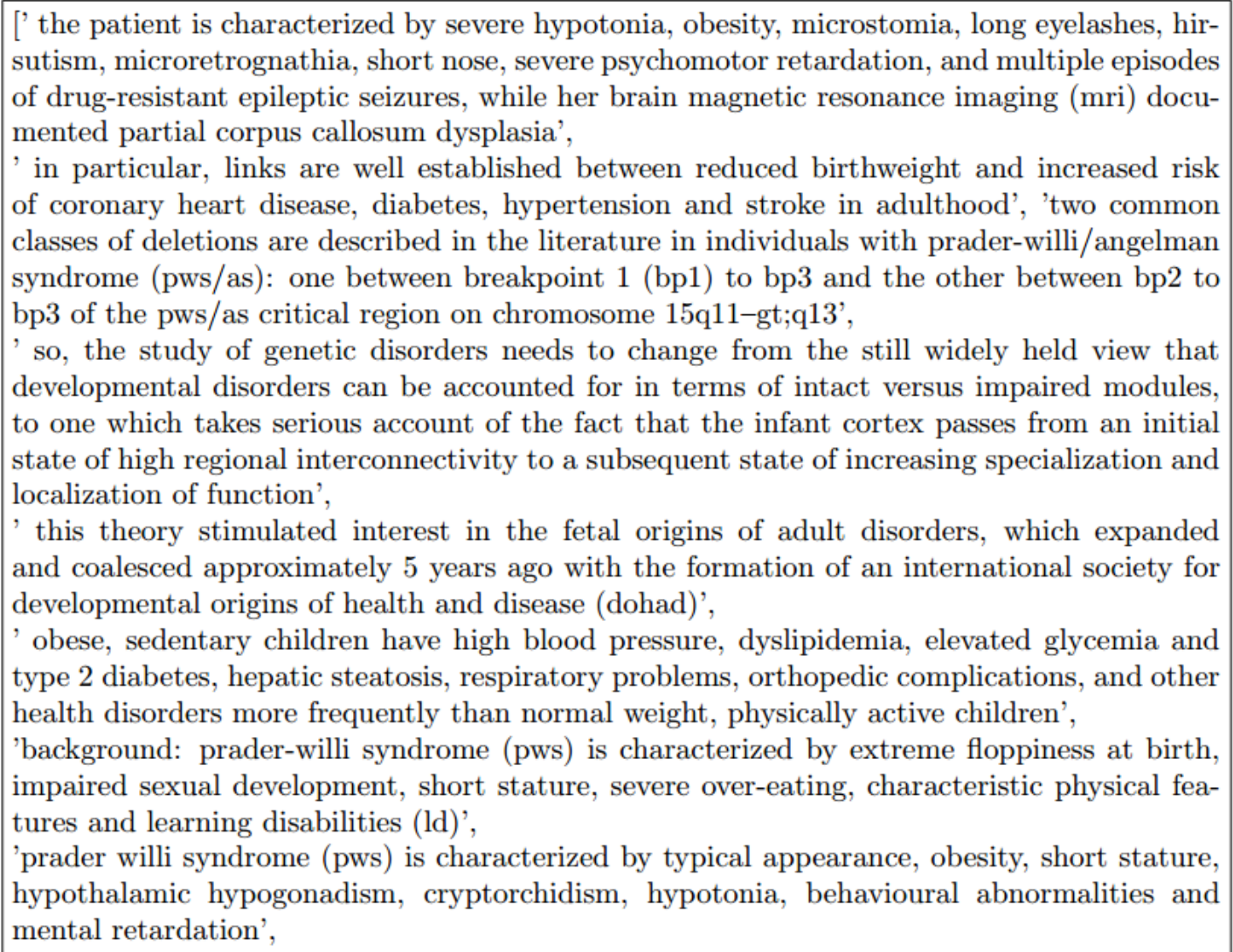

Figura 6.7: Exemplos de respostas candidatas do Paciente 2.

Na Tabela 6.7, a quantidade de respostas candidatas extraídas de cada paciente de acordo com a quantidade de documentos recuperados da coleção de referência é apresentada.

Tabela 6.7: Quantidade de respostas candidatas recuperadas de acordo com o tamanho da coleção de documentos recuperada.

\begin{tabular}{|c|c|c|c|c|c|}
\hline Paciente & $\mathbf{2 0 0}$ & $\mathbf{1 0 0}$ & $\mathbf{5 0}$ & $\mathbf{3 0}$ & $\mathbf{1 0}$ \\
\hline $\mathbf{p 2}$ & 51 & 29 & 15 & 10 & 3 \\
\hline $\mathbf{p 3}$ & 54 & 26 & 14 & 5 & 1 \\
\hline $\mathbf{p 1 8}$ & 97 & 47 & 31 & 22 & 5 \\
\hline $\mathbf{p 1 9}$ & 20 & 14 & 11 & 9 & 4 \\
\hline $\mathbf{p 2 4}$ & 10 & 5 & 2 & 2 & 1 \\
\hline $\mathbf{p 2 8}$ & 129 & 63 & 34 & 21 & 7 \\
\hline
\end{tabular}

Na tabela há uma diminuição gradual no número de respostas candidatas encontradas. Os pacientes "p18" e "p28" são os pacientes com o maior número de respostas candidatas encontradas, enquanto que o paciente "p24" é o paciente com o menor número de respostas candidatas encontradas. Quanto menor for o número de documentos recuperados mais restrita serão as respostas candidatas selecionadas pelo QASF. 


\subsubsection{Processamento da Resposta}

No módulo de "Processamento da Resposta", as respostas candidatas encontradas na etapa anterior são selecionadas e ordenadas de acordo com o grau de similaridade entre a questão e as respostas candidatas. Esse módulo divide-se entre "Seleção e Ordenação das Respostas" e "Validação das Respostas". A seguir, os resultados dos dois submódulos são apresentados.

\section{Ordenação e Seleção das Respostas}

O submódulo de "Ordenação e Seleção das Respostas" realiza a ordenação das respostas candidatas, por meio de medidas de similaridade, e apresenta ao usuário um número $n$ de respostas mais semelhantes. No QASF, o submódulo de "Ordenação e Seleção das Respostas" realiza o cálculo da similaridade do cosseno de duas maneiras distintas. Na primeira, nomeada como "cosseno1", os radicais das palavras são extraídos por meio de técnicas de stemming e lematização e as palavras sinônimas e hiperônimas são levadas em consideração. Na segunda maneira, nomeada como "cosseno2", o cálculo da similaridade é realizado com a pergunta e as respostas candidatas em sua forma gramatical original. Na Figura 6.8, as cinco primeiras frases mais similares e seus valores de similaridade de ambos os modelos são apresentados. 
(0.45700897912944699, ' conclusions: the diagnosis and management of this complex disorder
requires a multidisciplinary approach with particular emphasis on the importance of early
diagnosis using accredited genetic testing, use and monitoring of gh therapy from early
childhood, control of the food environment and regular exercise, appropriate management of
transition, consideration of group home placement in adulthood, and distinction of behavioral
problems from psychiatric illness')
$(0.43957387415506693$, ' the use of pwacr probes discriminates between a large group of
duplications of no apparent clinical significance and a smaller group, in which a maternally
derived pwacr duplication is consistently associated with developmental delay and speech dif-
ficulties but not with overt features of either prader-willi syndrome or angelman syndrome')
(0.42510809620808926, ' in accordance with this theory, sequelae of early life social and
environmental stressors, such as childhood abuse, neglect, poverty, and poor nutrition, have
been associated with the emergence of mental and physical illness (i')
(0.40756429660064375, ' why then does the population of developing countries currently
have a higher incidence of cvd than that of developed countries if they share the same risk
factors? we have proposed the existence of a higher susceptibility to the development of
systemic inflammation at low levels of abdominal obesity in the population of developing
countries and the consequent endothelial dysfunction, insulin resistance, dm 2 , and cvd')
(0.39934396916517478, ' this theory stimulated interest in the fetal origins of adult disor-
ders, which expanded and coalesced approximately 5 years ago with the formation of an
international society for developmental origins of health and disease (dohad)')
..

(a)

(0.42145903216760555, ' conclusions: the diagnosis and management of this complex disorder
requires a multidisciplinary approach with particular emphasis on the importance of early
diagnosis using accredited genetic testing, use and monitoring of gh therapy from early
childhood, control of the food environment and regular exercise, appropriate management of
transition, consideration of group home placement in adulthood, and distinction of behavioral
problems from psychiatric illness')
$(0.41549551595842993$, ' the use of pwacr probes discriminates between a large group of
duplications of no apparent clinical significance and a smaller group, in which a maternally
derived pwacr duplication is consistently associated with developmental delay and speech dif-
ficulties but not with overt features of either prader-willi syndrome or angelman syndrome')
(0.40831911157472001, ' in accordance with this theory, sequelae of early life social and
environmental stressors, such as childhood abuse, neglect, poverty, and poor nutrition, have
been associated with the emergence of mental and physical illness (i')
(0.38646190564371752, 'this theory stimulated interest in the fetal origins of adult disor-
ders, which expanded and coalesced approximately 5 years ago with the formation of an
international society for developmental origins of health and disease (dohad)')
(0.37653754420475849, ' why then does the population of developing countries currently
have a higher incidence of cvd than that of developed countries if they share the same risk
factors? we have proposed the existence of a higher susceptibility to the development of
systemic inflammation at low levels of abdominal obesity in the population of developing
countries and the consequent endothelial dysfunction, insulin resistance, dm 2 , and cvd')
..

(b)

Figura 6.8: Resultado do cálculo da similaridade. (a) Primeira maneira de calcular a similaridade ("cosseno1"). Nessa maneira, as palavras sinônimas são substituídas por uma palavra principal e as técnicas de stemming e lematização são aplicadas. (b) Segunda maneira de calcular a similaridade ("cosseno2"). A similaridade é calculada entre a pergunta e as frases candidatas na forma gramatical original.

Em ambas as figuras é possível que perceber que os valores de similaridade de "cosseno1" e o "cosseno2" são próximos e ambos alcançaram valores entre 0,40 e 0,46 de similaridade. Ambas as figuras possuem as mesmas respostas com praticamente a mesma ordenação. Apenas as duas últimas respostas alternam de posição. Portanto, não há muitas diferenças entre as duas formas de cálculo do cosseno para o QASF nessa experimentação. As duas abordagens poderiam ser usadas para a classificação das respostas candidatas. 


\section{Validação das Respostas}

Uma das formas mais conhecidas de avaliação e validação das respostas retornadas pelos sistemas de QA é realizada com o auxílio de corpora compostos por tuplas de perguntas e de respostas. No QASF, esta avaliação é realizada com o auxílio da coleção de referência EDRMrSa. Os artigos científicos desta coleção de referência foram relacionados aos prontuários e avaliados por médicos especialistas que os classificaram em quatro categorias ("Fortemente relevantes", "Relevantes", "Baixa relevância" e "Totalmente Irrelevantes") (Pollettini et al., 2014).

No contexto do QASF, a avaliação foi realizada comparando a pergunta representante de um prontuário com as respostas obtidas pelo QASF. Caso a resposta candidata pertença ao abstract de um artigo categorizado como "Fortemente relevante" ou "Relevante", esta resposta candidata é considerada "correta". Na Figura 6.9, a precisão média para as dez respostas candidatas apresentadas pelo QASF variando o paciente e a quantidade de artigos analisados pelo QASF é apresentada.

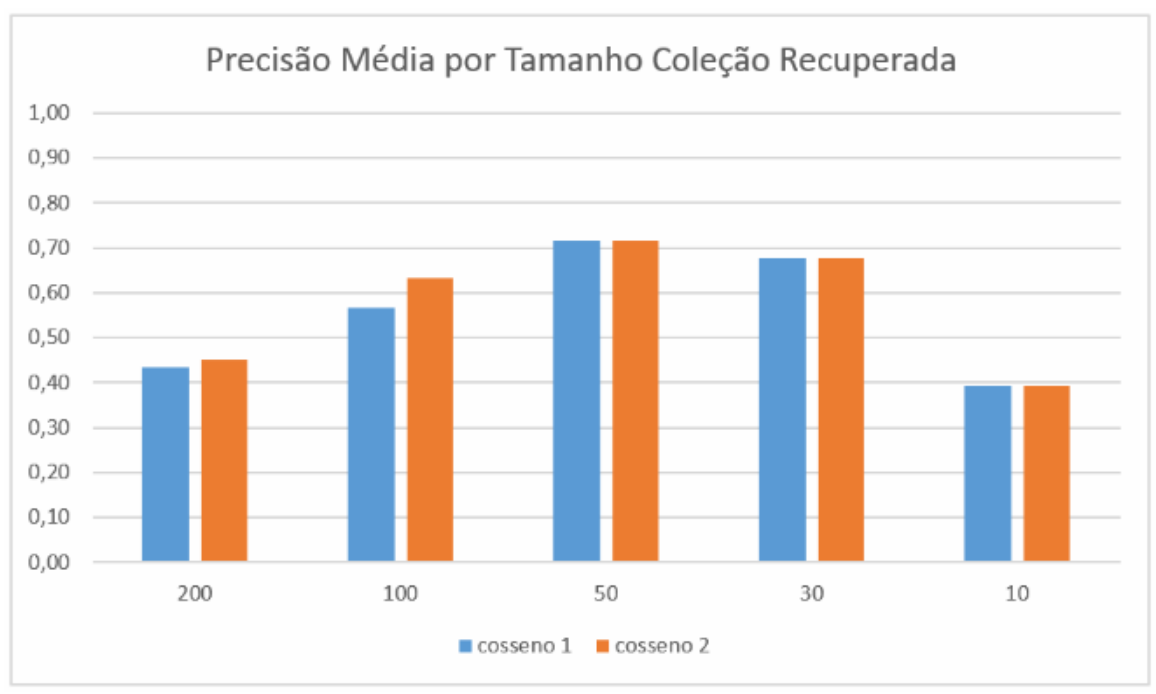

(a)

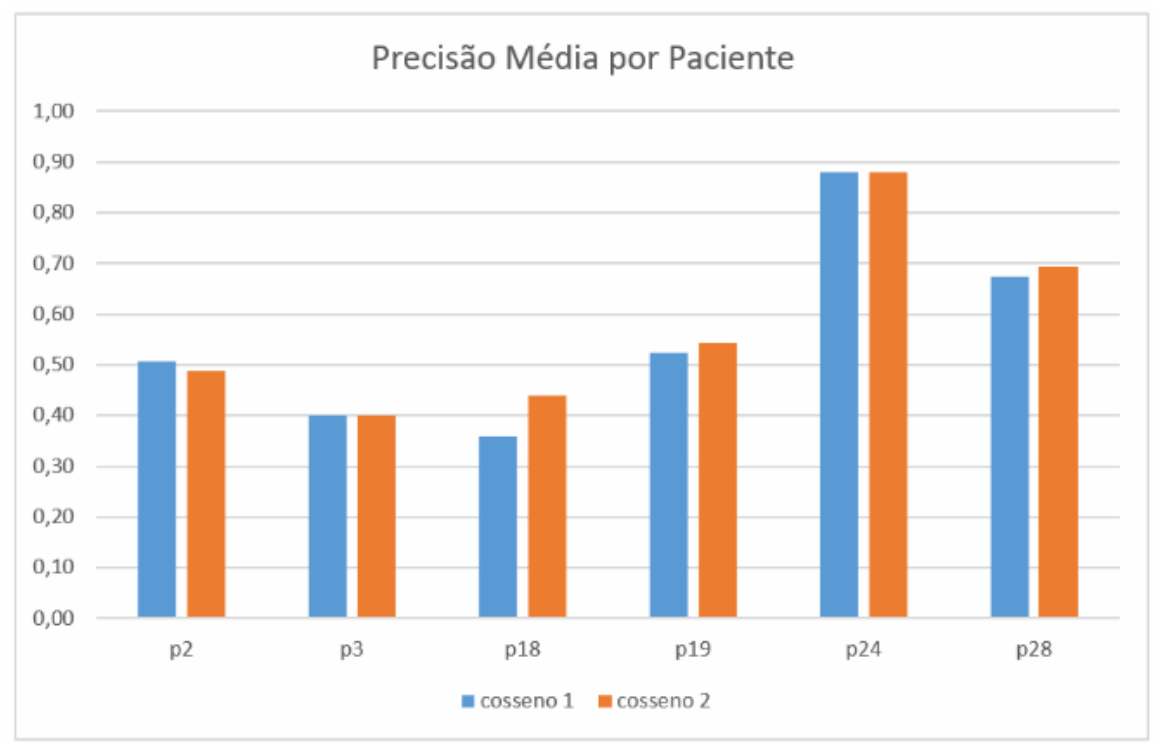

(b)

Figura 6.9: Precisão média calculada para os dois métodos de calcular o cosseno. (a) Precisão média variando a quantidade de artigos recuperados. (b) Precisão média por paciente. 
No gráfico apresentado na Figura 6.9a, a coleção recuperada com os 50 artigos mais similares apresenta os melhores resultados com precisão em torno de 0,7. As coleções com 200 e 10 artigos recuperados foram as que menos apresentaram bons resultados. Portanto, QASF não necessita de muitos artigos para obter respostas relevantes para as perguntas do usuário. No gráfico da Figura 6.9b, o paciente que obteve mais respostas precisas foi o paciente "p24". Um fato interessante é que, de acordo com a Tabela 6.3, o paciente "p24" não possui o maior número de termos médicos na pergunta do usuário, ao mesmo tempo que os pacientes "p3" e "p18" não possuem o menor número de termos médicos na pergunta do usuário. Portanto, a precisão das respostas recuperadas não é associada a quantidade de termos médicos da pergunta do usuário, mas a qualidade dos termos que compõem a consulta.

Um ponto a ser destacado nessa etapa de "Processamento das Respostas" é que, de acordo com a Figura 5.1, caso o QASF não encontre respostas compativeis com a pergunta do usuário, o próprio framework retorna para a etapa de "Ordenação e Seleção das Respostas" e busca por um novo conjunto de possíveis respostas corretas. Contudo, devido ao tempo restante para finalização do mestrado em contraponto ao número de tarefas à serem finalizadas, não foi possível implementar esse "retorno" do submódulo de "Ordenação e Seleção das Respostas" para o sumódulo de "Ordenação e Seleção das Respostas".

O QASF é um framework de Question Answering composto por três módulos distintos de processamento de informação, sendo eles: "Processamento da Questão", "Processamento dos Documentos"e o "Processamento das Respostas". Para que o QASF apresente desempenho satisfatório, técnicas computacionais distintas necessitam ser harmonicamente configuradas e empregadas. As pesquisadoras do QASF acreditam que este framework apresentou resultados satisfatórios, os quais poderão ser verificados e aprimorados com os trabalhos futuros propostos a seguir. 


\section{Capítulo 7}

\section{Conclusões}

Nas áreas biomédica e da saúde, investigar informações contidas em prontuários médico do paciente junto à pesquisas em informações científicas podem contribuir para o tratamento e para a prevenção de doenças. Porém, ler artigos científicos em busca de informações relevantes é uma tarefa que exige tempo e disposição. Portanto, o objetivo deste projeto é o desenvolvimento de um framework de Question Answering para suportar o desenvolvimento de sistemas de informações, que auxiliem profissionais da área da saúde na busca rápida por informações precisas. O sistema está sendo validado nos domínios de epigenética e doenças crônicas.

No módulo de "Processamento da Questão" do QASF, especificamente na etapa de "Análise da Questão", as avaliações mostram que a técnica SVM apresenta os melhores resultados na classificação de perguntas e que o dicionário WordNet busca por definições apenas quando os termos da frase são compostos por uma palavra. A etapa de "Elaboração da Consulta" foi construída em duas fases. Na primeira foram desconsiderados os pronomes interrogativos, as pontuações e as stopwords, portanto, nesta fase observou-se que as principais palavras que compõem o vetor de palavras-chave são os substantivos e os verbos. Na segunda fase, os termos sinônimos e hiperônimos foram acrescentados e as técnicas de lematização e stemming foram aplicadas.

O módulo de "Processamento dos Documentos" é composto pelos submódulos "Recuperação de Documentos" e "Extração das Respostas Candidatas. A recuperação dos documentos foi realizada por meio dos frameworks FREDS e SisViDAS. Atualmente, somente o SisViDAS foi avaliado na recuperação de artigos científicos para o QASF. O SisViDAS apresentou melhores resultados quando a quantidade de artigos recuperados pelo SisViDAS a partir de consultas formuladas considerando os prontuários médicos foi limitada a duzentos artigos. O número de respostas candidatas extraídas pelo QASF variou gradualmente conforme a quantidade de artigos recuperados pelo SisViDAS foi diminuindo.

O módulo de "Processamento das Respostas" do QASF ordena e seleciona as respostas por meio de dois métodos de cálculo da similaridade pelo cosseno. No primeiro, as palavras sinônimas são convertidas a palavra principal e as técnicas de lematização e stemming são aplicadas antes do cálculo da similaridade. No segundo método, a similaridade é calculada com a resposta candidata e a pergunta na forma original. Os resultados apontam que o primeiro método apresenta valores de similaridade ligeiramente melhores que o segundo. No contexto geral, o QASF alcançou valores de precisão máximo em torno de 0,7 quando a revocação era 0,3 e precisão mínima em torno de 0,2 quando a revocação era 0,6 e para ambos a quantidade de artigos recuperados foi 200. Levando em consideração que as perguntas inseridas no QASF são longas e complexas, com 70 termos por 
pergunta em média, o QASF apresentou resultados satisfatórios.

O QASF quando comparado a outros frameworks de QA como, por exemplo, o START, possui uma arquitetura atualizada e focada no contexto médico. Futuramente, o QASF possuirá o diferencial de poder ser acessado por pessoas em geral ou profissionais da área da saúde por meio de páginas WEB ou aplicativos mobile. Outro diferencial desse framework é o baixo custo financeiro para aquisição de equipamente apropriado, para implantação do framework e para o seu uso, uma vez que o QASF possui a interface do usuário simples e intuitiva. Além disso, o framework pode ser acessado sem a necessidade constante de acesso a internet. Somente em atividades mais precisas como, por exemplo a atualização da coleção de artigos é necessária a conexão com a internet.

Durante o mestrado, a aluna participou da construção de um artigo sobre o FREDS executando as seguintes tarefas: na construção da coleção de referência FnATI, no auxílio na experimentação do framework, na análise dos resultados publicados e na construção e correção do texto e das figuras do artigo. O artigo Morphometric Information Reducing Semantic Gap on the Characterization of Microscopic Images of Thyroid Nodules foi publicado no journal Computer Methods and Programs in Biomedicine (Macedo et al., 2016). Além desse artigo, a aluna escreveu um artigo sobre o QASF que foi aceito para o 16 Workshop de Informática Médica (WIM 2016) (Almansa e Macedo , 2016). Atualmente as pesquisadoras escrevem um artigo científico detalhando a arquitetura e os experimentos realizados no QASF para ser publicado em periódicos internacionais.

\subsection{Contribuições}

O projeto do QASF contribui com a construção de um framework de software que permite a criação de sistemas do tipo Question Answering. Neste framework, as respostas podem ser buscadas em diferentes modelos de dados (artigos científicos, registros médicos e laudos de exames médicos), de acordo com o nível de permissão de acesso ao usuário. Grande parte da arquitetura do QASF é genérica e preparada para suportar a transição entre domínios de aplicação, principalmente da área médica. Para alterar o domínio é necessário atualizar a base de artigos científicos utilizada na busca das respostas candidatas e a troca das ontologias e dicionários do domínio. As respostas retornadas pelo sistema de QA são uma tentativa de diminuir o tempo gasto por profissionais da saúde na busca por informações de interesse.

\subsection{Dificuldades e Limitações}

A principal dificuldade e limitação encontrada no desenvolvimento deste projeto foi a coleção de referência que necessitava ter perguntas e respostas curadas no domínio médico.

\subsection{Trabalhos Futuros}

Como trabalhos futuros, pretende-se: (i) avaliar o QASF em outros domínios de informação como, por exemplo, o câncer de tireoide incluindo o outro framework em informática biomédica do grupo de pesquisa, o FREDS (Pessotti, 2012), (ii) transformar o QASF em uma aplicação que composta por interfaces de usuário web e mobile que facilite a interação com o framework (iii) avaliar e comparar os resultados entre os dicionários do WordNet e outros dicionários da área médica, (iv) 
incluir o uso de UMLS e de ontologias do domínio como, por exemplo, a CDO, (v) acrescentar uma etapa de pré-processamento da questão na etapa de "Análise da Questão" por técnicas de AM contendo abordagens como, por exemplo, a bag-of-words e a named-entity recognition (NER) e realizar um estudo comparativo entre estas abordagens para descobrir quais técnicas agrupadas melhoram o desempenho dos classificadores SVM e (vi) criar uma etapa de pré-processamento da questão, onde será tratado os erros de ortografia. 


\title{
Apêndice A
}

\section{Prontuários dos Paciente Simulados}

\author{
Paciente: 3 \\ Diagnóstico nutricional: Ferropenia. \\ Crescimento: Baixa estatura. \\ Desenvolvimento (DNPM): Presença de indicadores de risco. \\ Vacinação: Efeitos colaterais diversos, como BCG ite, edema de glote, síndrome convulsiva. \\ Alimentação: Adequada. \\ Cotidiano infantil: Adequado. \\ Familiograma: Ambiente de risco para Doenças Crônicas. \\ Ambiente emocional: Violência. \\ Condições ambientais: Ambiente úmido. \\ Condições sócio-econômico-culturais: Baixa escolaridade da mãe. \\ Fatores de Risco: Criança manifestamente indesejada. \\ Fatores de proteção: Família continente. \\ Doenças atuais: Pré-natal com intercorrências como Hipertensão arterial. \\ Doenças anteriores ou crônicas: Pré-termo de 35 semanas completas. \\ Antecedentes familiares: Cardiopatia.
}




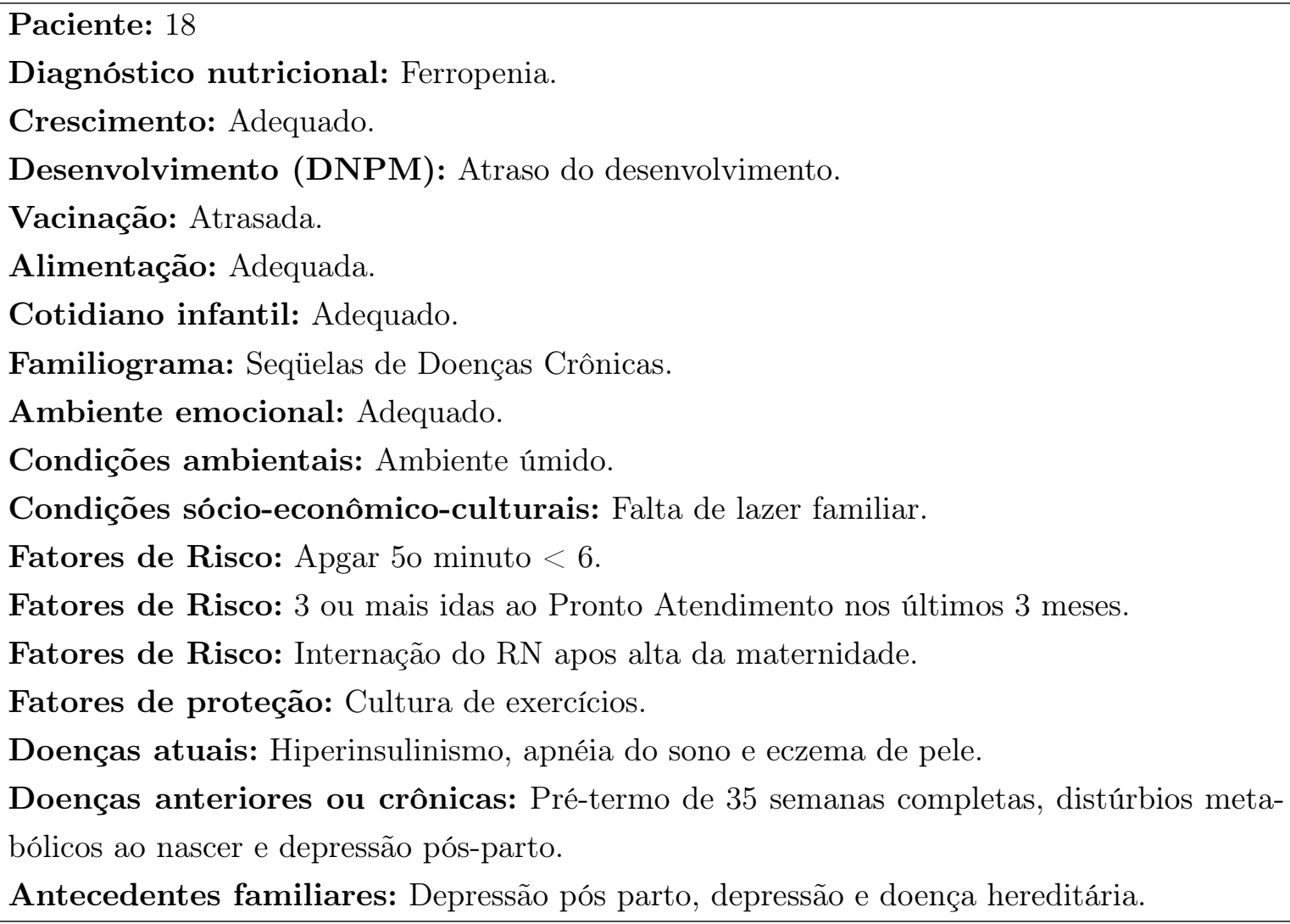

\section{Paciente: 19}

Diagnóstico nutricional: Distrofia.

Crescimento: Adequado.

Desenvolvimento (DNPM): Atraso do desenvolvimento.

Vacinação: Atualizada.

Alimentação: Lacto-vegetariana.

Cotidiano infantil: Lazer inativo.

Familiograma: Pais adolescentes.

Ambiente emocional: Violência.

Condições ambientais: Casa em área de enchentes.

Condições sócio-econômico-culturais: Baixa escolaridade da mãe.

Fatores de Risco: Ganho de peso insuficiente (menor que $8 \mathrm{Kg}$ ) ou excessivo (maior de 12 quilos) na gestação, gemelaridade e apgar 50 minuto $<6$.

Fatores de proteção: Vida saudável.

Doenças atuais: Restrição do crescimento intra-uterino, estresse e mau rendimento escolar.

Doenças anteriores ou crônicas: Transfusão feto-fetal, com quadro de insuficiência respiratória grave e UTI por 20 dias e septicemia precoce.

Antecedentes familiares: IAM, doença cerebrovascular e doença arterial coronariana. 


Paciente: 24
Diagnóstico nutricional: Distrofia.
Crescimento: Baixa estatura.
Desenvolvimento (DNPM): Presença de indicadores de risco.
Vacinação: Atrasada.
Alimentação: Adequada.
Cotidiano infantil: Sedentarismo.
Familiograma: Perda de familiares por Doenças Crônicas.
Ambiente emocional: Drogadição dos pais.
Condições ambientais: Adequadas.
Condições sócio-econômico-culturais: Família contribui com 20\% da renda familiar para
dízimo da igreja.
Fatores de Risco: Atitudes de resignação com a vida, violência familiar e criança manifes-
tamente indesejada.
Fatores de proteção: Presença de redes de apôio na comunidade.
Doenças atuais: Infecções de urina de repetição, doença de membrana hialina e hipoacusia
familiar.
Doenças anteriores ou crônicas: RN com Síndrome HELLP, convulsões neonatais e anó-
xia neonatal.
Antecedentes familiares: Síndrome do pânico, AVC e doença hereditária.




\begin{tabular}{l} 
Paciente: 28 \\
Diagnóstico nutricional: Sobrepeso ou obesidade. \\
Crescimento: Baixa estatura. \\
Desenvolvimento (DNPM): Atraso do desenvolvimento. \\
Vacinação: Atrasada. \\
Alimentação: Adequada. \\
Cotidiano infantil: Lazer inativo. \\
Familiograma: Seqüelas de Doenças Crônicas. \\
Ambiente emocional: Depressão materna. \\
Condições ambientais: Ambiente úmido. \\
Condições sócio-econômico-culturais: Família contribui com 20\% da renda familiar para \\
dízimo da igreja. \\
Fatores de Risco: Distúrbios do comportamento/ vínculo, saneamento básico precário, 3 \\
ou mais idas ao Pronto Atendimento nos últimos 3 meses, habitação inadequada (umidade, \\
falta ventilação, falta de insolação, falta de privacidade), desnutrição materna e carências de \\
micronutrientes e intercorrências neonatais no berçário. \\
Fatores de proteção: Presença de redes de apoio na comunidade. \\
Doenças atuais: Diabetes gestacional, polidactilia familiar, infecções de urina de repetição, \\
apnéia do sono, deficiência física e malformação congênita como pé torto congênito. \\
Doenças anteriores ou crônicas: Peso extremamente baixo, infecção perinatal, desnu- \\
trição materna na gestação, RN com risco para infecção por Streptococcus hemolítico, mãe \\
com DHEG e pré-eclâmpsia e filho de mãe diabética. \\
Antecedentes familiares: Depressão pós parto, doença vascular de extremidades, hiper- \\
tensão, dislipidemia, prole com baixa estatura e doença psiquiátrica. \\
\hline
\end{tabular}




\section{Referências Bibliográficas}

ABS (2005) Associação Brasileira de Psiquiatria ABS. A rotina estressante dos médicos, 2005. URL http://abp.org.br/2011/medicos/clippingsis/exibClipping/?clipping=298. Citado na pág. 2, 40

Albregtsen (2008) Fritz Albregtsen. Statistical Texture Measures Computed from Gray Level Coocurrence Matrices. Relatório técnico, Image Processing Laboratory, Department of Informatics, University of Oslo, Norway. URL http://www.uio.no/studier/emner/matnat/ifi/INF4300/ h08/undervisningsmateriale/glcm.pdf. Citado na pág. 36

Allam e Haggag (2012) Ali Mohamed Nabil Allam e Mohamed Hassan Haggag. The question answering systems: A survey. International Journal of Research and Reviews in Information Sciences (IJRRIS), 2(3):211-220. Citado na pág. 16, 17, 18, 19, 20, 40, 45, 47

Almansa e Macedo (2016) Luciana Almansa e Alessandra Alaniz Macedo. Sistema de Informação para Perguntas e Respostas em Doenças Crônicas. Em 160 Workshop de Informática Médica (evento paralelo ao Congresso da Sociedade Brasileira de Computação), Porto Alegre. Citado na pág. 61,74

Álvarez (2007) Alberto Cáceres Álvarez. Extração de informação de artigos científicos: uma abordagem baseada em indução de regras de etiquetagem. Dissertação de Mestrado, Universidade de São Paulo. Citado na pág. 11

Amorim et al. (2012) Marta Talitha Carvalho Freire de Amorim, Davidson Cury e Crediné Silva Menezes. Um Sistema Inteligênte Baseado em Ontologia para Apoio ao esclarecimento de Dúvidas., 2012. URL http://portais4.ufes.br/posgrad/teses/tese_5119_.pdf. Citado na pág. 27, 29

Aronson (2001) Alan R Aronson. Effective mapping of biomedical text to the umls metathesaurus: the metamap program. Em Proceedings of the AMIA Symposium, página 17. American Medical Informatics Association. Citado na pág. 26

Arrigo et al. (2014) Adriano Jorge Soares Arrigo, Elvio Gilberto Silva, Henrique Pachioni Martins e Patrick Pereira Silva. Desenvolvimento de um Sistema de Pergunta e Resposta Baseado em Corpus. Em 140 Congresso Nacional de Iniciação Científica (CONIC-SEMESP), páginas 1-6, São Paulo, SP. Citado na pág. 27, 29

Asahara e Matsumoto (2003) Masayuki Asahara e Yuji Matsumoto. Japanese named entity extraction with redundant morphological analysis. Em Proceedings of the 2003 Conference of the North American Chapter of the Association for Computational Linguistics on Human Language Technology-Volume 1, páginas 8-15. Association for Computational Linguistics. Citado na pág. 13

Athenikos e Han (2010) Sofia J. Athenikos e Hyoil Han. Biomedical question answering: A survey. Computer Methods and Programs in Biomedicine, 99(1):1 - 24. ISSN 0169-2607. doi: http: //dx.doi.org/10.1016/j.cmpb.2009.10.003. URL http://www.sciencedirect.com/science/article/ pii/S0169260709002879. Citado na pág. 16

Baeza-Yates e Ribeiro-Neto (1999) Ricardo Baeza-Yates e Berthier Ribeiro-Neto. Modern information retrieval, volume 463. ACM Press New York, 1nd ed. Citado na pág. x, 2, 5, 7, 8, 9, $10,11,14$ 
Baeza-Yates e Ribeiro-Neto (2013) Ricardo Baeza-Yates e Berthier Ribeiro-Neto. Recuperação de Informação: Conceitos e Tecnologia das Máquinas de Busca. Bookman Editora. ISBN 9788582600498. URL https://books.google.com.br/books?id=YWk3AgAAQBAJ. Citado na pág. 8, 9,10

Barker (2001) David James Purslove Barker. Fetal and infant origins of adult disease. Monatsschrift Kinderheilkunde, 149(1):S2-S6. ISSN 0026-9298. doi: 10.1007/s001120170002. URL http://dx.doi.org/10.1007/s001120170002. Citado na pág. 4, 30

Ben Abacha e Zweigenbaum (2015) Asma Ben Abacha e Pierre Zweigenbaum. MEANS: A medical question-answering system combining NLP techniques and semantic Web technologies. Information Processing \& Management, 51(5):570-594. ISSN 03064573. doi: 10.1016/j.ipm.2015. 04.006. URL http://www.sciencedirect.com/science/article/pii/S0306457315000515. Citado na pág. $11,26,28,29$

Bikel et al. (1997) Daniel M Bikel, Scott Miller, Richard Schwartz e Ralph Weischedel. Nymble: a high-performance learning name-finder. Em Proceedings of the fifth conference on Applied natural language processing, páginas 194-201. Association for Computational Linguistics. Citado na pág. 13

Bilotti e Nyberg (2006) Matthew W. Bilotti e Eric Nyberg. Evaluation for scenario question answering systems. Em Proceedings of the International Conference on Language Resources and Evaluation, páginas 1-6. Citado na pág. 20, 21, 56

Bird (2006) Steven Bird. Nltk: the natural language toolkit. Em Proceedings of the COLING/ACL on Interactive presentation sessions, páginas 69-72. Association for Computational Linguistics. Citado na pág. 32

Bird et al. (2009) Steven Bird, Ewan Klein e Edward Loper. Natural Language Processing with Python. O'Reilly Media. ISBN 9780596555719. URL https://books.google.com.br/books?id= KGIbfiiP1i4C. Citado na pág. 12, 43, 63

Blair (1979) David C. Blair. Information retrieval, 2nd ed. c.j. van rijsbergen. london: Butterworths; 1979: 208 pp. Journal of the American Society for Information Science, 30(6):374-375. ISSN 1097-4571. doi: 10.1002/asi.4630300621. URL http://dx.doi.org/10.1002/asi.4630300621. Citado na pág. 21, 56

Bodenreider (2004) Olivier Bodenreider. The unified medical language system (umls): integrating biomedical terminology. Nucleic acids research, 32(suppl 1):D267-D270. Citado na pág. 15

Bonfim (2006) Marcelo Erick Bonfim. Recuperação de documentos texto usando um modelo probabilístico estendido. Dissertação de Mestrado, Universidade Metodista de Piracicaba. URL https://www.unimep.br/phpg/bibdig/pdfs/2006/AAYQFMJVOJJW.pdf. Citado na pág. 9

Boser et al. (1992) Bernhard E. Boser, Isabelle M. Guyon e Vladimir N. Vapnik. A training algorithm for optimal margin classifiers. Em Proceedings of the fifth annual workshop on Computational learning theory, páginas 144-152. ACM. Citado na pág. 14

Brin (1999) Sergey Brin. Extracting patterns and relations from the world wide web. Em Selected Papers from the International Workshop on The World Wide Web and Databases, WebDB '98, páginas 172-183, London, UK, UK. Springer-Verlag. ISBN 3-540-65890-4. URL http://dl.acm. org/citation.cfm?id=646543.696220. Citado na pág. 15

Butte (2008) Atul J. Butte. Translational Bioinformatics: Coming of Age. Journal of the American Medical Informatics Association, 15(6):709-714. ISSN 10675027. doi: 10.1197/jamia.M2824. Citado na pág. 33 
Cao et al. (2011) YongGang Cao, Feifan Liu, Pippa Simpson, Lamont Antieau, Andrew Bennett, James J Cimino, John Ely e Hong Yu. AskHERMES: An online question answering system for complex clinical questions. Journal of biomedical informatics, 44(2):277-88. ISSN 1532-0480. doi: 10.1016/j.jbi.2011.01.004. URL http://www.sciencedirect.com/science/article/ pii/S1532046411000062. Citado na pág. 26, 28, 29, 56, 57, 60

Cardoso (2004) Olinda Nogueira Paes Cardoso. Recuperação de informação. INFOCOMP Journal of Computer Science, 2(1):33-38. Citado na pág. 8, 10

Chali et al. (2015) Yllias Chali, Sadid A. Hasan e Mustapha Mojahid. A reinforcement learning formulation to the complex question answering problem. Information Processing $\&$ Management, 51(3):252-272. ISSN 03064573. doi: 10.1016/j.ipm.2015.01.002. URL http://www.sciencedirect. $\mathrm{com} / \mathrm{science} / \mathrm{article} / \mathrm{pii} / \mathrm{S} 0306457315000035$. Citado na pág. 11

Cibas e Ali (2009) E. S. Cibas e S. Z. Ali. The Bethesda System for Reporting Thyroid Cytopathology. American Journal of Clinical Pathology, 132:658-665. ISSN 00029173. doi: 10.1309/AJCPPHLWMI3JV4LA. URL http://ajcp.ascpjournals.org/cgi/doi/10.1309/ AJCPPHLWMI3JV4LA. Citado na pág. 57

Ciccacci et al. (2013) Cinzia Ciccacci, Davide Di Fusco, Laura Cacciotti, Roberto Morganti, Cinzia D'Amato, Giuseppe Novelli, Federica Sangiuolo, Vincenza Spallone e Paola Borgiani. Tcf712 gene polymorphisms and type 2 diabetes: association with diabetic retinopathy and cardiovascular autonomic neuropathy. Acta Diabetologica, 50(5):789-799. ISSN 1432-5233. doi: 10.1007/s00592-012-0418-x. URL http://dx.doi.org/10.1007/s00592-012-0418-x. Citado na pág. x, 12

Cock et al. (2009) Peter J. A. Cock, Tiago Antao, Jeffrey T. Chang, Brad A. Chapman, Cymon J. Cox, Andrew Dalke, Iddo Friedberg, Thomas Hamelryck, Frank Kauff, Bartek Wilczynski et al. Biopython: freely available python tools for computational molecular biology and bioinformatics. Bioinformatics, 25(11):1422-1423. Citado na pág. 32

Cohen e Hunter (2008) K. Bretonnel Cohen e Lawrence Hunter. Getting started in text mining. 4:1-20. ISSN 1553734X. doi: 10.1371/journal.pcbi.0040020. Citado na pág. 1, 11

Cowie e Lehnert (1996) Jim Cowie e Wendy Lehnert. Information extraction. Communications of the ACM, 39(1):80-91. Citado na pág. 11

Dang et al. (2007) Hoa Trang Dang, Diane Kelly e Jimmy J. Lin. Overview of the TREC 2007 question answering track. Em TREC, volume 7, página 63. Citeseer. Citado na pág. 21

Daubechies (1992) Ingrid Daubechies. Ten Lectures on Wavelets, volume 61. ISBN 0898712742. doi: 10.1137/1.9781611970104. Citado na pág. 36

De Marneffe e Manning (2008) Marie-Catherine De Marneffe e Christopher D Manning. The stanford typed dependencies representation. Em Coling 2008: Proceedings of the workshop on Cross-Framework and Cross-Domain Parser Evaluation, páginas 1-8. Association for Computational Linguistics. Citado na pág. 26

Er e Cicekli (2013) Nagehan Pala Er e Ilyas Cicekli. A Factoid Question Answering System Using Answer Pattern Matching. Em International Joint Conference on Natural Language Processing, páginas 854-858, Nagoya, Japan. Citado na pág. 41

Ferrucci et al. (2010) David Ferrucci, Eric Brown, Jennifer Chu-Carroll, James Fan, David Gondek, Aditya A. Kalyanpur, Adam Lally, J. William Murdock, Eric Nyberg, John Prager et al. Building Watson: An overview of the DeepQA project. AI magazine, 31(3):59-79. Citado na pág. 24 
Frakes e Baeza-Yates (1992) William B. Frakes e Ricardo Baeza-Yates, editors. Information Retrieval: Data Structures and Algorithms. Prentice-Hall, Inc., Upper Saddle River, NJ, USA. ISBN 0-13-463837-9. Citado na pág. 5

Gaizauskas e Wilks (1998) Robert Gaizauskas e Yorick Wilks. Information extraction: Beyond document retrieval. Journal of documentation, 54(1):70-105. Citado na pág. 11

Galisson e Coste (1983) Robert Galisson e Daniel Coste. Dicionário de didáctica das línguas. Citado na pág. 43, 63

Green et al. (1961) Bert F. Green, Jr., Alice K. Wolf, Carol Chomsky e Kenneth Laughery. Baseball: An automatic question-answerer. Em Western Joint IRE-AIEE-ACM Computer Conference, IRE-AIEE-ACM '61 (Western), páginas 219-224, New York, NY, USA. ACM. doi: 10.1145/1460690.1460714. URL http://doi.acm.org/10.1145/1460690.1460714. Citado na pág. 22, 29

Grishman (1997) Ralph Grishman. Information extraction: Techniques and challenges. Em International Summer School on Information Extraction: A Multidisciplinary Approach to an Emerging Information Technology, SCIE '97, páginas 10-27, London, UK. Springer-Verlag. ISBN 3-540-63438-X. URL http://dl.acm.org/citation.cfm?id=645856.669801. Citado na pág. 11

Gruber (1993) Thomas R. Gruber. A translation approach to portable ontology specifications. Knowl. Acquis., 5(2):199-220. ISSN 1042-8143. doi: 10.1006/knac.1993.1008. URL http://dx. doi.org/10.1006/knac.1993.1008. Citado na pág. 15

Gupta e Gupta (2012) Poonam Gupta e Vishal Gupta. A survey of text question answering techniques. International Journal of Computer Applications, 53(4):1-8. Citado na pág. 19, 20, 45, 47

Haralick et al. (1973) R.M. Haralick, K. Shanmugam e Its'Hak Dinstein. Textural features for image classification. Systems, Man and Cybernetics, IEEE Transactions on, SMC-3(6):610-621. ISSN 0018-9472. doi: 10.1109/TSMC.1973.4309314. Citado na pág. 36

Hartawan e Suhartono (2015) Andrei Hartawan e Derwin Suhartono. Using Vector Space Model in Question Answering System. Procedia Computer Science, 59:305-311. ISSN 18770509. doi: 10.1016/j.procs.2015.07.570. URL http://www.sciencedirect.com/science/article/ pii/S1877050915020992. Citado na pág. 26, 29

Haykin (2001) S.S. Haykin. Redes Neurais - 2ed. Bookman Companhia Ed. ISBN 9788573077186. URL https://books.google.com.br/books?id=1Bp0X5qfyjUC. Citado na pág. 14

Hirschman e Gaizauskas (2001) L. Hirschman e R. Gaizauskas. Natural language question answering: the view from here, 2001. ISSN 1351-3249. Citado na pág. 16

Hull (1993) David Hull. Using statistical testing in the evaluation of retrieval experiments. Em Proceedings of the 16th annual international $\{A C M\}\{S I G I R\}$ conference on Research and development in information retrieval, páginas 329-338. ISBN 0-89791-605-0. doi: 10.1145/160688. 160758. Citado na pág. 10

IBM (2012) IBM. Memorial Sloan-Kettering Cancer Center, IBM to Collaborate in Applying Watson Technology to Help Oncologists, 2012. URL http://www-03.ibm.com/press/us/en/ pressrelease/37235.wss. Citado na pág. 24

IBM (2014) IBM. The New York Genome Center and IBM Watson Group Announce Collaboration to Advance Genomic Medicine, 2014. URL http://www-03.ibm.com/press/us/en/pressrelease/ 43444.wss. Citado na pág. 24 
IBM (2015) IBM. Watson to Gain Ability to "See" with Planned \$1B Acquisition of Merge Healthcare, 2015. URL https://www-03.ibm.com/press/us/en/pressrelease/47435.wss. Citado na pág. 24

INCA (2014) Estimativa INCA. Incidência do câncer no brasil/instituto nacional de câncer josé alencar gomes da silva, coordenação de prevenção e vigilância. 2014. Rio de Janeiro. Disponivel http://www.inca.gov.br/estimativa/2014/, 20. Citado na pág. 33, 35

Joachims (1998) Thorsten Joachims. Text categorization with support vector machines: Learning with many relevant features. Springer. Citado na pág. 15

Jurafsky e Martin (2000) Daniel Jurafsky e James H. Martin. Speech and Language Processing: An Introduction to Natural Language Processing, Computational Linguistics, and Speech Recognition, volume 21. ISBN 0130950696. doi: 10.1162/089120100750105975. URL http://www.mitpressjournals.org/doi/pdf/10.1162/089120100750105975. Citado na pág. 13

Katz (1990) Boris Katz. Artificial intelligence at MIT expanding frontiers. chapter Using English for Indexing and Retrieving, páginas 134-165. MIT Press, Cambridge, MA, USA. ISBN 0-26223150-6. URL http://dl.acm.org/citation.cfm?id=106626.106635. Citado na pág. 23, 29

Katz (1997) Boris Katz. Annotating the world wide web using natural language. Em RIAO, páginas 136-159. Citado na pág. 23, 29

Kollias (2006) S. Kollias. Artificial Neural Networks - ICANN 2006: 16th International Conference, Athens, Greece, September 10-14, 2006, Proceedings. Artificial Neural Networks: ICANN 2006 : 16th International Conference, Athens, Greece, September 10-14, 2006 : Proceedings. Springer. ISBN 9783540386254. URL https://books.google.com.br/books?id=TcEKEKexiewC. Citado na pág. 33

Kolomiyets e Moens (2011) Oleksandr Kolomiyets e Marie-Francine Moens. A survey on question answering technology from an information retrieval perspective. Information Sciences, 181(24):5412 - 5434. ISSN 0020-0255. doi: http://dx.doi.org/10.1016/j.ins.2011.07.047. URL http://www.sciencedirect.com/science/article/pii/S0020025511003860. Citado na pág. 3, 22, 23

Lafferty (2001) John Lafferty. Conditional random fields: Probabilistic models for segmenting and labeling sequence data. páginas 282-289. Morgan Kaufmann. Citado na pág. 26

Larsen e von Ins (2010) Peder Olesen Larsen e Markus von Ins. The rate of growth in scientific publication and the decline in coverage provided by Science Citation Index. Scientometrics, 84 (3):575-603. ISSN 0138-9130. doi: 10.1007/s11192-010-0202-z. URL http://link.springer.com/ 10.1007/s11192-010-0202-z. Citado na pág. 1

Learning (2016) M. Learning. Machine Learning Proceedings 1995: Proceedings of the Twelfth International Conference on Machine Learning, Tahoe City, California, July 9-12 1995. Elsevier Science. ISBN 9781483298665. URL https://books.google.com.br/books?id=akijBQAAQBAJ. Citado na pág. 33

Leidner e Callison-Burch (2003) Jochen L. Leidner e Chris Callison-Burch. Evaluating question answering systems using FAQ answer injection. Em In 6th Annual CLUK Research Colloquium. Citado na pág. 21

Lin e Demner-Fushman (2005) Jimmy Lin e Dina Demner-Fushman. Automatically evaluating answers to definition questions. Em Proceedings of the conference on Human Language Technology and Empirical Methods in Natural Language Processing, páginas 931-938. Association for Computational Linguistics. Citado na pág. 21 
Lopes et al. (2007) João Ladislau Lopes, Ana Marilza Pernas, Fernando Afonso, Giovani Librelotto, Iara Augustin, Luiz Antônio Palazzo e Adenauer Yamin. Uma abordagem baseada em ontologias para sensibilidade ao contexto na computação pervasiva. Em Anais do I Workshop on Pervasive and Ubiquitous Computing (WPUC). Citado na pág. 15

Lorena e de Carvalho (2007) Ana Carolina Lorena e André CPLF de Carvalho. Uma introdução às support vector machines. Revista de Informática Teórica e Aplicada, 14(2):43-67. Citado na pág. 14

Macedo et al. (2016) Alessandra A. Macedo, Hugo C. Pessotti, Luciana F. Almansa, Joaquim C. Felipe e Edna T. Kimura. Morphometric information to reduce the semantic gap in the characterization of microscopic images of thyroid nodules. Computer Methods and Programs in Biomedicine, páginas -. ISSN 0169-2607. doi: http://dx.doi.org/10.1016/j.cmpb.2016.03.017. URL http://www.sciencedirect.com/science/article/pii/S016926071630236X. Citado na pág. 3, 30, $36,39,45,52,64,65,74$

Macedo et al. (2015) Alessandra Alaniz Macedo, Juliana T. Pollettini e Ethan V. Munson. A Chronic Illness System Using Biomedical Knowledge Sources and Relevance Feedback. Em 2015 IEEE 28th International Symposium on Computer-Based Medical Systems, páginas 244249. IEEE. ISBN 978-1-4673-6775-2. doi: 10.1109/CBMS.2015.45. URL http://ieeexplore.ieee. org $/$ lpdocs $/$ epic03/wrapper.htm?arnumber $=7167494$. Citado na pág. 30, 31, 32, 52, 57

Machado Junior et al. (2009) Danilo Machado Junior, Juliano Henrique Foleiss e Vinícius Mourão Alves de Souza. SQAS: Um Sistema Automático de Question-Answering para Textos Jornalísticos. Em 7th Brazilian Symposium in Information and Human Language Tecnology, páginas 1-3, São Carlos, SP. URL http://www.nilc.icmc.usp.br/til/stil2009_English/Proceedings/ olincom/MachadoJrFoleissdeSouza.pdf. Citado na pág. 27, 29

Magnini et al. (2004) Bernardo Magnini, Simone Romagnoli, Alessandro Vallin, Jesús Herrera, Anselmo Penas, Víctor Peinado, Felisa Verdejo e Maarten de Rijke. The multiple language question answering track at CLEF 2003. Em Comparative Evaluation of Multilingual Information Access Systems, páginas 471-486. Springer. Citado na pág. 21, 23, 56

Manning et al. (2008) Christopher D. Manning, Prabhakar Raghavan e Hinrich Schütze. Introduction to information retrieval, volume 1. Cambridge university press Cambridge. Citado na pág. 9

Marton e Radul (2006) Gregory Marton e Alexey Radul. Nuggeteer: Automatic nugget-based evaluation using descriptions and judgements. Em Proceedings of the main conference on Human Language Technology Conference of the North American Chapter of the Association of Computational Linguistics, páginas 375-382. Association for Computational Linguistics. Citado na pág. 21

Matsubara et al. (2003) Edson Takashi Matsubara, Claudia Aparecida Martins e Maria Carolina Monard. Pretext: Uma ferramenta para pré-processamento de textos utilizando a abordagem bag-of-words. Technical Report 209, ICMC - USP, São Carlos - SP. URL ftp://ftp.icmc.sc.usp. $\mathrm{br} / \mathrm{pub} /$ BIBLIOTECA/rel_tec/RT_209.pdf. Citado na pág. 12, 13, 14

Medeiros (2004) Ericles Alves de Medeiros. Técnica de Aprendizagem de Máquina para Categorização de Textos. Dissertação de Mestrado, Universidade de Pernambuco. URL http: //tcc.ecomp.poli.br/20061/EriclesMedeiros.pdf. Citado na pág. x, 15

MEDLINE (2004) MEDLINE. MEDLINE : FACT SHEET, 2004. URL http://www.nlm.nih. gov/pubs/factsheets/medline.html. Citado na pág. 1 
MEDLINE (2003a) MEDLINE. MEDLINE: Citation Counts by Year of Publication (as of mid November 2014), 2003a. URL http://www.nlm.nih.gov/bsd/medline_cit_counts_yr_pub.html. Citado na pág. $\mathrm{x}, 2$

MEDLINE (2003b) MEDLINE. MEDLINE: Number of Citations to English Language Articles; Number of Citations Containing Abstracts (as of mid - November 2014)*, 2003b. URL http: //www.nlm.nih.gov/bsd/medline_lang_distr.html. Citado na pág. x, 2

Monz (2003) Christof Monz. From document retrieval to question answering. Institute for Logic, Language and Computation. Citado na pág. 18, 19, 20, 42, 45

Moreda et al. (2011) Paloma Moreda, Hector Llorens, Estela Saquete e Manuel Palomar. Combining semantic information in question answering systems. Information Processing 83 Management, 47(6):870-885. ISSN 03064573. doi: 10.1016/j.ipm.2010.03.008. URL http://www.sciencedirect. com/science/article/pii/S0306457310000282. Citado na pág. 24, 29

Mourão et al. (2015) André Mourão, Flávio Martins e João Magalhães. Multimodal medical information retrieval with unsupervised rank fusion. Computerized Medical Imaging and Graphics, 39:35-45. ISSN 08956111. doi: 10.1016/j.compmedimag.2014.05.006. URL http://linkinghub. elsevier.com/retrieve/pii/S0895611114000664. Citado na pág. 3

Moura et al. (2010) Maria Fernanda Moura, Bruno Magalhães Nogueira, Merley da Silva Conrado, Fabiano Fernandes dos Santos e Solange Oliveira Rezende. Um modelo para a seleção de ngramas significativos e não redundantes em tarefas de mineração de textos. Boletim de Pesquisa e Desenvolvimento. Campinas: EMBRAPA Informática Agropecuária, 23. Citado na pág. 12

MSKCC (2014) Memorial Sloan Kettering Cancer Center MSKCC. Memorial Sloan Kettering Trains IBM Watson to Help Doctors Make Better Cancer Treatment Choices, 2014. URL https: //www.mskcc.org/blog/msk-trains-ibm-watson-help-doctors-make-better-treatment-choices. Citado na pág. 24

Muller (1954) David E Muller. Application of boolean algebra to switching circuit design and to error detection. Transactions of the IRE Professional Group on Electronic Computers, (3):6-12. Citado na pág. 8

Murussi et al. (2001) Marcia Murussi, Cláudio E. F. N. Pereira, Beatriz Assis Brasil e Balduino Tschiedel. Punção aspirativa de tireóide com agulha fina em um hospital geral: estudo de 754 punções. Arquivos Brasileiros de Endocrinologia 63 Metabologia, 45(6):576-583. Citado na pág. 35

Nadeau e Sekine (2007) David Nadeau e Satoshi Sekine. A survey of named entity recognition and classification. Lingvistica e Investigationes, 30(1):3-26. Citado na pág. 13

NCBI (2010) Bethesda (MD): National Center for Biotechnology Information (US) NCBI. Entrez Programming Utilities Help [Internet]., 2010. URL http://www.ncbi.nlm.nih.gov/books/ NBK25501/. Citado na pág. 32

Nguyen e Armitage (2008) Thuy T. T. Nguyen e Grenville Armitage. A survey of techniques for internet traffic classification using machine learning. Communications Surveys 85 Tutorials, IEEE, 10(4):56-76. Citado na pág. 14

NLTK (2015) NLTK. Categorizing and Tagging Words, 2015. URL http://www.nltk.org/book/ ch05.html. Citado na pág. 13

Olvera-Lobo e Gutiérrez-Artacho (2015) María Dolores Olvera-Lobo e Juncal GutiérrezArtacho. Question answering track evaluation in TREC, CLEF and NTCIR. Em Alvaro Rocha, Ana Maria Correia, Sandra Costanzo e Luis Paulo Reis, editors, New Contributions in Information Systems and Technologies, volume 353 of Advances in Intelligent Systems and 
Computing, páginas 13-22. Springer International Publishing. ISBN 978-3-319-16485-4. doi: 10.1007/978-3-319-16486-1_2. URL http://dx.doi.org/10.1007/978-3-319-16486-1_2. Citado na pág. 21,56

OMS (2009a) OMS. Organização Mundial de Saúde: Cardiovascular Diseases (CVDs), 2009a. URL http://www.who.int/mediacentre/factsheets/fs317/en/. Citado na pág. 30

OMS (2009b) OMS. Organização Mundial de Saúde: Diabetes, 2009b. URL http://www.who. int/mediacentre/factsheets/fs312/en/. Citado na pág. 30

OMS (2009c) OMS. Organização Mundial de Saúde: Obesity and overweight, 2009c. URL http: //www.who.int/mediacentre/factsheets/fs311/en/. Citado na pág. 30

Otsu (1975) Nobuyuki Otsu. A threshold selection method from gray-level histograms. Automatica, 11(285-296):23-27. Citado na pág. 35

Padovani Jr et al. (2007) JA Padovani Jr, R. Monteiro, T. Zan, R. Azoubel, D. De Santi, S. Taboga e A. Martins. Morphometric analysis of nucleus and nucleolar organizer regions (nors) in tongue squamous cell carcinoma (scc). International Journal of Morphology, 25(3):493-499. Citado na pág. 36

Parkin et al. (2005) D. M. Parkin, J. Ferlay, S. L. Whelan e H. H. Storm. Cancer incidence in five continents, volume 1. Diamond Pocket Books (P) Ltd. Citado na pág. 33

Pessotti (2012) Hugo César Pessotti. Uso de Mapeamento Conceitual para Redução de Descontinuidade Semântica na Recuperação de Imagens Microscópicas de Carcinoma Tireoidiano. Dissertação de Mestrado, Universidade de São Paulo. Citado na pág. xi, xii, 30, 35, 39, 45, 52, 54, 65,74

Pollettini et al. (2009) JT Pollettini, R Tinos, S Panico, JC Daneluzzi e AA Macedo. Vigilância em atenção básica à saúde a partir do uso de relevance feedback para classificação de pacientes em diferentes níveis de cuidado em saúde. Em Workshop de Informática Médica (evento paralelo ao XXIX Congresso da Sociedade Brasileira de Computação), páginas 1945-1954. Citado na pág. 33

Pollettini (2008) Juliana Pollettini. Definição automática de medidas que identificam pessoas requerendo diferentes graus de vigilância para atendimento em atenção básica à saúde: uma abordagem utilizando Relevance Feedback e a Classificação Internacional de Doenças. Tese de Doutorado, Universidade de São Paulo. Citado na pág. 33

Pollettini et al. (2012) Juliana T. Pollettini, Sylvia R.G. Panico, Julio C. Daneluzzi, Renato Tinós, José A. Baranauskas e Alessandra A. Macedo. Using machine learning classifiers to assist healthcare-related decisions: Classification of electronic patient records. Journal of Medical Systems, 36(6):3861-3874. ISSN 0148-5598. doi: 10.1007/s10916-012-9859-6. URL http://dx.doi.org/10.1007/s10916-012-9859-6. Citado na pág. 30, 31, 33, 52, 57

Pollettini (2011) Juliana Tarossi Pollettini. Auxílio na prevenção de doenças crônicas por meio de mapeamento e relacionamento conceitual de informações em biomedicina. Dissertação de Mestrado, Universidade de São Paulo. Citado na pág. xi, xii, 34, 54

Pollettini et al. (2014) Juliana Tarossi Pollettini, José Augusto Baranauskas, Evandro Seron Ruiz, Maria Graça Pimentel e Alessandra Alaniz Macedo. Surveillance for the prevention of chronic diseases through information association. BMC Medical Genomics, 7(1):7. Citado na pág. xi, 3, 30, $31,33,52,57,64,71$

Prestes (2011) Kassius Vargas Prestes. Avaliação de métodos de seleção da resposta de um sistema de perguntas e respostas. Relatório técnico. URL https://www.lume.ufrgs.br/bitstream/handle/ 10183/36881/000819142.pdf?sequence=1. Citado na pág. 27, 29 
Priya e Sundaram (2011) S. Shanmuga Priya e Sandhya Sundaram. Morphology to morphometry in cytological evaluation of thyroid lesions. Journal of cytology / Indian Academy of Cytologists, 28(3):98-102. ISSN 0970-9371. doi: 10.4103/0970-9371.83462. Citado na pág. 36

Roberts e Johnson (1996) Don Roberts e Ralph Johnson. Evolving frameworks: A pattern language for developing object-oriented frameworks. Em Proceedings of the Third Conference on Pattern Languages and Programming. Addison-Wesley. Citado na pág. 3, 40

Robertson e Spärck Jones (1976) Stephen E. Robertson e Karen Spärck Jones. Relevance Weighting of Search Terms. Journal of the American Society for Information Science, (June): 129-146. ISSN 00028231. doi: 10.1002/asi.4630270302. URL http://onlinelibrary.wiley.com/doi/ 10.1002/asi.4630270302/full. Citado na pág. 9

Rocchio (1971) J. J. Rocchio. Relevance feedback in information retrieval. The Smart Retrieval System: Experiments in Automatic Document Processing, páginas 313-323. URL http://ci.nii.ac. jp/naid/10000036124/en/. Citado na pág. 9

Ryu et al. (2014) Pum-Mo Ryu, Myung-Gil Jang e Hyun-Ki Kim. Open domain question answering using Wikipedia-based knowledge model. Information Processing \& Management, 50(5): 683-692. ISSN 03064573. doi: 10.1016/j.ipm.2014.04.007. URL http://www.sciencedirect.com/ science/article/pii/S0306457314000351. Citado na pág. 25, 29

Rzhetsky et al. (2009) Andrey Rzhetsky, Michael Seringhaus e Mark Gerstein. Getting Started in Text Mining: Part Two. PLoS Comput Biol, 5(7):e1000411+. ISSN 1553-7358. doi: 10.1371/ journal.pcbi.1000411. URL http://dx.doi.org/10.1371/journal.pcbi.1000411. Citado na pág. 1

Salton e McGill (1986) Gerard Salton e Michael J. McGill. Introduction to Modern Information Retrieval. McGraw-Hill, Inc., New York, NY, USA. ISBN 0070544840. Citado na pág. 12

Sanchís (1982) Enrique Bernárdez Sanchís. Introducción a la lingüistica del texto. Espasa Calpe. Citado na pág. 43

Santos (2002) Eulanda Miranda dos Santos. Teoria e aplicação de support vector machines à aprendizagem e reconhecimento de objetos baseado na aparência. Dissertação de Mestrado, Universidade Federal da Paraíba. Citado na pág. 14

Sekine (1998) Satoshi Sekine. Nyu: Description of the japanese NE system used for MET-2. Em Proceedings of the Message Understanding Conference, páginas 1-6. Computer Science Departament. Citado na pág. 13

Shi (1992) Zhongzhi Shi. Principles of machine learning. International Academic Publishers. Citado na pág. 14

Shortliffe (1976) Edward H Shortliffe. Mycin: Computer-based medical consultations, 1976. Citado na pág. 22,29

Shortliffe e Cimino (2013) Edward H. Shortliffe e James J. Cimino. Biomedical informatics: computer applications in health care and biomedicine. Springer Science \& Business Media. Citado na pág. 1,40

Silva et al. (2003) Mário J. Silva, Bruno Martins e Miguel Costa. Avaliação de sistemas de recuperação de informação da web em português: Uma proposta inicial à comunidade. Relatório técnico. Citado na pág. 10

Singhal (2001) Amit Singhal. Modern Information Retrieval: A Brief Overview. Bulletin of the IEEE Computer Society Technical Committee on Data Engineering, 24:1-9. ISSN 00218979. doi: 10.1.1.117.7676âĂ Ô. Citado na pág. 8 
Smola et al. (2000) Alexander J. Smola, P. Bartlett, Bernhard Schölkopf e C. Schuurmans. Introduction to large margin classifiers. Advances in Large Margin Classifiers, páginas 1-26. Citado na pág. 15

Srihari e Li (1999) Rohini Srihari e Wei Li. Information extraction supported question answering. Relatório técnico, DTIC Document. Citado na pág. xiii, 17, 18

Suresh kumar e Zayaraz (2015) G. Suresh kumar e G. Zayaraz. Concept relation extraction using Naïve Bayes classifier for ontology-based question answering systems. Journal of King Saud University - Computer and Information Sciences, 27(1):13-24. ISSN 13191578. doi: 10.1016/j. jksuci.2014.03.001. URL http://www.sciencedirect.com/science/article/pii/S1319157814000020. Citado na pág. 25, 29

Takahashi (2015) Carla Caldeira Takahashi. Mapeamento Explícito como Kernel em Aprendizado de Máquinas de Vetores de Suporte. Dissertação de mestrado, Universidade Federal de Minas Gerais. URL http://www.ppgee.ufmg.br/defesas/1134M.PDF. Citado na pág. 14

Thong e Son (2015) Nguyen Tho Thong e Le Hoang Son. HIFCF: An effective hybrid model between picture fuzzy clustering and intuitionistic fuzzy recommender systems for medical diagnosis. Expert Systems with Applications, 42(7):3682-3701. ISSN 09574174. doi: 10.1016/j.eswa. 2014.12.042. URL http://www.sciencedirect.com/science/article/pii/S0957417414008215. Citado na pág. 3

Tsuruoka e Tsujii (2004) Yoshimasa Tsuruoka e Jun'ichi Tsujii. Improving the performance of dictionary-based approaches in protein name recognition. Journal of biomedical informatics, 37 (6):461-470. Citado na pág. 15

University e Company (1995) R.W.S.A.P.M.E.C. University e I.D.R.H.C.W. Company. Spoken Natural Language Dialog Systems : A Practical Approach: A Practical Approach. Oxford University Press, USA. ISBN 9780195357912. URL https://books.google.com.br/books?id= E9o6SFxK6s4C. Citado na pág. 23

Vallin et al. (2006) Alessandro Vallin, Bernardo Magnini, Danilo Giampiccolo, Lili Aunimo, Christelle Ayache, Petya Osenova, Anselmo Peñas, Maarten de Rijke, Bogdan Sacaleanu, Diana Santos e Richard Sutcliffe. Overview of the clef 2005 multilingual question answering track. Em Carol Peters, Fredric C. Gey, Julio Gonzalo, Henning Müller, Gareth J.F. Jones, Michael Kluck, Bernardo Magnini e Maarten de Rijke, editors, Accessing Multilingual Information Repositories, volume 4022 of Lecture Notes in Computer Science, páginas 307-331. Springer Berlin Heidelberg. ISBN 978-3-540-45697-1. doi: 10.1007/11878773_36. URL http://dx.doi.org/10.1007/11878773_36. Citado na pág. 21

Vapnik (2013) Vladimir Vapnik. The nature of statistical learning theory. Springer Science \& Business Media. Citado na pág. 14

Verma et al. (2009) Anju Verma, Nikola Kasabov, Elaine Rush e Qun Song. Ontology based personalized modeling for chronic disease risk analysis: An integrated approach. 5506:1204-1210. doi: 10.1007/978-3-642-02490-0_146. URL http://dx.doi.org/10.1007/978-3-642-02490-0_146. Citado na pág. 30, 31, 62

Voorhees e Harman (2001) Ellen M. Voorhees e Donna Harman. Overview of TREC 2001. Em Trec. Citado na pág. 10

Voorhees e Tice (2000) Ellen M. Voorhees e Dawn M. Tice. Building a question answering test collection. Em Proceedings of the 23rd Annual International ACM SIGIR Conference on Research and Development in Information Retrieval, SIGIR '00, páginas 200-207, New York, NY, USA. ACM. ISBN 1-58113-226-3. doi: 10.1145/345508.345577. URL http://doi.acm.org/10. 1145/345508.345577. Citado na pág. 21, 23, 56 
Wallace (2003) Richard Wallace. The elements of aiml style. Alice AI Foundation. Citado na pág. 27

Wilensky et al. (1988) Robert Wilensky, David N. Chin, Marc Luria, James Martin, James Mayfield e Dekai Wu. The berkeley unix consultant project. Computational Linguistics, 14: 35-84. Citado na pág. 23, 29

Wilhelm et al. (2013) Reinhard Wilhelm, Helmut Seidl e Sebastian Hack. Compiler design: Syntactic and semantic analysis. Springer Science \& Business Media. Citado na pág. 13

Wilkens et al. (2010) Rodrigo Wilkens, Aline Villavicencio, Daniel Muller, Leandro Wives, Fabio Da Silva e Stanley Loh. Comunica: a question answering system for brazilian portuguese. Em Proceedings of the 23rd International Conference on Computational Linguistics: Demonstrations, páginas 21-24. Association for Computational Linguistics. Citado na pág. 27, 29

Winograd (1971) Terry Winograd. Procedures as a representation for data in a computer program for understanding natural language. Tese de Doutorado, Massachusetts Institute of Technology, Dept. of Mathematics. Citado na pág. 22, 29

Woods et al. (1972) William A. Woods, Ronald M. Kaplan e Bonnie Nash-Webber. The lunar sciences natural language information system: Final report. Bolt Beranek and Newman. Citado na pág. 22, 29

Xu e Croft (1996) Jinxi Xu e W. Bruce Croft. Query expansion using local and global document analysis. Em Proceedings of the 19th Annual International ACM SIGIR Conference on Research and Development in Information Retrieval, SIGIR '96, páginas 4-11, New York, NY, USA. ACM. ISBN 0-89791-792-8. doi: 10.1145/243199.243202. URL http://doi.acm.org/10. 1145/243199.243202. Citado na pág. 9

Yen et al. (2013) Show-Jane Yen, Yu-Chieh Wu, Jie-Chi Yang, Yue-Shi Lee, Chung-Jung Lee e Jui-Jung Liu. A support vector machine-based context-ranking model for question answering. Information Sciences, 224:77 - 87. ISSN 0020-0255. doi: http://dx.doi.org/10.1016/j.ins.2012. 10.014. URL http://www.sciencedirect.com/science/article/pii/S0020025512006792. Citado na pág. $11,25,28,29$

Zhang e Lee (2003) Dell Zhang e Wee Sun Lee. Question classification using support vector machines. Em Proceedings of the 26th Annual International ACM SIGIR Conference on Research and Development in Informaion Retrieval, SIGIR '03, páginas 26-32, New York, NY, USA. ACM. ISBN 1-58113-646-3. doi: 10.1145/860435.860443. URL http://doi.acm.org/10.1145/ 860435.860443. Citado na pág. 18, 42 